ADRIANA MACEDO DE CARVALHO

\title{
INTERAÇÕES ENTRE CALOS DE CANA-DE-AÇÚCAR E BACTÉRIAS DIAZOTRÓFICAS ENDOFÍTICAS ISOLADAS DE CANA-DE-AÇÚCAR
}

Dissertação apresentada ao Programa de PósGraduação Interunidades em Biotecnologia USP/Instituto Butantan/IPT, para obtenção do Título de Mestre em Biotecnologia. 
ADRIANA MACEDO DE CARVALHO

\section{INTERAÇÕES ENTRE CALOS DE CANA-DE-AÇÚCAR E BACTÉRIAS DIAZOTRÓFICAS ENDOFÍTICAS ISOLADAS DE CANA-DE-AÇÚCAR}

Dissertação apresentada ao Programa de PósGraduação Interunidades em Biotecnologia USP/Instituto Butantan/IPT, para obtenção do Título de Mestre em Biotecnologia.

Área de concentração: Biotecnologia

Orientador: Prof. Dra. Heloiza Ramos Barbosa

Versão original 


\section{DADOS DE CATALOGAÇÃO NA PUBLICAÇÃO (CIP)}

Serviço de Biblioteca e Informação Biomédica do Instituto de Ciências Biomédicas da Universidade de São Paulo

(C) reprodução total

Carvalho, Adriana Macedo de.

Interações entre calos de cana-de-açúcar e bactérias diazotróficas endofíticas isoladas de cana-de-açúcar / Adriana Macedo de Carvalho. -- São Paulo, 2013.

Orientador: Profa. Dra. Heloiza Ramos Barbosa.

Dissertação (Mestrado) - Universidade de São Paulo. Instituto de Ciências Biomédicas. Programa de Pós-Graduação Interunidades em Biotecnologia USP/IPT/Instituto Butantan. Área de concentração: Biotecnologia. Linha de pesquisa: Bactérias fixadoras de nitrogênio em associação com cana-de-açúcar.

Versão do título para o inglês: Interactions between sugarcane callus and endophytic bacteria diazothrophic isolated from sugarcane.

1. Bactérias fixadoras de nitrogênio 2. Bactérias fitopatogênicas 3 . Cana-de-açúcar I. Barbosa, Profa. Dra. Heloiza Ramos II. Universidade de São Paulo. Instituto de Ciências Biomédicas. Programa de Pós-Graduação Interunidades em Biotecnologia USP/IPT/Instituto Butantan. III. Título. 
UNIVERSIDADE DE SÃO PAULO

Programa de Pós-Graduação Interunidades em Biotecnologia

Universidade de São Paulo, Instituto Butantan, Instituto de Pesquisas Tecnológicas

Candidato(a):

Título da Dissertação:

Orientador(a):
Adriana Macedo de Carvalho.

Interações entre calos de cana-de-açúcar e bactérias diazotróficas isoladas de cana de açúcar.

Heloiza Ramos Barbosa.

A Comissão Julgadora dos trabalhos de Defesa da Dissertação de Mestrado, em sessão pública realizada a ..................., considerou

\section{( ) Aprovado(a) ( ) Reprovado(a)}

Examinador(a): Assinatura:

Nome:

Instituição:

Examinador(a): Assinatura:

Nome:

Instituição:

Presidente: Assinatura:

Nome:

Instituição: 


\section{CERTIFICADO DE ISENÇÃO}

Certificamos que o Protocolo (I:P-ICB N”335/09, referente ao projeto intitulado: Interações entre calos de cana-de-açucar e bactérias diazotróficas endofiticas isoladas de cana-deaçucar" sob a responsabilidade de Adriana Macedo de Carvalho, foi analisado na

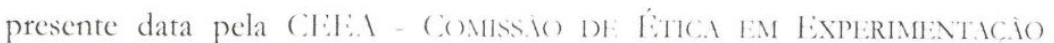

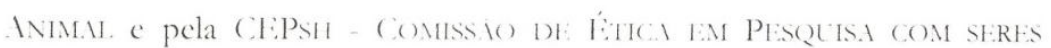
IILMLINOS, tendo sido deliberado que o referido projeto nào envolve manipulaçào animal ou humana que justifique uma aprovaçào quanto aos princípios éticos exigidos por ambas as (omissòes.

Sào Paulo, 25 de agosto de 2009.

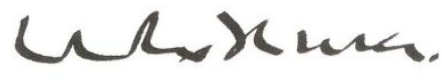

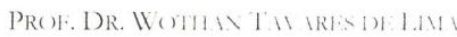
Coordenador da (

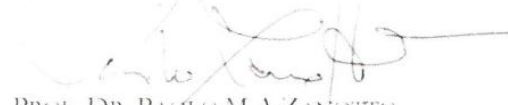

PR()1. DR. PUST() M. 1\%.N()TT()

Vice-Coordenador da CEPsh - ICB/ [S] 
A minha mãe querida que me incentivou e apoiou em todos os momentos. Aos meus amigos pela paciência e momentos de descontração. Muito obrigada! 


\section{RESUMO}

CARVALHO, A. M. Interações entre calos de cana-de-açúcar e bactérias diazotróficas endofíticas isoladas de cana-de-açúcar 2013. 99 f. Dissertação (Mestrado em Biotecnologia) - Instituto de Ciências Biomédicas, Universidade de São Paulo, São Paulo, 2013.

No Brasil, a cana-de-açúcar apresenta elevada importância econômica e agrícola, com uma produção anual estimada de 589 milhões de toneladas. Sabe-se que as bactérias diazotróficas desempenham importante papel na manutenção dos níveis de nitrogênio combinado em solos, como a cana-de-açúcar. Os ganhos com a fixação são dependentes das variedades de cana-deaçúcar utilizadas e diferentes estudos têm mostrado que até $60 \%$ do $\mathrm{N}$ acumulado pela planta pode ser derivado da FBN. Estes fatos tornam as bactérias fixadoras de nitrogênio as maiores fontes naturais de nitrogênio reduzido. Algumas misturas bacterianas permitem que os microrganismos interajam entre si, pelo fornecimento de nutrientes, pela remoção de produtos inibitórios e pelo estímulo mútuo em certos aspectos de suas fisiologias, como a fixação de nitrogênio. Neste trabalho, foram escolhidos diferentes gêneros bacterianos, Gram-negativos, endofíticos e fixadores de nitrogênio, isolados de cana-de-açúcar, com o objetivo de pesquisar interações entre os gêneros e as células de cana-de-açúcar, na forma de calos. Os experimentos foram feitos com misturas bacterianas para avaliar como dois gêneros seriam capazes de interagir entre si, interferindo em seus desenvolvimentos e nas possíveis contribuições às células vegetais. As linhagens bacterianas foram colocadas em contato com os calos em meios de cultura carentes ou não de nitrogênio combinado. A influência dos calos sobre as bactérias foi avaliada por medidas de crescimento microbiano e de atividade da nitrogenase. O efeito inverso foi avaliado por medida do conteúdo proteico dos calos. Foi determinado também o conteúdo de óxido nítrico e de espécies reativas de oxigênio. Na fase estácionária Pseudomonas sp. ICB383, e Pantoea sp. ICB409, sofreram inibição do crescimento enquanto Enterobacter sp. ICB113 foi estimulado. Pseudomonas sp. ICB383 mostrou-se ser uma fraca competidora em relação a Pantoea sp. ICB409, uma vez que foi eliminada. Quando associadas, a morte de Pseudomonas sp. foi estimulada por Pantoea sp. e este efeito foi mais acentuado na presença do calo., quando ambas as bactérias foram exterminadas. Os efeitos do calo na atividade da nitrogenase foi observado pontualmente, enquanto que os efeitos na crescimento ocorreram por períodos maiores. Não foi observada influência da presença da(s) bactéria(s) no conteúdo proteico dos calos. A produção de EROs auxiliou na interpretação dos resultados em relação à patogenicidade das linhagens utilizadas no presente trabalho. Os valores de $\mathrm{ON}$ não foram esclarecedores.

Palavras-chave:Calo de cana-de-açúcar. Bactérias Diazotróficas. Nitrogenase. Competição Bacteriana. 


\begin{abstract}
CARVALHO, A. M. Interactions between sugarcane callus and endophytic bacteria diazothrophic isolated from sugarcane 2013. 99 p. Masters thesis (Biotechnology) Instituto de Ciências Biomédicas, Universidade de São Paulo, São Paulo, 2013.

In Brazil, sugarcane has high economic importance and agricultural, with an estimated annual production of 589 million tonnes. It is known that the diazotrophs play an important role in maintaining the levels of combined nitrogen in soils, such as sugarcane. The gains are dependent on the setting of the varieties of sugarcane used and various studies have shown that up to $60 \%$ of $\mathrm{N}$ uptake by the plant can be derived from BNF. These facts make the nitrogen fixing bacteria the highest natural sources of reduced nitrogen. Some mixtures allow bacterial microorganisms interact, by supplying nutrients, removal of inhibitory products and by mutual stimulation in certain aspects of its physiology, such as nitrogen fixation. In this work, we chose different bacterial genera, Gram-negative, endophytic and nitrogen fixers, isolated from sugarcane, with the goal of researching interactions between gender and the cells of sugarcane, in the form of callus. The experiments were made with bacterial mixtures to evaluate how two genres would be able to interact with each other, interfering in their developments and possible contributions to plant cells. The bacterial strains were placed in contact with the callus culture media lacking combined nitrogen or not. The influence of calluses on bacteria was evaluated by measurements of microbial growth and activity of nitrogenase. The opposite effect was evaluated by measuring the protein content of the callus. Was also determined the contents of nitric oxide and reactive oxygen species. In the stationary phase Pseudomonas sp. ICB383, and Pantoea sp. ICB409, suffered growth inhibition while Enterobacter sp. ICB113 was stimulated. Pseudomonas sp. ICB383 proved to be a "poor" competitor against Pantoea sp. ICB409 since been deleted. When attached, the death of Pseudomonas sp. was stimulated by Pantoea sp. and this effect was more pronounced in the presence of callus, when both bacteria were exterminated. The effects of callus nitrogenase activity were observed occasionally, while the effects on growth occurred for longer periods. There was no effect of the presence of bacterium in the protein content of the callus. The production of ROS assisted in interpreting the results in relation to the pathogenicity of strains used in this study. The values of NO were not informative.
\end{abstract}

Keywords: Sugarcane callus. Diazotrophic Bacteria. Nitrogenase. Bacterial Competition. 


\section{LISTA DE TABELAS}

Tabela 1 - Composição dos meios MS e MSM....................................................................28

Tabela 2 - Composição do meio JNFb.............................................................................29

Tabela 3 - Tempo de geração de Enterobacter sp. ICB113em cultura pura e em cultura mista, em presença ou ausência de calo. 48

Tabela 4 - Tempo de geração de Pseudomonas sp. ICB383em cultura pura e em cultura mista, em presença ou ausência de calo. .48

Tabela 5 - Tempo de geração de Pantoea sp. ICB409em cultura pura e em cultura mista, em presença ou ausência de calo. .48 


\section{LISTA DE ILUSTRAÇÕES}

Figura 1 - Foto do frasco de co-cultura. .30

Figura 2 - Curvas de crescimento de Enterobacter sp. ICB113 cultivada com ou sem a presença de calo. .34

Figura 3 - Curvas de crescimento de Enterobacter sp. ICB113 cultivada em ausência de calo (Enterobacter cultura pura) e em mistura com Pantoea sp. ICB409 (Enterobacter + Pantoea) e Pseudomonas sp. ICB383 (Enterobacter + Pseudomonas) em ausência de calo. .36

Figura 4 - Curvas de crescimento de Enterobacter sp. ICB113 cultivada em ausência de calo (Enterobacter cultura pura) e em mistura com Pantoea sp. ICB409 (Enterobacter + Pantoea) e Pseudomonas sp. ICB383 (Enterobacter + Pseudomonas) em ausência de calo. .36

Figura 5 - Curvas de crescimento de Enterobacter sp. ICB113 cultivada em presença de calo $($ Enterobacter + calo) e em mistura com Pantoea sp. ICB409 (Enterobacter + Pantoea + calo) e com Pseudomonas sp. ICB383 (Enterobacter + Pseudomonas + calo) em presença de calo.

Figura 6 - Curvas de crescimento de Enterobacter sp. ICB113 cultivada em presença de calo $($ Enterobacter + calo) e em mistura com Pantoea sp. ICB409 (Enterobacter + Pantoea + calo) e com Pseudomonas sp. ICB383 (Enterobacter + Pseudomonas + calo) em presença de calo

Figura. 7 - Curvas de crescimento de Pseudomonas sp. ICB383 cultivada com ou sem a presença de calo 39

Figura 8 - Curvas de crescimento de Pseudomonas sp. ICB383 cultivada em ausência de calo (Pseudomonas cultura pura) e em mistura com Enterobacter sp. ICB113 (Pseudomonas + Enterobacter) e com Pantoea sp. ICB409 (Pseudomonas + Pantoea) sem a presença de calo

Figura 9 - Curvas de crescimento de Pseudomonas sp. ICB383 cultivada em ausência de calo (Pseudomonas cultura pura) e em mistura com Enterobacter sp. ICB113 (Pseudomonas + Enterobacter) e com Pantoea sp. ICB409 (Pseudomonas + Pantoea) sem a presença de calo.

Figura 10 - Curvas de crescimento de Pseudomonas sp. ICB383 cultivada em presença de calo (Pseudomonas + calo) e em mistura com Enterobacter sp. ICB113 (Pseudomonas + Enterobacter + calo) e com Pantoea sp. ICB409 (Pseudomonas + Pantoea + calo) em presença de calo. 
Figura 11 - Curvas de crescimento de Pseudomonas sp. ICB383 cultivada em presença de calo (Pseudomonas + calo) e em mistura com Enterobacter sp. ICB113 (Pseudomonas + Enterobacter + calo) e com Pantoea sp. ICB409 (Pseudomonas + Pantoea + calo) em presença de calo.

Figura 12 - Curvas de crescimento de Pantoea sp. ICB409 cultivada com ou sem a presença de calo

Figura 13 - Curvas de crescimento de Pantoea sp. ICB409 cultivada em ausência de calo (Pantoea cultura pura) e em mistura com Enterobacter sp. ICB113 (Pantoea + Enterobacter) e com Pseudomonas sp. ICB383 (Pantoea + Pseudomonas) em ausência de calo.

Figura 14 - Curvas de crescimento de Pantoea sp. ICB409 cultivada em ausência de calo (Pantoea cultura pura) e em mistura com Enterobacter sp. ICB113 (Pantoea + Enterobacter) e com Pseudomonas sp. ICB383 (Pantoea + Pseudomonas) em ausência de calo. .45

Figura 15 - Curvas de crescimento de Pantoea sp. ICB409 cultivada em presença de calo $($ Pantoea + calo) e em mistura com Enterobacter sp. ICB113 (Pantoea + Enterobacter + calo) e com Pseudomonas sp. ICB383 (Pantoea + Pseudomonas + calo) em presença de calo......46 Figura 16 - Curvas de crescimento de Pantoea sp. ICB409 cultivada em presença de calo $($ Pantoea + calo) e em mistura com Enterobacter sp. ICB113 (Pantoea + Enterobacter + calo) e com Pseudomonas sp. ICB383 (Pantoea + Pseudomonas + calo) em presença de calo......47 Figura 17 - Curvas de atividade específica da nitrogenase de Enterobacter sp. ICB113 cultivada com ou sem a presença de calo.

Figura 18 - Curvas de atividade específica da nitrogenase de Enterobacter sp. ICB113 cultivada com ou sem a presença de calo. .50

Figura 19 - Curvas de atividade específica da nitrogenase de Pseudomonas sp. ICB383 cultivada com ou sem a presença de calo.

Figura 20 - Curvas de atividade específica da nitrogenase de Pseudomonas sp. ICB383 cultivada com ou sem a presença de calo. .51

Figura 21 - Curvas de atividade específica da nitrogenase de Pantoea sp. ICB409 cultivada com ou sem a presença de calo.

Figura 22 - Curvas de atividade específica da nitrogenase de Pantoea sp. ICB409 cultivada com ou sem a presença de calo.....

Figura 23 - Curvas de atividade específica da nitrogenase da mistura bacteriana Enterobacter sp. ICB113 e Pseudomonas sp. ICB383 em ausência de calo. .54 
Figura 24 - Curvas de atividade específica da nitrogenase da mistura bacteriana Enterobacter sp. ICB113 e Pseudomonas sp. ICB383 em ausência de calo.

Figura 25 - Curvas de atividade específica da nitrogenase da mistura bacteriana Enterobacter sp. ICB113 e Pseudomonas sp. ICB383 em presença de calo.

Figura 26 - Curvas de atividade específica da nitrogenase da mistura bacteriana Enterobacter sp. ICB113 e Pseudomonas sp. ICB383 em presença de calo 56

Figura 27 - Curvas de atividade específica da nitrogenase da mistura bacteriana Enterobacter sp. ICB113 e Pantoea sp. ICB409 em ausência de calo.

Figura 28 - Curvas de atividade específica da nitrogenase da mistura bacteriana Enterobacter sp. ICB113 e Pantoea sp. ICB409 em ausência de calo.

Figura 29 - Curvas de atividade específica da nitrogenase da mistura bacteriana Enterobacter sp. ICB113 e Pantoea sp. ICB409 em presença de calo. .58

Figura 30 - Curvas de atividade específica da nitrogenase da mistura bacteriana Enterobacter sp. ICB113 e Pantoea sp. ICB409 em presença de calo. .59

Figura 31 - Curvas de atividade específica da nitrogenase da mistura bacteriana Pseudomonas sp. ICB383 e Pantoea sp. ICB409 em ausência de calo.

Figura 32 - Curvas de atividade específica da nitrogenase da mistura bacteriana Pseudomonas sp. ICB383 e Pantoea sp. ICB409 em ausência de calo.

Figura 33 - Curvas de atividade específica da nitrogenase da mistura bacteriana Pseudomonas sp. ICB383 e Pantoea sp. ICB409 em presença de calo....

Figura 34- Curvas de atividade específica da nitrogenase da mistura bacteriana Pseudomonas sp. ICB383 e Pantoea sp. ICB409 em presença de calo.

Figura 35 - Curvas de conteúdo proteico do calo em co-cultura com Enterobacter sp. ICB113 (Enterobacter + calo), em meio MS completo (CN) e em meio MSM (SN).

Figura 36 - Curvas de conteúdo proteico do calo em co-cultura com Pseudomonas sp. ICB383 (Pseudomonas + calo), em meio MS com nitrogênio $(\mathrm{CN})$ e em meio MSM $(\mathrm{SN})$

Figura 37 - Curvas de conteúdo proteico do calo em co-cultura com Pantoea sp. ICB409 $($ Pantoea + calo), em meio MS com nitrogênio (CN) e em meio MSM (SN)

Figura 38 - Curvas de conteúdo proteico do calo em co-cultura com a mistura Enterobacter sp. ICB113 e Pseudomonas sp. ICB383 (Enterobacter + Pseudomonas + calo), em meio MS com nitrogênio $(\mathrm{CN})$ e em meio $\mathrm{MSM}(\mathrm{SN})$.. 
Figura 39 - Curvas de conteúdo proteico do calo em co-cultura com a mistura Enterobacter sp. ICB113 e Pantoea sp. ICB409 (Enterobacter + Pantoea + calo), em meio MS com nitrogênio $(\mathrm{CN})$ e em meio MSM (SN).

Figura 40 - Curvas de conteúdo proteico do calo em co-cultura com a mistura Pseudomonas sp. ICB383e Pantoea sp. ICB409(Pseudomonas + Pantoea + calo), em meio MS com nitrogênio $(\mathrm{CN})$ e em meio MSM $(\mathrm{SN})$.

Figura 41 - Conteúdo intra e extracelular de ON das suspensões celulares cultivadas com Enterobacter sp. ICB113 68

Figura 42 - Conteúdo intra e extracelular de ON das suspensões celulares cultivadas com Pseudomonas sp. ICB383

Figura 43 - Conteúdo intra e extracelular de ON das suspensões celulares cultivadas com Pantoea sp. ICB409

Figura 44 - Conteúdo intra e extracelular de ON das suspensões celulares cultivadas com Enterobacter sp. ICB113 e Pseudomonas sp. ICB383 .70

Figura 45 - Conteúdo intra e extracelular de ON das suspensões celulares cultivadas com Enterobacter sp. ICB113 e Pantoea sp. ICB409. .71

Figura 46 - Conteúdo intra e extracelular de ON das suspensões celulares cultivadas com Pseudomonas sp. ICB383 e Pantoea sp. ICB409. .71

Figura 47 - Conteúdo de EROs das suspensões celulares cultivadas com Enterobacter sp. ICB113 73

Figura 48 - Conteúdo de EROs das suspensões celulares cultivadas com Pseudomonas sp. ICB383 73

Figura 49 - Conteúdo de EROs das suspensões celulares cultivadas com Pantoea sp. ICB409

Figura 50 - Conteúdo de EROs das suspensões celulares cultivadas com Enterobacter sp. ICB113 e Pseudomonas sp. ICB383. 75

Figura 51 - Conteúdo de EROs das suspensões celulares cultivadas com Enterobacter sp. ICB113 e Pantoea sp. ICB409 .75

Figura 52 - Conteúdo de EROs das suspensões celulares cultivadas com Pseudomonas sp. ICB383 e Pantoea sp. ICB409 


\section{SUMÁRIO}

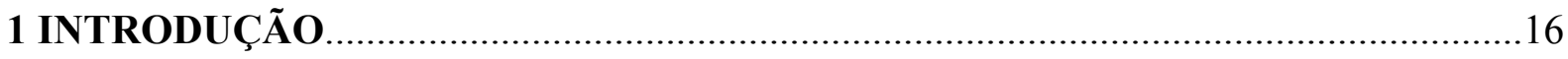

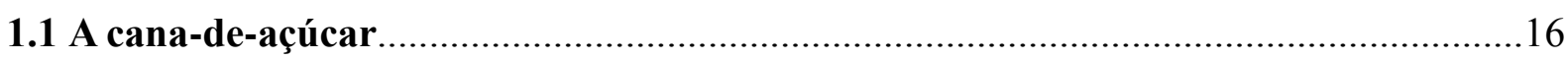

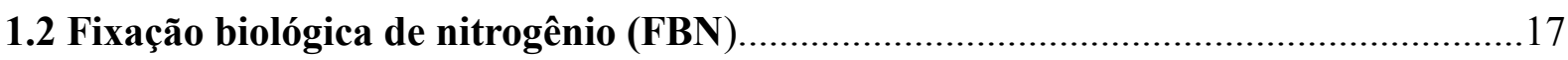

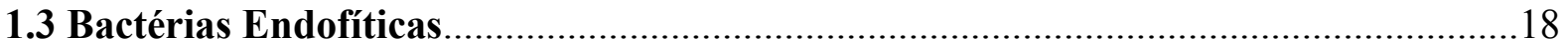

1.4 Interações entre bactérias fixadoras de nitrogênio e plantas......................................19

1.5 Co-culturas como modelo para analisar interações entre bactérias e plantas...........20

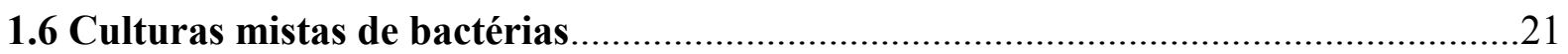

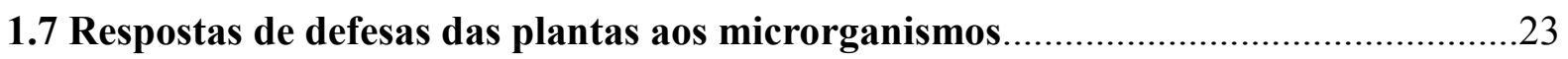

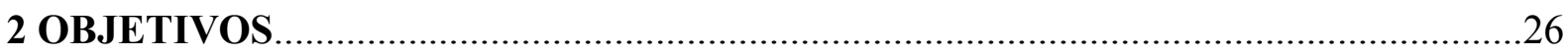

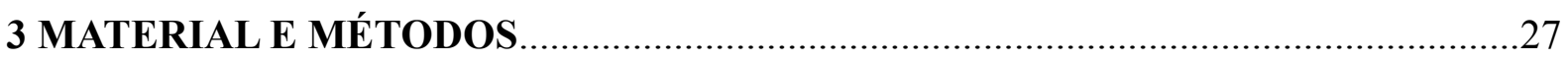

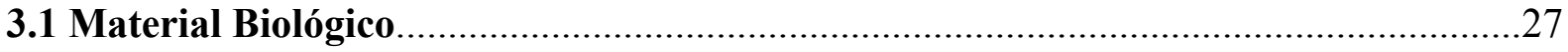

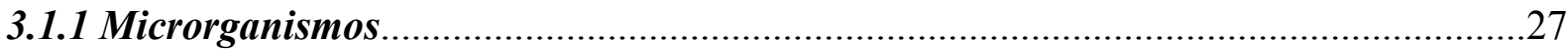

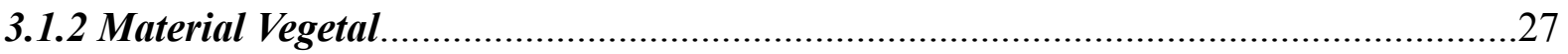

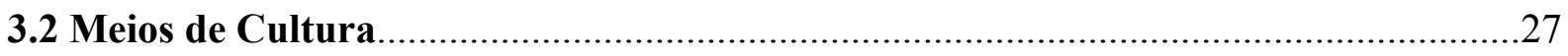

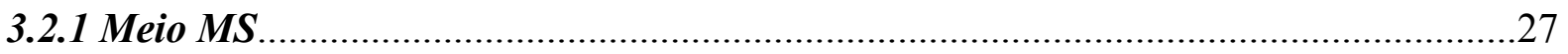

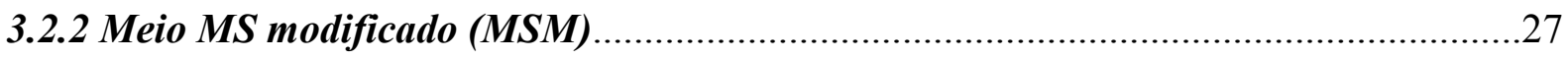

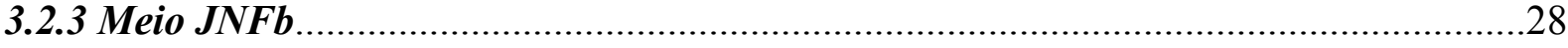

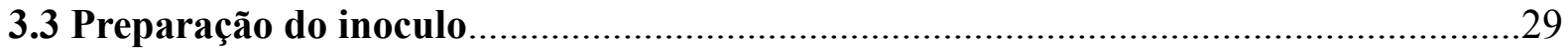

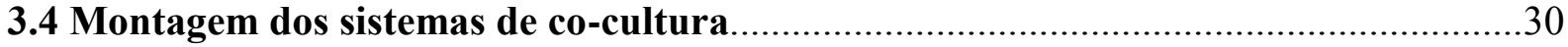

3.5 Verificação do efeito dos calos sobre as bactérias............................................................

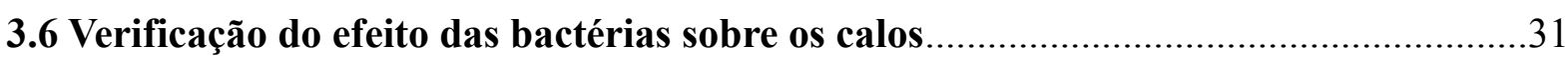

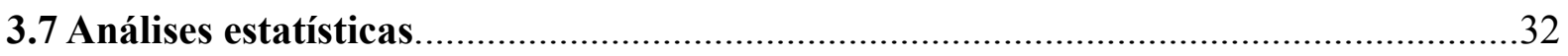

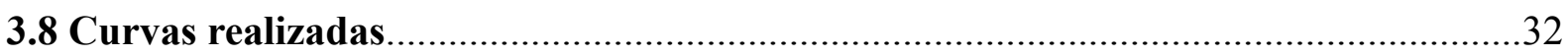

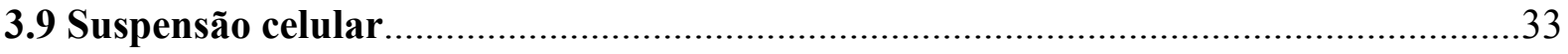

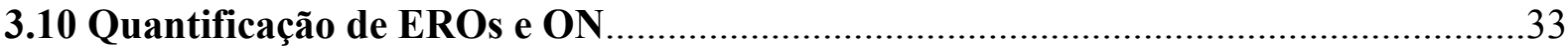

4 RESULTADOS

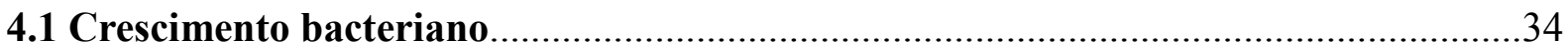

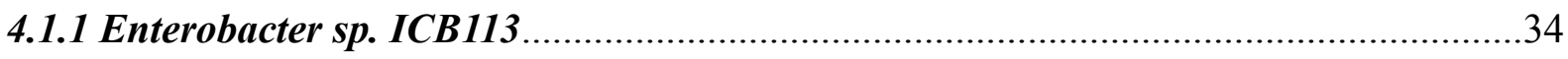

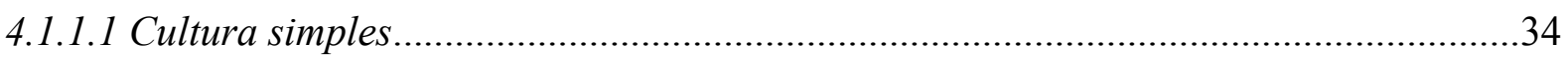

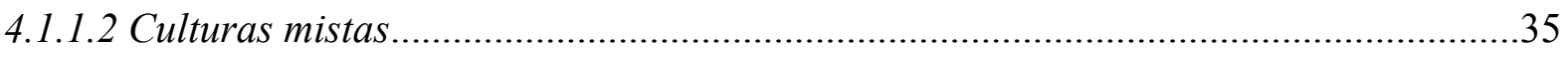

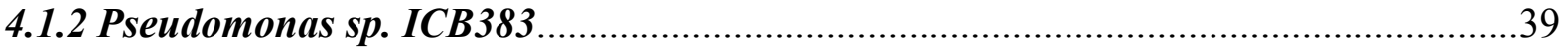


4.1.2.1 Cultura simples

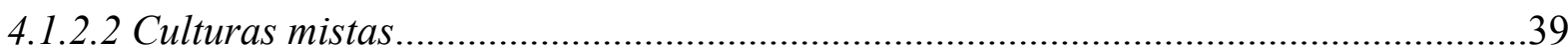

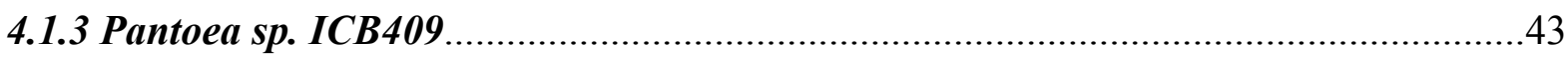

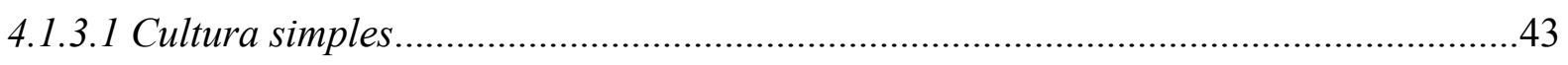

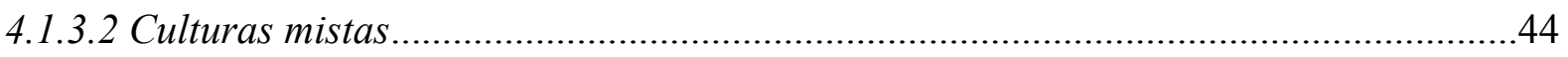

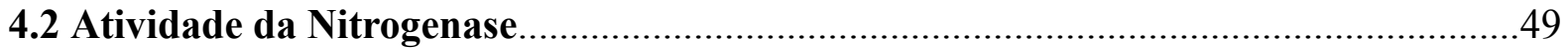

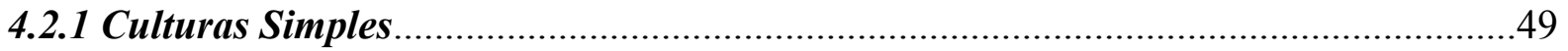

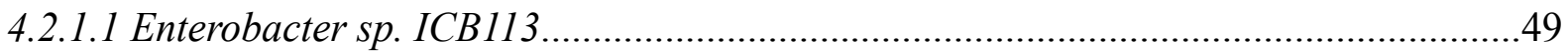

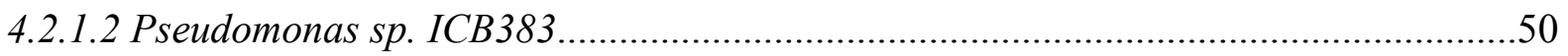

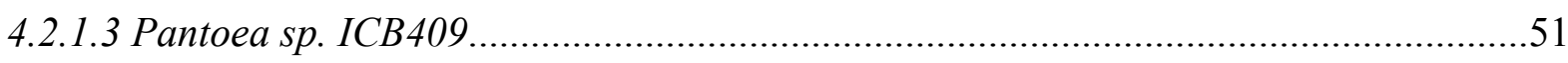

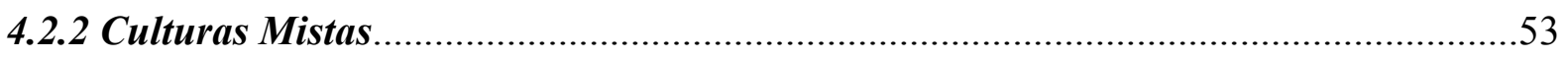

4.2.2.1 Enterobacter sp. ICB113 + Pseudomonas sp. ICB383............................................53

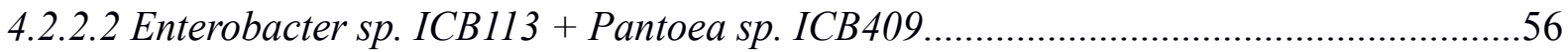

4.2.2.3 Pseudomonas sp. ICB383+ Pantoea sp. ICB409 ..........................................................59

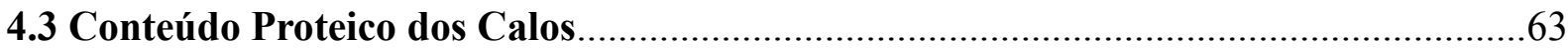

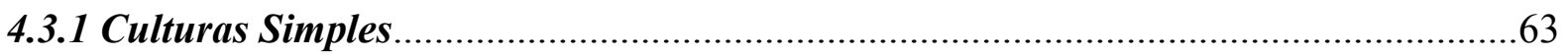

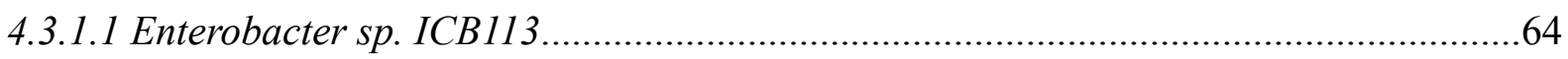

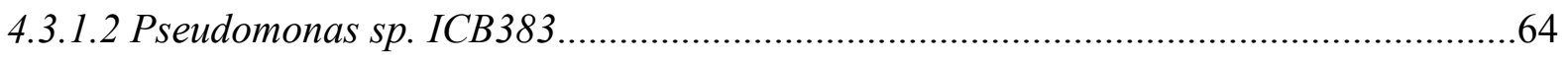

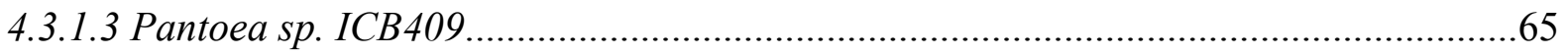

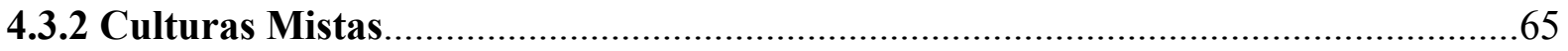

4.3.2.1 Enterobacter sp. ICB113 + Pseudomonas sp. ICB383 .................................................66

4.3.2.2 Enterobacter sp. ICB113 + Pantoea sp. ICB409.......................................................66

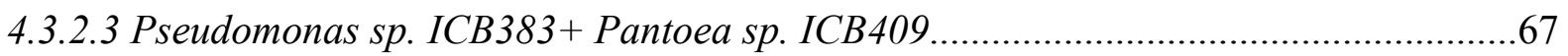

4.4 Conteúdo de ON e EROS nos calos em presença de bactérias....................................67

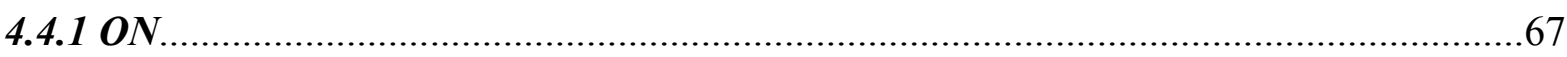

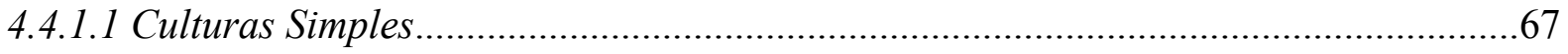

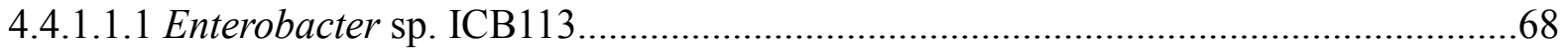

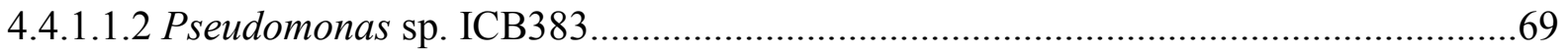

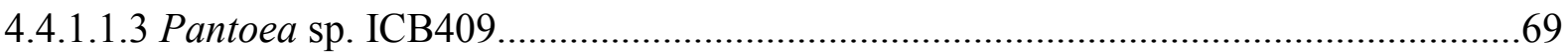

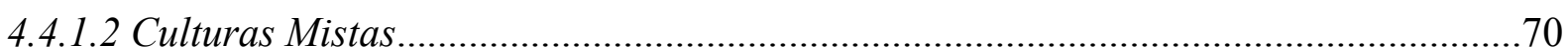

4.4.1.2.1 Enterobacter sp. ICB113 + Pseudomonas sp. ICB383 ........................................70

4.4.1.2.2 Enterobacter sp. ICB113 + Pantoea sp. ICB409.................................................71

4.4.1.2.3 Pseudomonas sp. ICB383 + Pantoea sp. ICB409.................................................71 


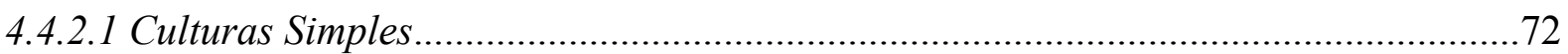

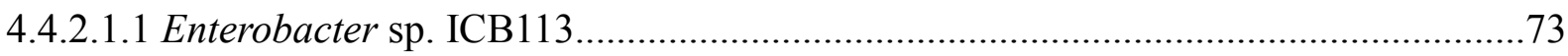

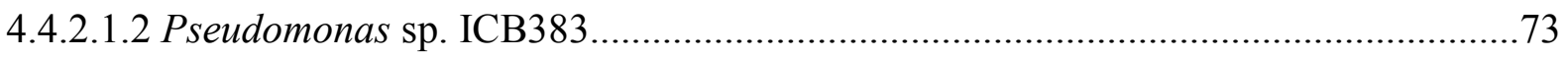

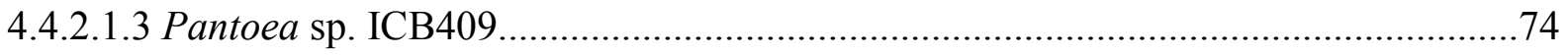

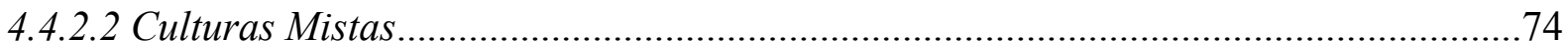

4.4.2.2.1 Enterobacter sp. ICB113 + Pseudomonas sp. ICB383 ........................................75

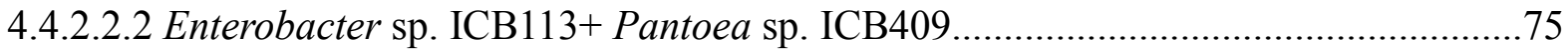

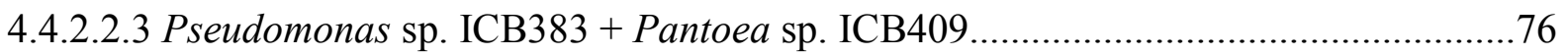

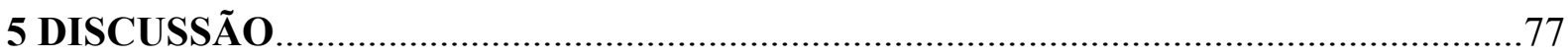

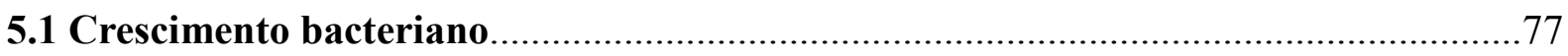

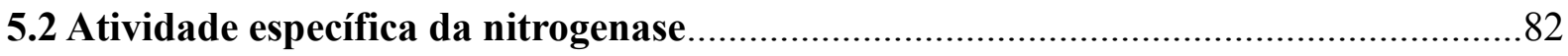

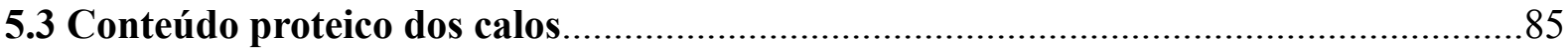

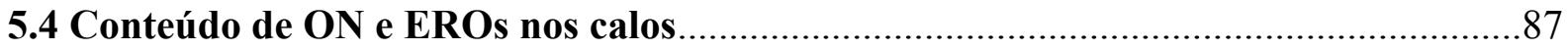

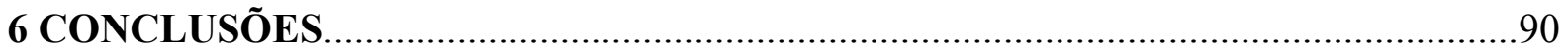

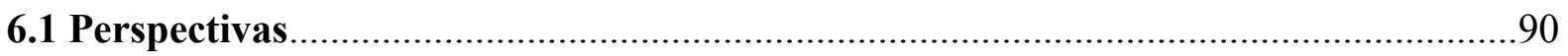

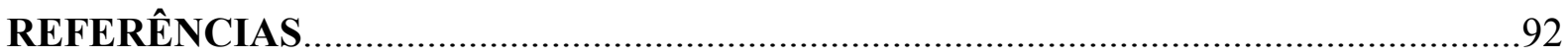




\section{INTRODUÇÃO}

\subsection{A cana-de-açúcar}

A cana-de-açúcar é uma planta perene, pertencente à família Poaceae e ao gênero Saccharum. É uma cultura que produz, em curto período, um alto rendimento de matéria verde, energia e fibras, sendo considerada uma das plantas com maior eficiência fotossintética (COSTA et al., 2001).

O Brasil é o maior produtor mundial, seguido pela Índia, Tailândia e Austrália. No Brasil, a cana-de-açúcar apresenta elevada importância econômica e agrícola, pois é cultivada em uma área total de 7 milhões de hectares. Sua produção anual é de 589 milhões de toneladas e a tendência é que esse número aumente ainda mais. No Estado de São Paulo, a cana-de-açúcar ocupa 4,4 milhões de hectares, sendo 52,6\% da área nacional plantada. Aproximadamente 55\% da cana-de-açúcar brasileira é utilizada para a produção de álcool e $45 \%$ para a produção de açúcar. Cada tonelada do vegetal tem um potencial energético equivalente ao de 1,2 barril de petróleo (ÚNIÃO DA INDÚSTRIA DE CANA-DEAÇÚCAR, 2008).

Interações entre plantas e microrganismos têm causado grande efeito no desenvolvimento das civilizações, desde que a humanidade começou a depender extensivamente de culturas para subsistência. Diversos microrganismos interagem com os tecidos e células das plantas, com diferentes graus de dependência, podendo desenvolver interações benéficas (simbióticas ou não) (SMITH, 1992; WELLER, 1988) ou patogênicas (SMITH; READ, 1996).

Determinadas espécies de bactérias têm sido encontradas dentro dos tecidos de gramíneas e algumas dessas plantas, como certas variedades de cana-de-açúcar, são altamente beneficiadas nutricionalmente com a associação, pois podem obter uma percentagem substancial dos seus requerimentos de nitrogênio a partir da fixação biológica de $\mathrm{N}_{2}$, realizada pelas bactérias diazotróficas (BODDEY et al., 1995). Em um experimento de campo, conduzido na Embrapa Agrobiologia, onde uma mistura com essas bactérias foiinoculada nas plantas de cana-de-açúcar antes do plantio,foi observado um incremento de até $35 \%$ na produção dematéria seca e $29 \%$ do $\mathrm{N}$ acumulado foi oriundo da fixaçãobiológica (REIS JUNIOR; MENDES; REIS, 2008). 


\subsection{Fixação biológica de nitrogênio (FBN)}

Depois do carbono, do oxigênio e do hidrogênio, o nitrogênio é o elemento mais abundante na matéria viva, participando, entre outras, da composição de moléculas de ácidos nucléicos e proteínas. Com exceção da água, o nitrogênio é considerado o nutriente mais limitante para o crescimento de plantas (FRANCO; DÖBEREINER, 1994). Na atmosfera, apresenta-se em grandes quantidades (78\%) e quimicamente muito estável, não sendo assimilável pela maioria dos seres vivos. Para que possa haver assimilação, é requerida sua transformação para uma forma combinada. Somente as bactérias diazotróficas são capazes de reduzir o nitrogênio atmosférico. Dessa forma, atribui-se a essas bactérias o importante papel da manutenção dos níveis de nitrogênio em solos com plantas não leguminosas, como cereais e cana-de-açúcar (DÖBEREINER, 1997).

A fixação biológica de nitrogênio é um processo complexo que requer a expressão de um conjunto de genes, os mais estudados são denominados genes nif (nitrogen fixing), os quais codificam para proteínas envolvidas diretamente no processo de FBN. O estudo da genética de Klebsiella pneumoniae levou à descoberta de 20 genes envolvidos na FBN (ARNOLD et al., 1998).

Em todos os organismos diazotróficos, a FBN ocorre pela reação de redução de $\mathrm{N}_{2}$ a $\mathrm{NH}_{3}$, catalisada pela ação da enzima nitrogenase, que apresenta propriedades químicas excepcionais. Existem vários tipos de nitrogenase, a mais estudada, é um sistema composto por duas proteínas: Mo-Fe-proteína (componente I) e Fe-proteína (componente II). Quando a enzima está ativa, um substrato reduzido doa elétrons ao componente II. Em seguida há a transferência de elétrons entre as duas proteínas, que está acoplada à hidrólise de ATP. A redução do substrato e liberação de ADP ocorrem concomitante com a dissociação da $\mathrm{Fe}$ proteína e Mo-Fe-proteína. Este ciclo repete-se até que um determinado número de elétrons e prótons seja acumulado e reduza suficientemente o substrato (POSTGATE, 1998).

Em condições ótimas, a estequiometria da reação catalítica responsável pela redução do $\mathrm{N}_{2}$ a duas moléculas de amônia, é usualmente descrita como abaixo (SIMPSON; BURRIS, 1984):

$$
\mathrm{N}_{2}+8 \mathrm{e}^{-}+8 \mathrm{H}^{+}+16 \mathrm{Mg}-\mathrm{ATP} \rightarrow 2 \mathrm{NH}_{3}+\mathrm{H}_{2}+16 \mathrm{Mg}-\mathrm{ADP}+16 \mathrm{Pi}
$$

A nitrogenase, além de catalisar a redução de $\mathrm{N}_{2}$ a amônia, reduz prótons a hidrogênio e também pequenas moléculas insaturadas como acetileno, azida e cianeto (KIM; REES, 1994). Uma reação particularmente importante é a redução de acetileno $\left(\mathrm{C}_{2} \mathrm{H}_{2}\right)$ a etileno 
$\left(\mathrm{C}_{2} \mathrm{H}_{4}\right)$, que é muito utilizada para se medir indiretamente a fixação de nitrogênio por cromatografia gasosa. Nesta reação, há a quebra da ligação entre os carbonos com a adição de duas moléculas de hidrogênio, semelhante ao que ocorre quando o substrato é o nitrogênio, há a quebra da tripla ligação entre os nitrogênios e a adição de três moléculas de hidrogênio. Além de econômica, esta técnica é bastante sensível e rápida (RIVAS, 2002).

Uma importante característica da nitrogenase é a inibição do componente II por oxigênio. Os microrganismos aeróbios fixadores de nitrogênio apresentam diferentes estratégias para excluir o oxigênio do sítio onde o processo ocorre (POSTGATE, 1998). Quando as bactérias são endofíticas, a proteção à nitrogenase é favorecida por uma localização adequada dos microrganismos em condições de microaerofilia (RAMOS et al., 2002).

Várias espécies de bactérias diazotróficas vivem livres no solo. Outras estabelecem relações simbióticas específicas com plantas superiores, formando nódulos em raízes de legumes e há ainda aquelas que colonizam endofiticamente folhas, caules e raízes das mais diferentes famílias de plantas (ROSENBLUETH; MARTÍNEZ-ROMERO, 2006).

\subsection{Bactérias endofíticas}

Bactérias interagem com plantas de quatro maneiras: como patógenos, simbiontes, epifíticos ou endofíticos. Desses quatro tipos de interação bactéria-planta, a interação por endofíticos é a menos compreendida. (INIGUEZ et al., 2005)

Bactérias endofíticas podem ser classificadas como aquelas que, na maior parte dos seus ciclos de vida, habitam o interior dos tecidos de plantas, sem causar sinais de patogenia. Consequentemente, as verdadeiras endofíticas são aquelas que, quando isoladas do interior de tecidos vegetais e, novamente em contato com a planta, são capazes de recolonizá-la (REINHOLD-HUREK; HUREK, 1998).

Determinados pontos do interior da planta proporcionam um ambiente adequado para o desenvolvimento das bactérias endofíticas. Espaços intercelulares na região epidérmica e cortical e células lisadas de plantas são os principais sítios de colonização. Tecido vascular e células do xilema também podem ser colonizados, mas sempre em menor densidade (REINHOLD-HUREK; HUREK, 2011)

A colonização do vegetal por esses microrganismos é também determinada por fatores ambientais, como a temperatura e a umidade, que influenciam na sobrevivência das bactérias. Estas bactérias podem penetrar no vegetal através de várias maneiras: a partir de injúrias 
presentes na superfície das raízes (SPRENT; DE FARIA, 1988), na saída de raízes laterais, entre as células da epiderme e através dos pelos das raízes (COCKING, 2003) e na zona de alongamento e diferenciação das raízes (ROSENBLUETH; MARTÍNEZ-ROMERO, 2006). Além disso, existem bactérias capazes de penetrar ativamente nos tecidos vegetais, devido à capacidade de secretar enzimas hidrolíticas, como pectinases e celulases (BEKRI et al., 1999).

Existem relatos de bactérias associadas a várias culturas vegetais, como tomate, alface, batata, milho, arroz e algodão com capacidade de promoção do crescimento vegetal (HALLMANN et al., 1997; HUREK et al., 2002). O estímulo ao crescimento pode ocorrer pela síntese de fitormônios (BENT et al., 2001) e vitaminas, que acarretam na maior absorção de nutrientes pelo aumento de raízes e na resistência da planta ao estresse. Maiores ofertas de nutrientes são observadas pela solubilização de fosfato inorgânico e mineralização de fosfato orgânico promovida por produtos bacterianos (KENNEDY; ISLAM, 2001; REYES; BERNIER; ANTOUN, 2002). Os microrganismos endofíticos também são capazes de minimizar, indiretamente, os efeitos deletérios de microrganismos patogênicos através da síntese de antibacterianos e antifungicos (DOBBELAERE; VANDERLEYDEN; OKON, 2003; ROMERO et al., 2007). Além disso, bactérias endofíticas podem ser fixadoras de nitrogênio (diazotróficas).

\subsection{Interações entre bactérias fixadoras de nitrogênio e plantas}

Uma das interações entre planta-microrganismo mais estudada é a simbiose, onde bactérias do grupo dos rizóbios (Rhizobium,Bradyrhizobium, Azorhizobium etc), se associam com plantas da família Leguminosae, formando nódulos exclusivamente nas raízes (STACEY et al., 1992). Nestas relações, sabe-se que os microrganismos fixam $\mathrm{N}_{2}$ e fornecem nutrientes nitrogenados às plantas que, por sua vez, contribuem com nutrientes energéticos, gerados pelo processo fotossintético (GLENN et al., 1985).

Há trabalhos que também mostram a transferência, para a planta, de nitrogênio fixado pelas bactérias, mesmo quando as interações não são simbióticas. Determinados trabalhos mostraram que a quantidade de nitrogênio total de variedades de plantas de cana-de-açúcar inoculadas com bactérias endofíticas diazotróficas aumentou substancialmente. Pode-se sugerir que este aumento aconteceu devido à passagem, para a planta, do nitrogênio fixado biologicamente pela bactéria (NJOLOMA et al., 2006). No entanto, este resultado não é 
sempre observado. Por isso, há a necessidade de estudos para se chegar a conclusões sobre essa cooperação bacteriana.

Urquiaga e colaboradores (1992) mostraram que diferentes cultivares de cana-deaçúcar obtiveram significantes quantidades de nitrogênio fixado por bactérias endofíticas. No entanto, Boddey e Döbereiner (1988) não evidenciaram ocorrência de fixação biológica de nitrogênio em resposta à inoculação com Azospirillum sp. em trigo. Aparentemente a transferência de nitrogênio fixado é dependente da planta e da bactéria envolvida (BODDEY et al., 2003). Segundo Döbereiner e Baldani (1982), as respostas de inoculações a plantas da mesma espécie da qual a bactéria foi isolada são melhores do que aquelas obtidas com inoculações heterólogas.

Outras contribuições bacterianas para os vegetais, além da fixação de nitrogênio, podem ser a liberação de vitaminas e o estímulo ao crescimento pela síntese de fitormônios (BENT et al., 2001). Foi observada a potencialidade de diferentes bactérias endofíticas fixadoras de nitrogênio de produzir, in vitro, fitormônios, giberelinas (BASTIÁN et al., 1998), citocininas, etileno (STRZELCZYK et al., 1994) ácido indolacético e aminoácidos (THULER et al., 2003) que acarretam na maior absorção de nutrientes pelo aumento de raízes e na resistência da planta ao estresse. Também contribuem com a solubilização de fosfato inorgânico e mineralização de fosfato orgânico (KENNEDY; ISLAM, 2001; REYES; BERNIER; ANTOUN, 2002).

\subsection{Co-culturas como modelo para analisar interações entre bactérias e plantas}

A cultura de tecidos vegetais é utilizada como ferramenta biotecnológica para estudos da morfogênese in vitro, que compreende aspectos bioquímicos, moleculares e estruturais. Quando se coloca um fragmento vegetal de um organismo íntegro em um meio de cultura com reguladores de crescimento, as células vegetais são liberadas do controle que estavam mantidas e são submetidas a uma nova condição, na qual a capacidade de divisão pode ser readquirida (desdiferenciação). Durante este processo, o genoma das células pode expressarse de novas formas, conduzindo-as a novos padrões de diferenciação. Portanto, esses eventos podem levar à formação de novas estruturas: raízes, brotos, embriões somáticos ou calos (FLOH; HANDRO, 1990; GEORGE, 1993).

A utilização de calos provenientes de cultura de células vegetais para estudos de associação com microrganismos apresenta inúmeras vantagens, destacando-se: a 
disponibilidade constante de matéria-prima pouco diferenciada, a relativa homogeneidade celular, a sincronia da fase de desenvolvimento, a facilidade de transferência para repicagem e a ausência de microrganismos interferentes (CHARLWOOD; RHODES, 1990; ZENK, 1991).

Outra vantagem na utilização de calos é a possibilidade de seleção das células de interesse. Hammerschlag (1990) inoculouXanthomonas campestris pv. pruni em duas linhagens de calos de pêssego, uma suscetível e outra com moderada resistência à doença causada por essa bactéria. Após vários sub-cultivos dos calos, em condições adequadas, conseguiu produzir embriões que foram regenerados em plantas que se mostraram mais resistentes a doença.

Sistemas artificiais entre bactérias fixadoras de nitrogênio e células vegetais como componentes podem ser adequados para o estudo de contribuições recíprocas dos organismos envolvidos. O uso de co-culturas permite o estudo dos efeitos da célula vegetal sobre os microrganismos e vice-versa. Essas associações possibilitam o estudo da fisiologia dos microrganismos e das células vegetais com relação ao desenvolvimento populacional, a avaliação da atividade de enzimas importantes e a produção de moléculas fundamentais.

Child e Kurz (1978) observaram que calos de diferentes espécies de plantas foram capazes de liberar nutrientes aptos a suprir deficiências nutricionais de microrganismos diazotróficos (Spirillum e Rhizobium), quando em co-cultura com células de arroz, trigo, cenoura e tabaco. DeMoranville et al. (1981) demonstraram que extrato de células de soja estimulou o crescimento de Rhizobium sp.

Pence et al. (1982) estudaram os efeitos de produtos de suspensão de células embriogênicas de Pennisetum americanum e de Panicum maximum, sobre o crescimento e atividade da nitrogenase de Azospirillum brasilense. Observou-se que as células vegetais liberaram substâncias estimulantes da atividade da nitrogenase e do crescimento bacteriano.

Os trabalhos de DeMoranville et al. (1981), Holsten et al. (1971), Pence et al. (1982) e Preininger et al. (1997) evidenciaram que estímulos ou inibições no crescimento dos microrganismos e na atividade da nitrogenase bacteriana dependem da planta, da bactéria e do meio utilizado para a realização das co-culturas.

Apesar de Vasil et al. (1979) mostrarem que calos de tabaco, Pennisetum americanum e Eremochloa ophiuroides não sobreviviam quando inoculados com Azospirillum brasilense em meio sem fonte de nitrogênio combinado, calos de cana-de-açúcar puderam ser cocultivados com esta bactéria com sucesso. O microrganismo assegurou a sobrevivência e o 
crescimento dos tecidos da planta em meio deficiente de nitrogênio, por mais de 18 meses (BERG; VASIL; VASIL, 1979).

\subsection{Culturas mistas de bactérias}

A fixação biológica de nitrogênio pelas bactérias diazotróficas pode ser estimulada quando há a associação entre duas ou mais bactérias (DOBBELAERE; VANDERLEYDEN; OKON, 2003). No entanto, segundo Drozdowicz e Ferreira Santos (1987) e Isopi et al. (1995), a interação entre uma bactéria diazotrófica com outra bactéria, além de estimular a fixação de nitrogênio, também pode inibi-la. Algumas misturas bacterianas permitem que os microrganismos interajam entre si, pelo fornecimento de nutrientes, pela remoção de produtos inibitórios e pelo estímulo mútuo em certos aspectos fisiológicos, como a fixação de nitrogênio (BASHAN, 1998).

Culturas mistas entre as bactérias dos gêneros Bacillus e Azospirillum resultaram em um aumento nas capacidades de degradação de pectina e de fixação de nitrogênio (KHAMMAS; KAISER, 1992). Azospirillum brasilense e Enterobacter cloacae, quando juntas, apresentaram uma maior eficiência na fixação de nitrogênio (KAISER, 1995). De forma semelhante, Holguin e Bashan (1996), mostraram que a atividade da nitrogenase de Azospirillum brasilense pode ser aumentada pela presença de outras bactérias. Porém, nem todas as bactérias não diazotróficas têm essa capacidade. Além deste mecanismo, Paerl e Pinckney (1996) verificaram que alguns microrganismos, em contato com bactérias diazotróficas, podem aumentar suas taxas de respiração e, dessa maneira, abaixam a concentração de oxigênio do meio, protegendo a nitrogenase dessas bactérias contra a inibição.

Quando em associação, duas espécies diferentes podem ter seu crescimento estimulado ou não. O desenvolvimento populacional de culturas de Klebsiella sp. e Bacillus sp. foi superior quando essas bactérias foram associadas (SHRESTHA et al., 2007). Por outro lado, Holguin e Bashan (1996) não encontraram diferenças significativas no crescimento de Azospirillumbrasilense e Staphylococcus sp., quando crescidas juntas, ou separadas.

$\mathrm{Na}$ agricultura, a mistura de duas ou mais bactérias geralmente apresenta um efeito mais positivo no crescimento da planta, quando comparada com inóculos simples (somente uma bactéria). Aparentemente, misturas de bactérias proporcionam às plantas uma nutrição 
mais balanceada, com aumento na absorção de nitrogênio, fósforo e outros nutrientes minerais (BASHAN; HOLGUIN, 1997).

Os efeitos benéficos que bactérias do gênero Azospirillum proporcionam às plantas são estimulados quando esta bactéria associa-se com determinados microrganismos (BASHAN; HOLGUIN, 1997). Medicago sativa (ITZIGSOHN et al., 1993), soja (SINGH; SUBBA RAO, 1979) e outras plantas leguminosas (BURDMAN; JURKEVITCH; OKON, 2000; RODELAS et al., 1996), quando inoculadas concomitantemente com Azospirillum e Rhizobium, apresentaram maior desenvolvimento do que quando inoculadas com as bactérias separadamente. Ao contrário disso, estudos com plantas de amendoim (RAVERKAR; KONDE, 1990) e feijão (KUNDU; KUHAD; NANDWAL, 1993) mostraram não haver favorecimento maior às plantas inoculadas com uma mistura de Rhizobium e Azospirillum, comparadas com inoculações simples. A presença de Azospirillum brasilense Az39e de Bradyrhizobium japonicum E109 mostraram a capacidade de promover a germinação de sementes, formação de nódulos e desenvolvimento precoce de milho e soja (CASSÁN et al., 2009).

Não foram encontrados trabalhos que avaliam os efeitos de misturas de bactérias sobre células vegetais na forma de calos. Segundo Rodelas et al. (1999), experimentos de associações in vitro ajudariam a avaliar o desempenho e as características particulares dos organismos envolvidos para futuramente se desenvolver um inoculante para o cultivo de fava em campo.

\subsection{Respostas de defesas das plantas aos microrganismos}

As plantas estão associadas naturalmente com diversos microrganismos de diferentes formas. Mas como a planta reconhece essa bactéria como benéfica ou não? Existem dois tipos de defesas realizadas pelas plantas: a ISR (Induced systemic resistance) e a SAR (Systemic acquired resistance). SAR é desencadeada quando há a invasão por um microrganismo patogênico, ocorrendo a produção de PRs (pathogenesis-related proteins) e de ácido salicílico pela planta (VALLAD; GOODMAN, 2004). Este tipo de defesa pode ocasionar a morte das células vegetais envolvidas na região da infecção (JONES; DANGL, 2006). ISR é eficaz contra diferentes tipos de patógenos mas difere de SAR pois, também é induzido por PGPRs (plant growth-promoting rhizobacteria) e não causa sintomas visíveis na planta hospedeira. Este mecanismo de defesa está relacionado com a produção de ácido jasmônico e etileno 
(COMPANT et al., 2005). Sementes de Medicago sativa tratadas com ACC (1aminocyclopropane-1-carboxylic acid), molécula precursora do etileno, e inoculadas com Klebsiella pneumoniae 342 (Kp342), apresentaram menor número de bactérias nas raízes do que as plantas controle, somente inoculadas com as bactérias (INIGUEZ et al., 2004). Estes dados evidenciaram que a produção de etileno endógeno limita a colonização por endofíticas, mostrando o papel do etileno na defesa da planta.

A rede de sinalização das respostas de defesas das plantas contra patógenos ou organismos benéficos é um fino balanço entre a proteção contra um agressor e a aquisição de benéficos (VAM WEES et al., 2008). Bordiec et al. (2010) estudaram a resposta de defesa da planta frente a bactérias endofíticas e não endofítcas. Os autores inocularam, em células de uva em suspensão, a endofítica Burkholderia phytofirmans PsJN e a não-endofítica Pseudomonas syringae pv pisi. Foi observado que ambas as espécies interagem fisicamente com as células vegetais (adesão), porém, Burkholderia phytofirmans PsJN desencadeou uma resposta imune local que é mais fraca do que a resposta a Pseudomonas syringae pv pisi.

Muitos trabalhos publicados ultimamente mostraram a utilização de PGPBs (plant growth-promoting bacteria) como biocontroladoras de doenças. Endofíticas podem conferir proteção às plantas conta patógenos pela indução de mecanismos de defesa vegetal, secreção de substâncias antagonistas a patógenos ou através de competição por sítios de colonização e por nutrientes (REINHOLD-HUREK; HUREK, 2011).

$\mathrm{O}$ óxido nítrico $(\mathrm{ON})$ é uma molécula sinal altamente reativa que facilmente se difunde e permeia membranas de células. $\mathrm{ON}$ reage rapidamente com proteínas, com varios receptores e fatores de transcrição. É um radical livre que tanto recebe quanto doa elétrons de estruturas mais favoráveis energeticamente. A molécula quando recebe elétrons se torna o radical nitroxil $\left(\mathrm{NO}^{-}\right)$e quando perde um elétron se torna o cátion nitrosium $\left(\mathrm{NO}^{+}\right)$ (ROMERO-PUERTAS et al., 2004). Em células animais, a produção de ON é catalizada pela enzima óxido nítrico sintase (ONS), sendo que a atividade desta enzima não é encontrada em células vegetais, porém, proteínas NOS-like foram detectadas em tecidos de plantas. Uma das fontes de ON nas plantas ocorre pela ação das enzims nitrato/nitrito redutases, cujos produtos geram ON com a participação de NAD(P)H (ARASIMOWICZ; FLORYSZAKWIECZOREK, 2007). Na literatura, o ON está associado à morte celular, fragmentação celular, estímulo da germinação de sementes em diferentes espécies, regulação do fechamento de estômatos induzido por ácido abicísico, amadurecimento de frutos e senescência de flores, 
e o principal para este trabalho, possui função de sinalização na vias de defesa de plantas contra patógenos.

Espécies reativas de oxigênio (EROs) são uma consequência inevitável do metabolismo aeróbio sendo produzido em mitocôndrias e cloroplastos na cadeia de transporte de elétrons. EROs inclui radicais livres como: $\mathrm{O}_{2}, \mathrm{O}_{2}^{-}, \mathrm{H}_{2} \mathrm{O}_{2}$ e $\mathrm{OH}^{-}$. Excesso de EROs é danoso para as células vegetais, podendo causar peroxidação de lipídios, oxidação de proteínas, danos no ácido nucleico e inibição de enzimas. É produzido diante de um estresse ambiental como: seca, salinidade e refrigeração. Pode também limitar o ingresso do patógeno, indução de morte celular e na transdução de sinal em vários processos de defesa (BARNA et al., 2012). A produção de EROs é rápida na planta como uma resposta de defesa contra a invasão por patógenos. (BOWELL et al., 2001). Ao mesmo tempo em que há a produção de EROs há um controle por parte da planta na produção de enzimas antioxidantes como: superóxido dismutase (SOD), catalase (CAT), glutationa redutase (GR), entre outras (SHARMA et al., 2012). Esta produção de antioxidantes ocorre para que o dano causado pelas EROs não se espalhe por toda a planta e haja somente na região da infecção, causando assim a morte das células da própria planta e por consequencia a morte do patógeno.

Muito dos efeitos causados por $\mathrm{ON}$ são mediados pela associação com $\mathrm{O}_{2}{ }^{-}$que forma um potente oxidante chamado peroxinitrito na reação: $\mathrm{ON}+\mathrm{O}_{2}{ }^{-} \rightarrow{ }^{-} \mathrm{ONOO}$. Altos níveis de peroxinitrito causam dano oxidativo profundo especialmente em ácidos nucleicos (MUR; CARVER; PRATS, 2005). 


\section{OBJETIVOS}

- Verificar se células vegetais, na forma de calos, atuam sobre o crescimento e a atividade da nitrogenase de bactérias diazotróficas, endofíticas isoladas de cana-deaçúcar;

- verificar se as bactérias contribuem com o teor proteico dos calos;

- analisar qual o tipo de interação ocorre quando dois gêneros bacterianos, estão associados;

- analisar se essas bactérias, quando combinadas, contribuem para células vegetais, aumentando seu teor proteico;

- analisar se o calo é um modelo de estudo para as interações planta-bactéria. 


\section{MATERIAL E MÉTODOS}

\subsection{Material Biológico}

\subsubsection{Microrganismos}

Neste trabalho foram estudadas 3 diferentes linhagens de bactérias endofíticas fixadoras de nitrogênio, Gram-negativas, isoladas de cana-de-açúcar da variedade SP 801816 no Laboratório de Fisiologia de Microorganismos/ICB/USP: Pseudomonas sp. (ICB383), Pantoea sp. (ICB409) e Enterobacter sp. (ICB113). Estas bactérias foram selecionadas a partir de estudos anteriores realizados no Laboratório de Fisiologia de Microrganismos.

\subsubsection{Material Vegetal}

Culturas de calos de cana-de-açúcar (Saccharum sp.), gentilmente fornecidas pelo Centro de Tecnologia Canavieira (CTC), induzidas a partir de tecidos de cana-de-açúcar da linhagem SP 801816.

\subsection{Meios de Cultura}

\subsubsection{Meio MS}

As culturas de calos foram mantidas a $\pm 25^{\circ} \mathrm{C}$, no escuro, em meio de cultura MS (tabela 1) suplementado com $3 \mathrm{mg} . \mathrm{L}^{-1}$ de 2,4-D (ácido 2,4-diclorofenoxiacético) e 20 g.L $\mathrm{L}^{-1}$ de sacarose. Os calos foram multiplicados por subculturas periódicas (20-30 dias) no Laboratório de Biologia Celular de Plantas (BIOCEL)/IB/USP.

\subsubsection{Meio MS modificado (MSM)}

Meio MS isento de fontes de nitrogênio combinado (tabela 1) foi utilizado nas coculturas para possibilitar a ocorrência da fixação de nitrogênio. Para o preparo dos meios sólido e semi-sólido foram adicionados 7 e 1,8 g.L $\mathrm{L}^{-1}$ deágar, respectivamente. 
Tabela 1 - Composição dos meios MS e MSM*

\begin{tabular}{|c|c|c|}
\hline Soluções & MS (g.L $\left.L^{-1}\right)$ & $\operatorname{MSM}\left(\right.$ g. $\left.L^{-1}\right)$ \\
\hline $\mathrm{NH}_{4} \mathrm{NO}_{3}$ & 1,65 & - \\
\hline $\mathrm{KNO}_{3}$ & 1,90 & - \\
\hline $\mathrm{K}_{2} \mathrm{HPO}_{4}$ & 0,17 & 0,17 \\
\hline $\mathrm{H}_{3} \mathrm{BO}_{3}$ & 0,0062 & 0,0062 \\
\hline KI & 0,0083 & 0,0083 \\
\hline $\mathrm{Na}_{2} \mathrm{MoO}_{4} \cdot 2 \mathrm{H}_{2} \mathrm{O}$ & 0,00025 & 0,00025 \\
\hline $\mathrm{CoCl}_{2} \cdot 6 \mathrm{H}_{2} \mathrm{O}$ & 0,000025 & 0,000025 \\
\hline $\mathrm{CaCl}_{2} \cdot 2 \mathrm{H}_{2} \mathrm{O}$ & 0,44 & 0,44 \\
\hline $\mathrm{MgSO}_{4} \cdot 7 \mathrm{H}_{2} \mathrm{O}$ & 0,37 & 0,37 \\
\hline $\mathrm{MnSO}_{4} \cdot \mathrm{H}_{2} \mathrm{O}$ & 0,0169 & 0,0169 \\
\hline $\mathrm{ZnSO}_{4} \cdot 7 \mathrm{H}_{2} \mathrm{O}$ & 0,0086 & 0,0086 \\
\hline $\mathrm{CuSO}_{4} .5 \mathrm{H}_{2} \mathrm{O}$ & 0,00025 & 0,00025 \\
\hline $\mathrm{Na}_{2}$ EDTA.2H $\mathrm{H}_{2} \mathrm{O}$ & 0,0373 & 0,0373 \\
\hline $\mathrm{FeSO}_{4} \cdot 7 \mathrm{H}_{2} \mathrm{O}$ & 0,0278 & 0,0278 \\
\hline Tiamina-HCl & 0,0001 & 0,0001 \\
\hline Piridoxina-HCl & 0,0005 & 0,0005 \\
\hline Ácido nicotínico & 0,0005 & 0,0005 \\
\hline Glicina & 0,002 & 0,002 \\
\hline Mio-inositol & 0,1 & 0,1 \\
\hline Sacarose & 20 & 20 \\
\hline
\end{tabular}

*MURASHIGE; SKOOG, 1962

\subsubsection{Meio JNFb}

Para o inóculo, manutenção das culturas e para a contagem de UFC das bactérias, foi utilizado o meio JNFb, meio este isento de nitrogênio combinado (tabela 2). 
Tabela 2 - Composição do meio JNFb*

\begin{tabular}{|c|c|}
\hline Composto & Concentração Final g.L ${ }^{-1}$ \\
\hline Ácido Málico & 5 \\
\hline $\mathrm{K}_{2} \mathrm{HPO}_{4}$ & 0,6 \\
\hline $\mathrm{KH}_{2} \mathrm{PO}_{4}$ & 1,8 \\
\hline $\mathrm{MgSO}_{4} .7 \mathrm{H}_{2} \mathrm{O}$ & 0,2 \\
\hline $\mathrm{NaCl}$ & 0,1 \\
\hline $\mathrm{CaCl}_{2} \cdot 2 \mathrm{H}_{2} \mathrm{O}$ & 0,02 \\
\hline $\mathrm{NaMoO}_{4} \cdot 2 \mathrm{H}_{2} \mathrm{O}$ & 0,002 \\
\hline $\begin{array}{c}\text { Azul de Bromotimol }(0,5 \% \\
\text { em } 2 \mathrm{~N} \text { de } \mathrm{KOH})\end{array}$ & $2 \mathrm{~mL}$ \\
\hline FeEDTA $(1,64 \%)$ & $4 \mathrm{~mL}$ \\
\hline КОH & 4,5 \\
\hline $\mathrm{CuSO}_{4} .5 \mathrm{H}_{2} \mathrm{O}$ & 0,00008 \\
\hline $\mathrm{ZnSO}_{4} .7 \mathrm{H}_{2} \mathrm{O}$ & 0,0024 \\
\hline $\mathrm{H}_{3} \mathrm{BO}_{3}$ & 0,0028 \\
\hline $\mathrm{MnSO}_{4} \cdot \mathrm{H}_{2} \mathrm{O}$ & 0,00235 \\
\hline Biotina & 0,00001 \\
\hline Piridoxol-HCl & 0,00002 \\
\hline
\end{tabular}

*DÖBEREINER; BALDANI; BALDANI, 1995

\subsection{Preparação do inóculo}

O inóculo de cada linhagem bacteriana foi preparado no meio de cultura seletivo líquido (JNFb), ao qual foi adicionado 1,0 g. $\mathrm{L}^{-1}$ de sulfato de amônio e foi incubado com agitação por 16 horas a $\pm 30{ }^{\circ} \mathrm{C}$. Alíquotas de $100 \mu \mathrm{L}$ desta cultura foram inoculadas em frascos tipo penicilina de $15 \mathrm{~mL}$ de volume, contendo 6,0 $\mathrm{mL}$ de meio MSM semi-sólido. Para os ensaios envolvendo mistura bacteriana $50 \mu \mathrm{L}$ de cada inóculo foram adicionados aos frascos e mantidos sob as mesmas condições. 


\subsection{Montagem dos sistemas de co-cultura}

Figura 1 - Foto do frasco de co-cultura

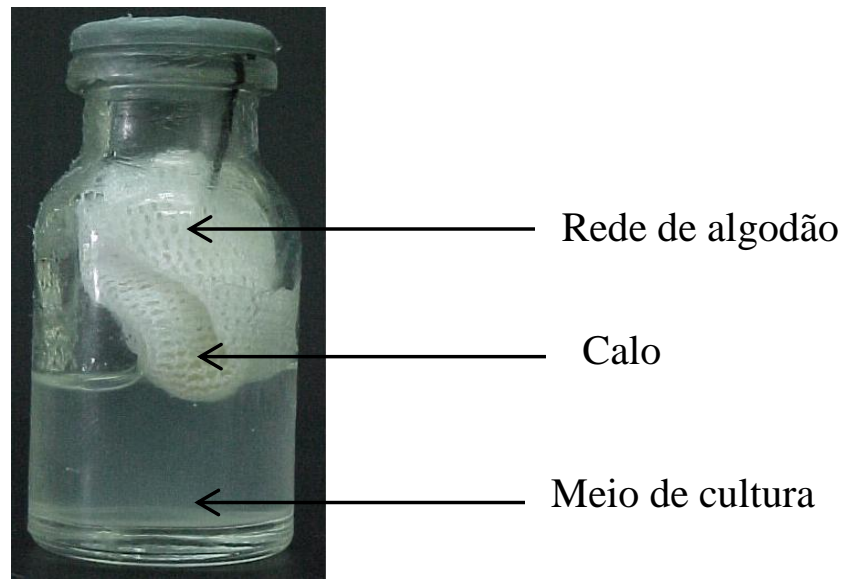

Para o estabelecimento dos sistemas de co-cultura foram usados calos de $0,2 \mathrm{~g}$. O calo foi colocado na superfície do meio recém-inoculado com a(s) bactéria(s) e sustentado por uma rede de algodão estéril presa à boca do frasco por uma linha (figura 1).

Primeiramente, os ensaios foram realizados com co-culturas (cultura + calo) e culturas puras das 3 bactérias, individualmente. Após isto, mais três ensaios foram realizados com a combinação de duas bactérias sem calo e com calo. Os ensaios com as bactérias individualmente foram utilizados como base de comparação das respostas das diferentes bactérias frente aos calos, quando a co-cultura foi feita com mais de uma bactéria associada.

Para cada ensaio foram inoculados 160 frascos contendo meio semi-sólido: 100 frascos para as co-culturas com calo (mistas ou simples) em meio MSM; 60 frascos para as culturas sem calo de bactérias (individuais ou misturadas) em meio MSM; 35 frascos apenas com o calo em meio MSM e 35 frascos apenas com o calo em meio MS. Os frascos foram incubados em estufa a $\pm 25{ }^{\circ} \mathrm{C}$, sem agitação, no escuro, por até sete semanas. As amostras foram retiradas periodicamente. Os tempos de medidas para UFC e atividade da nitrogenase foram: 0, 4,8, 24, 30, 48, 72, 96, 264, 600, 936, 1272 e na curvas realizadas com Pantoea sp. (figuras 12 e 15) foi acrescentado um ponto de 1392 horas. Para se medir o conteúdo proteico as amostras foram retiradas semanalmente durante sete semanas, ou seja: 0, 168, 336, 552, $720,888,1056,1224$ horas. 


\subsection{Verificação do efeito dos calos sobre as bactérias}

Para a verificação do efeito dos calos sobre as bactérias foram utilizados, por amostragem, 2 frascos de co-cultura e 2 da cultura pura para a contagem de unidades formadoras de colônias (UFC). O número de UFC das co-culturas simples foi determinado pelo método da gota (BARBOSA et al., 1995), enquanto que nos ensaios com as misturas de bactérias, foi utilizado o método de semeadura por espalhamento (MADIGAN; MARTINKO; PARKER, 2004). Para realizar a contagem de UFC das bactérias nas co-culturas simples, os microrganismos foram semeados no meio JNFb. Para a contagem em co-cultura mista, utilizou-se o mesmo meio, e as bactérias por serem morfologicamente distintas, foram facilmente diferenciadas e contadas.

A atividade da nitrogenase das bactérias foi analisada pelo método da redução de acetileno (ARA) (ANDERSON et al., 2004). De cada cultura a ser analisada, foi retirado $10 \%$ do volume do frasco $(1,5 \mathrm{ml})$ e adicionado $10 \%$ do volume da fase aérea $(0,9 \mathrm{ml})$ e em seguida incubados sem agitação, a $\pm 30{ }^{\circ} \mathrm{C}$, por 24 horas. Para cada amostragem foram utilizados 3 frascos de cada tratamento (co-cultura e cultura pura). A produção de etileno foi avaliada quantitativamente por cromatografia gasosa e as concentrações das amostras foram calculadas considerando-se os valores da curva padrão de etileno e aplicando-se a equação geral dos gases:

$$
\mathrm{n}=\mathrm{PV} / \mathrm{RT}
$$

\subsection{Verificação do efeito das bactérias sobre os calos}

Para a verificação do efeito das bactérias sobre os calos em cada amostragem, foram utilizados 5 calos para a determinação do conteúdo proteico. Os calos foram macerados em nitrogênio líquido e em seguida segui-se a extração de proteínas.

Para se extrair as proteínas $0,8 \mathrm{~mL}$ de tampão fosfato $(\mathrm{pH} 7,5)$ contendo $50 \mathrm{mM}$ de fosfato de sódio dibásico, $10 \mathrm{mM}$ de 2-mercaptoetanol e $50 \mathrm{mM}$ de fluoreto de fenilmetilsulfonil (PMSF) foram aplicados às amostras, que foram incubadas durante 30 minutos a $\pm 4{ }^{\circ} \mathrm{C}$. O material foi centrifugado por 10 minutos a $20000 \mathrm{~g} \mathrm{a} \pm 4{ }^{\circ} \mathrm{C}$. O precipitado foi re-extraído com $0,2 \mathrm{~mL}$ deste mesmo tampão. O sobrenadante, contendo as proteínas, foi armazenado a $-20{ }^{\circ} \mathrm{C}$ (SILVEIRA et al., 2004). A concentração de proteínas foi determinada 
utilizando-se o método de Bradford (1976), com albumina bovina como padrão em um espectrofotômetro Cary 50 Bio Spectrophotometer.

\subsection{Análises estatísticas}

Os dados foram analisados estatisticamente por ANOVA $(\mathrm{p}<0,05)$ seguido pelo teste Tukey $(p<0,05)$.

\subsection{Curvas realizadas}

Para um melhor entendimento dos gráficos, as legendas presentes neste trabalho serão explicadas a seguir, pois, podem acarretar dúvidas na interpretação dos resultados. As curvas obtidas nos ensaios realizados foram nomeadas em cultura pura e "Linhagem + calo" primeiramente: a curva cultura pura corresponde ao ensaio realizado em ausência de calo com somente uma bactéria presente e a curva "Linhagem + calo" corresponde ao experimento que foi executado na presença de calo com somente uma bactéria presente. Quando se realizou as culturas mistas as curvas dos gráficos foram nomeadas de acordo com as bactérias envolvidas no ensaio. Quando não houve a presença de calo, a curva foi nomeada de "Linhagem + Linhagem" e quando a mistura foi cultivada com o calo "Linhagem + Linhagem + calo".

Nas curvas de crescimento de culturas mistas apresentadas (figuras 3, 4, 5, 6, 8, 9, 10, $11,13,14,15,16)$ deve-se considerar que o nome do gênero que está escrito em primeiro lugar é o gênero bacteriano que está sendo analisado na figura em questão, por exemplo, quando se lê "Pantoea + Pseudomonas + calo" entende-se que a cultura analisada naquele gráfico é a de Pantoea sp.. Porém, nas curvas de atividade especifica da nitrogenase isto não é verdadeiro(figuras 19 - 22, 25 - 28, 31 - 34). Isto ocorreu porque para se calcular os valores da atividade específica da nitrogenase nas culturas mistas, utilizou-se a soma dos valores de UFC de Pseudomomas sp. e Pantoea sp. ou de Pseudomomas sp. e Enterobacter sp. O método utilizado para se medir a atividade da enzima é um método onde se detecta a quantidade de um produto (etileno) gasoso, assim, não foi possível diferenciar qual(ais) bactéria(s) foi capaz de reduzir o acetileno uma vez que o produto em questão mistura-se na fase aérea dos frascos analisados.

Nota-se também, que nos gráficos de UFC e de atividade da nitrogenase (figuras 4, 6, $9,11,14,16,18,20,22,24,26,28,30,32,34)$, houve uma adaptação dos eixos das abiscisas. 
Isto ocorreu para permitir uma melhor visualização dos valores obtidos na fase logarítimica do crescimento. Nos gráficos de atividade (figuras $24,26,28,30,32,34$ ) para se visualizar melhor os picos obtidos alterou-se também os eixos das ordenadas.

\subsection{Suspensão celular}

Quinhentos miligramas de células de cana-de-açúcar cultivadas em meio MS semisólido foram dissociadas e inoculadas em $50 \mathrm{ml}$ de meio MS líquido em frascos de $250 \mathrm{~mL}$. Estes frascos foram mantidos sob agitação $(120 \mathrm{rpm})$ a $25^{\circ} \mathrm{C} \pm 2$ no escuro realizando-se subcultivos a cada 21 dias. As células foram filtradas em peneira de dissociação celular Sigma $^{\circledR}$ S-1145 (Sigma-Aldrich, São Paulo, S.P., Brasil) malha $100 \mu \mathrm{m}$ e as células retidas foram utilizadas para os ensaios de medição de ON e EROs.

\subsection{Quantificação de EROs e ON}

A quantificação de EROs e ON nas suspensões celulares foram realizadas de acordo com a metodologia descrita por Silveira et al. (2006). Foram utilizadas $60 \mathrm{mg}$ das células em suspenção (seção 3.9), as quais foram inoculadas em $1 \mathrm{~mL}$ de meio MS líquido e mantidas por 1 hora sob agitação de $60 \mathrm{rpm}$, a $25^{\circ} \mathrm{C} \pm 2$.

Para a quantificação de ON, adicionou-se um marcador de fluorescência, o reagente DAR-4M (diaminorhodamine 4M) que é impermeável a membrana plasmática, determinando-se assim, o ON extracelular liberado. Para se quantificar o ON intracelular utilizou-se o reagente DAR-4M AM (diaminorhodamine 4M acetoxymethyl ester) que é permeável à membrana plasmática. Para a quantificação de EROs utilizou-se o reagente $\mathrm{H}_{2}$ DCFDA (2,7-dichlorodihydrofluorescein diacetate).Após a adição destes reagentes, foram adicionadas as células bacterianas em uma concetração de aproximadamente $10^{4}$ unidades formadoras de colônias.

A quantificação da fluorescência, após a incubação, foi determinada utilizando-se um fluorômetro (Victor 3TM - PerkingElmer), com excitação em comprimento de onda de 560 $\mathrm{nm}$, e emissão em $575 \mathrm{~nm}$ para DAR-4M e DAR-4M AM. Para $\mathrm{H}_{2}$ DCFDA utilizou-se o comprimento de onda de excitação em 502 nm e de emissão em $523 \mathrm{~nm}$. 


\section{RESULTADOS}

\subsection{Crescimento bacteriano}

\subsubsection{Enterobacter sp. ICB113}

\subsubsection{Cultura simples}

A figura 2 mostra as curvas de crescimento de Enterobacter sp. em cultura pura ou em co-cultura com calo. Quando em cultura pura, a bactéria apresentou um tempo de geraçãode 158 minutos (tabela 3). Após esta fase, a população permaneceu em fase estacionária até 600 horas, quando entrou em fase de declínio até o final do experimento. Quando em co-cultura, a população bacteriana apresentou um tempo de geração 147 minutos (tabela 3). Após este período, a população permaneceu constante igualmente até 600 horas sofrendo uma queda em seguida. As análises estatísticas mostraram que houve diferenças significativas entre as curvas de cultura pura e co-cultura entre 48 e 936 horas, sendo que a população bacteriana da cocultura foi favorecida, crescendo mais que a cultura pura.

Figura 2 - Curvas de crescimento de Enterobacter sp. ICB113 cultivada com ou sem a presença de calo.

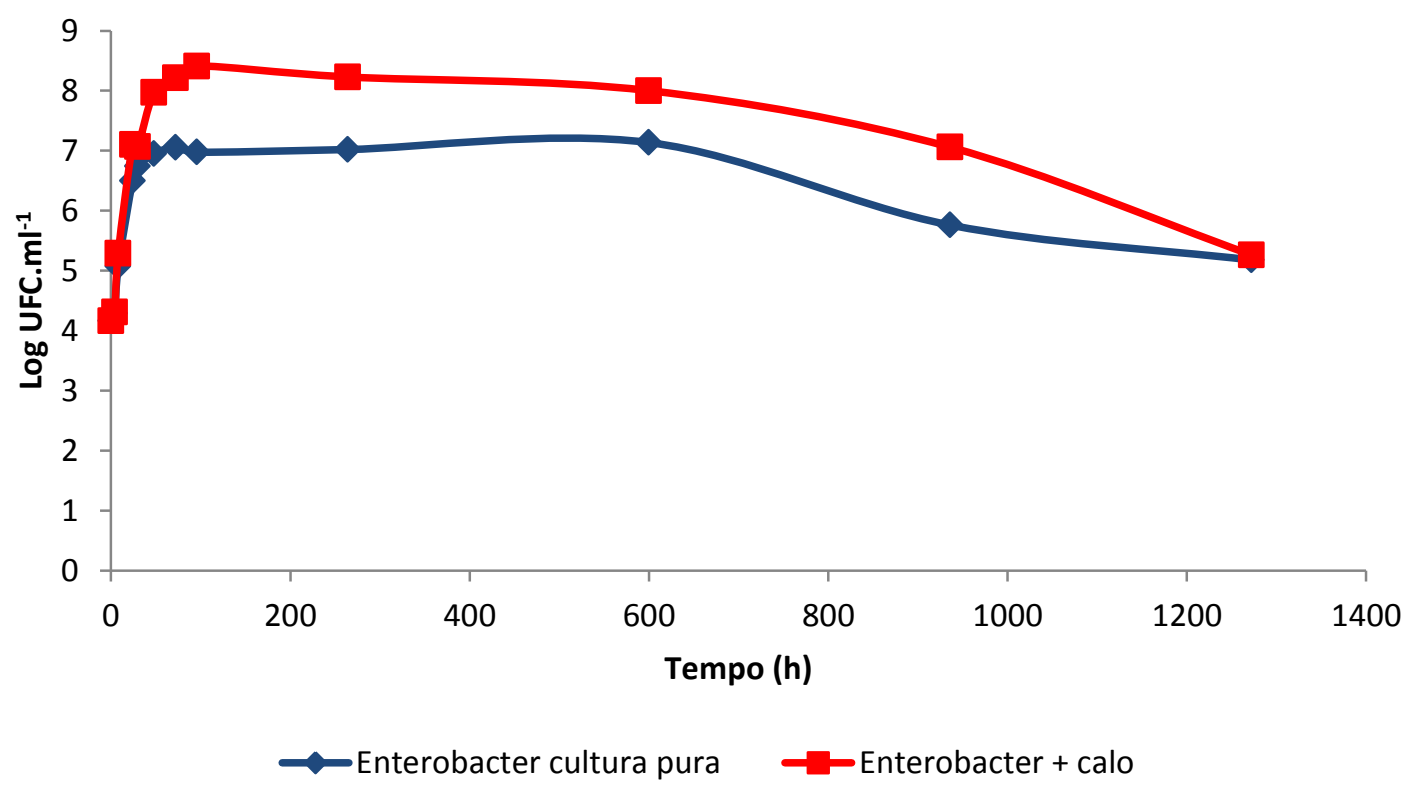




\subsubsection{Culturas mistas}

A figura 3 e 4 mostram o crescimento de Enterobacter spcultivada com Pseudomonas sp. ou com Pantoea sp., em ausência de calo. A figura 4 destaca as primeiras 200 horas de experimento e foi utilizada para se visualizar melhor as fases logarítmicas de crescimento. A curva "Enterobacter cultura pura" é a mesma mostrada na figura 2 e foi utilizada neste gráfico com o objetivo de se comparar o crescimento desta linhagem quandopura ou em presença das outras duas linhagens.Enterobacter sp. quando cultivada com Pantoea sp. apresentou um tempo de geração de 141 minutos (tabela 3). Após esta fase a população sofreu uma queda e, em seguida, permaneceu constante até 600 horas, quando houve um decréscimo gradual até o final do experimento. Houve diferença estatística entre as curvas "Enterobacter cultura pura" e "Enterobacter + Pantoea" a partir de 30 horas de experimento, uma vez que, a curva "Enterobacter + Pantoea" apresentou um crescimento menor que a curva "Enterobacter cultura pura". Quando Enterobacter sp. foi cultivada conjuntamente com Pseudomonas sp. apresentou um tempo de geração de 97 minutos (tabela 3). Após esta fase, a população foidecaindo ao longo do experimento, estabilizando-se após 936 horas. Houve diferença significativa entre as curvas "Enterobacter cultura pura" e "Entrerobacter + Pseudomonas" a partir de 8 horas de experimento, primeiro a curva "Entrerobacter + Pseudomonas" apresentou maior crescimento (figura 4), porém, após 264 horas, houve uma queda da população de Enterobacter sp. na curva "Entrerobacter + Pseudomonas", e a curva "Enterobacter cultura pura" apresentou maiores valores. 
Figura 3 - Curvas de crescimento de Enterobacter sp. ICB113 cultivada em ausência de calo (Enterobactercultura pura) e em mistura com Pantoea sp. ICB409 (Enterobacter + Pantoea) e Pseudomonas sp. ICB383 (Enterobacter + Pseudomonas) em ausência de calo.

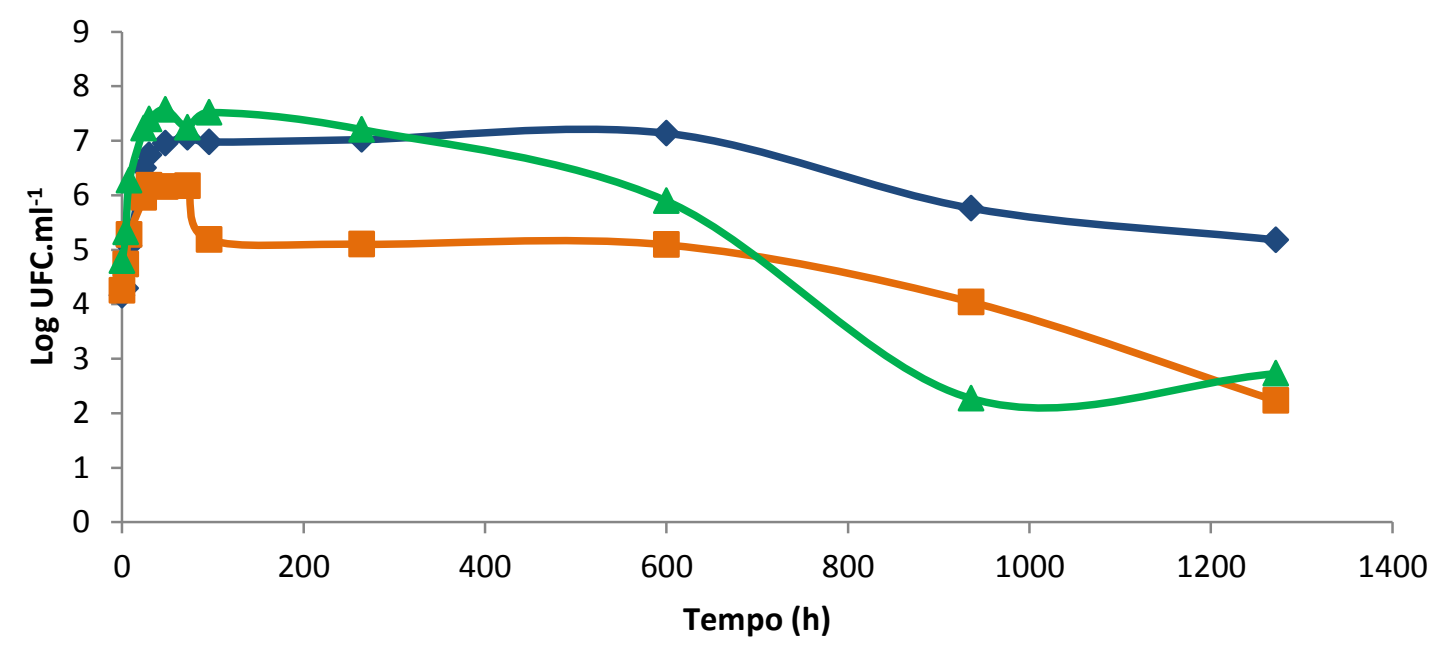

Enterobacter cultura pura $\longrightarrow$ Enterobacter + Pantoea $\rightarrow$ Enterobacter + Pseudomonas

Figura 4 - Curvas de crescimento de Enterobacter sp. ICB113 cultivada em ausência de calo (Enterobacter cultura pura) e em mistura com Pantoea sp. ICB409 (Enterobacter + Pantoea) e Pseudomonas sp. ICB383 (Enterobacter + Pseudomonas) em ausência de calo.

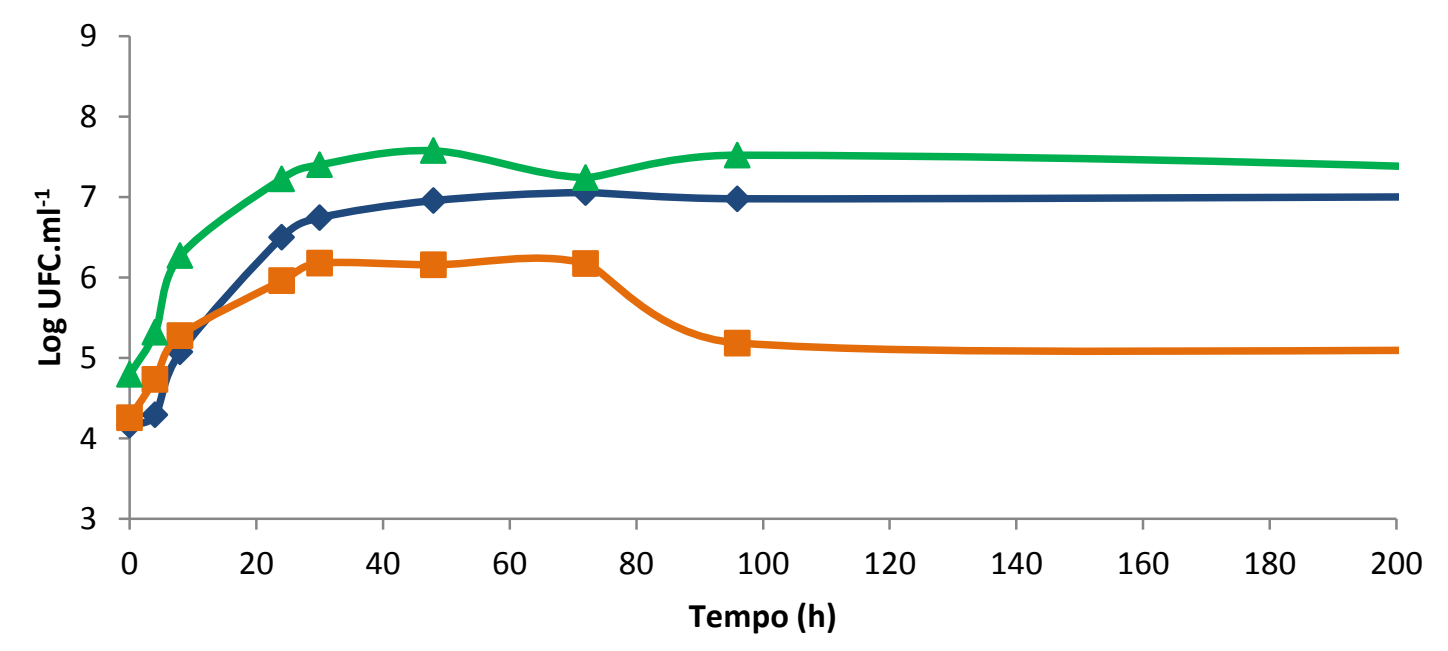

$\sim$ Enterobacter cultura pura $\longrightarrow$ Enterobacter + Pantoea $\longrightarrow$ Enterobacter + Pseudomonas

As figuras 5 e 6 mostram o crescimento de Enterobacter sp.quando cultivada com Pseudomonas sp. ou com Pantoea sp., ambas em presença de calo. A curva "Enterobacter + calo" é a mesma mostrada na figura 2 e foi utilizada neste gráfico com o objetivo de se 
comparar o crescimento desta linhagem, na presença de calo, quando cultivada sozinha, com o cultivo com as outras duas linhagens.

Enterobacter sp. cultivada em mistura com Pantoea sp. (figura 6) em presença de calo apresentou um tempo de geração de 82 minutos (tabela 3). O número de células aumentou até 24 horas quando sofreu uma queda e se manteve praticamente constante até o final do experimento. Houve diferenças significativas entre as curvas "Enterobacter + calo" e "Enterobacter + Pantoea + calo" entre 4 e 8 horas, onde "Enterobacter + Pantoea + calo" apresentou um crescimento maior e a partir de 48 horas, quando a curva "Enterobacter + Pantoea + calo" sofreu uma queda. Quando Enterobacter sp. foi cultivada com Pseudomonas sp. e calo, a população de Enterobacter sp. apresentou um tempo de geração de 80 minutos (tabela 3). Após 72 horas, observou-se uma diminuição da população seguida de estabilização. Houve diferença significativa entre as curvas "Enterobacter + calo" e "Enterobacter + Pseudomonas + calo" entre os pontos 8 e 30 horas quando a curva "Enterobacter + Pseudomonas + calo" apresentou maior crescimento e após 96 horas até 936 horas quando a curva "Enterobacter + Pseudomonas + calo" sofreu uma diminuição de seus valores.

Figura 5 - Curvas de crescimento de Enterobacter sp. ICB113 cultivada em presença de calo $($ Enterobacter + calo) e em mistura com Pantoea sp. ICB409 (Enterobacter + Pantoea + calo) e com Pseudomonas sp. ICB383 (Enterobacter + Pseudomonas + calo) em presença de calo.

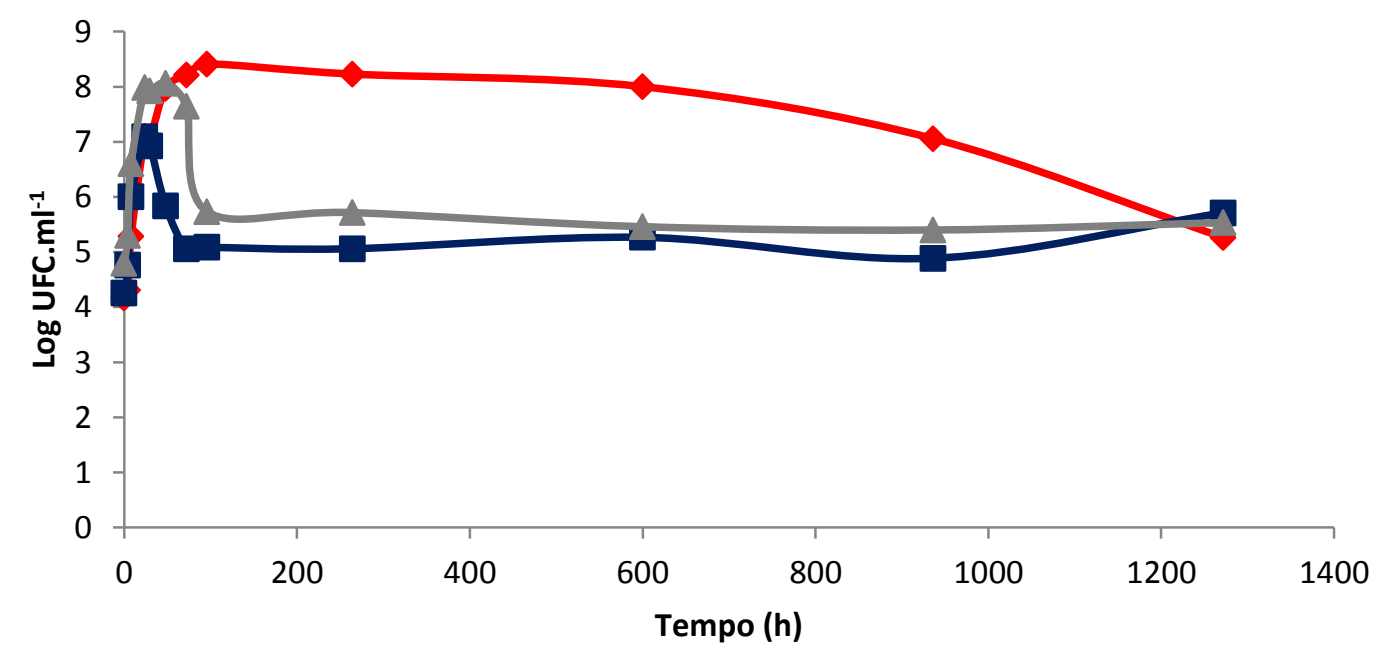

$\sim$ Enterobacter + calo $\neg$ Enterobacter + Pantoea + calo $\longrightarrow$ Enterobacter + Pseudomonas + calo 
Figura 6 - Curvas de crescimento de Enterobacter sp. ICB113 cultivada em presença de calo (Enterobacter + calo) e em mistura com Pantoea sp. ICB409 (Enterobacter + Pantoea + calo) e com Pseudomonas sp. ICB383 (Enterobacter + Pseudomonas + calo) em presença de calo.

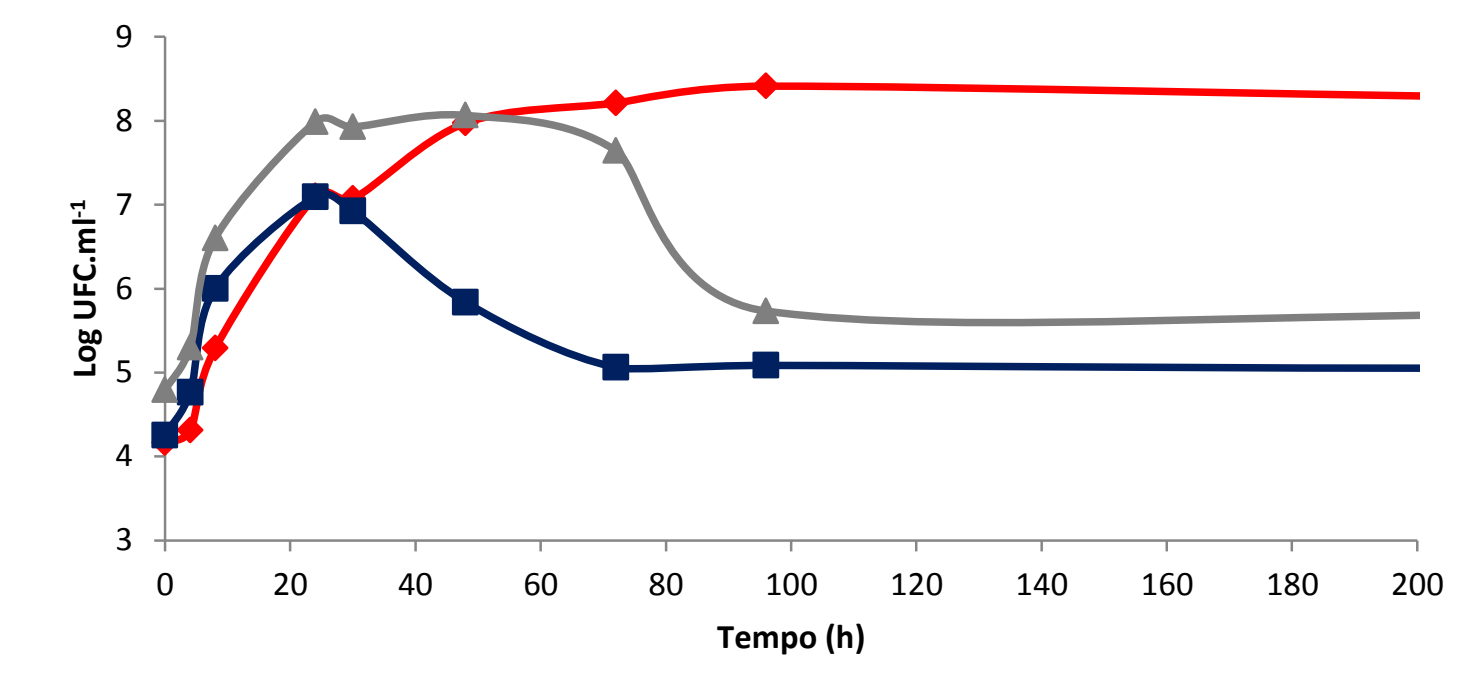

$\longrightarrow$ Enterobacter + calo $\longrightarrow$ Enterobacter + Pantoea + calo - Enterobacter + Pseudomonas + calo

Para se analisar o que ocorreu quando a mistura foi cultivada com calo ou sem calo, viu-se a necessidade de se comparar as figuras 3 e 4 com as figuras 5 e 6 . Observou-se que, quando Enterobacter sp. foi cultivado com Pantoea sp. sem calo, sua população apresentou um tempo de geração de 141 minutos (tabela 4) e após a fase exponencial, houve uma queda populacional. Quando a mistura foi cultivada com calo, a população de Enterobacter sp. apresentou um tempo de geração de 82 minutos (tabela 3), sofreu queda após a fase exponencial e mateve-se constante até o final do experimento. As curvas "Enterobacter + Pantoea" e "Enterobacter + Pantoea + calo" só são diferentes sigificativamente a partir de 936 horas quando a curva "Enterobacter + Pantoea" sofreu uma queda. Quando Enterobacter sp. foi cultivada com Pseudomonas sp. (figura 4) sem calo, o tempo de geração foi de 97 minutos (tabela 3) diminuindo a população após 600 horas, quando a mistura foi cultivada com o calo (figura 6), a população de Enterobacter sp. apresentou um tempo de geração de 80 minutos, após a fase exponencial de crescimento houve uma queda dos valores que permaneceram constantes até o final do experimento. As curvas "Enterobacter + Pseudomonas" e "Enterobacter + Pseudomonas + calo" são diferente entre 96 e 264 horas com a curva "Enterobacter + Pseudomonas" apresentando maiores valores, e a partir de 600 horas, quando esta mesma curva sofreu uma queda brusca, apresentando valores menores que a curva "Enterobacter + Pseudomonas + calo". 


\subsubsection{Pseudomonas sp. ICB383}

\subsubsection{Cultura simples}

A figura 7 mostra as curvas de crescimento de Pseudomonas sp. cultivada com e sem calo. Quando em cultura pura, a população bacteriana apresentou um tempo de geração de 103 minutos (tabela 4). Após 96 horas de cultivo ocorreu uma leve queda na população, que em seguida, se estabilizou. Quando em co-cultura com o calo, Pseudomonas sp. apresentou um tempo de geração de 84 minutos (tabela 4). Semelhante à queda ocorrida na curva de cultura pura, a população diminuiu após 96 horas e após 264 horas estabilizou-se até o final do experimento. Neste caso, a queda no número de bactérias foi maior que no controle. Houve diferença significativa entre as curvas da figura 7 entre 264 e 936 horas.

Figura 7 - Curvas de crescimento de Pseudomonas sp. ICB383 cultivada com ou sem a presença de calo.

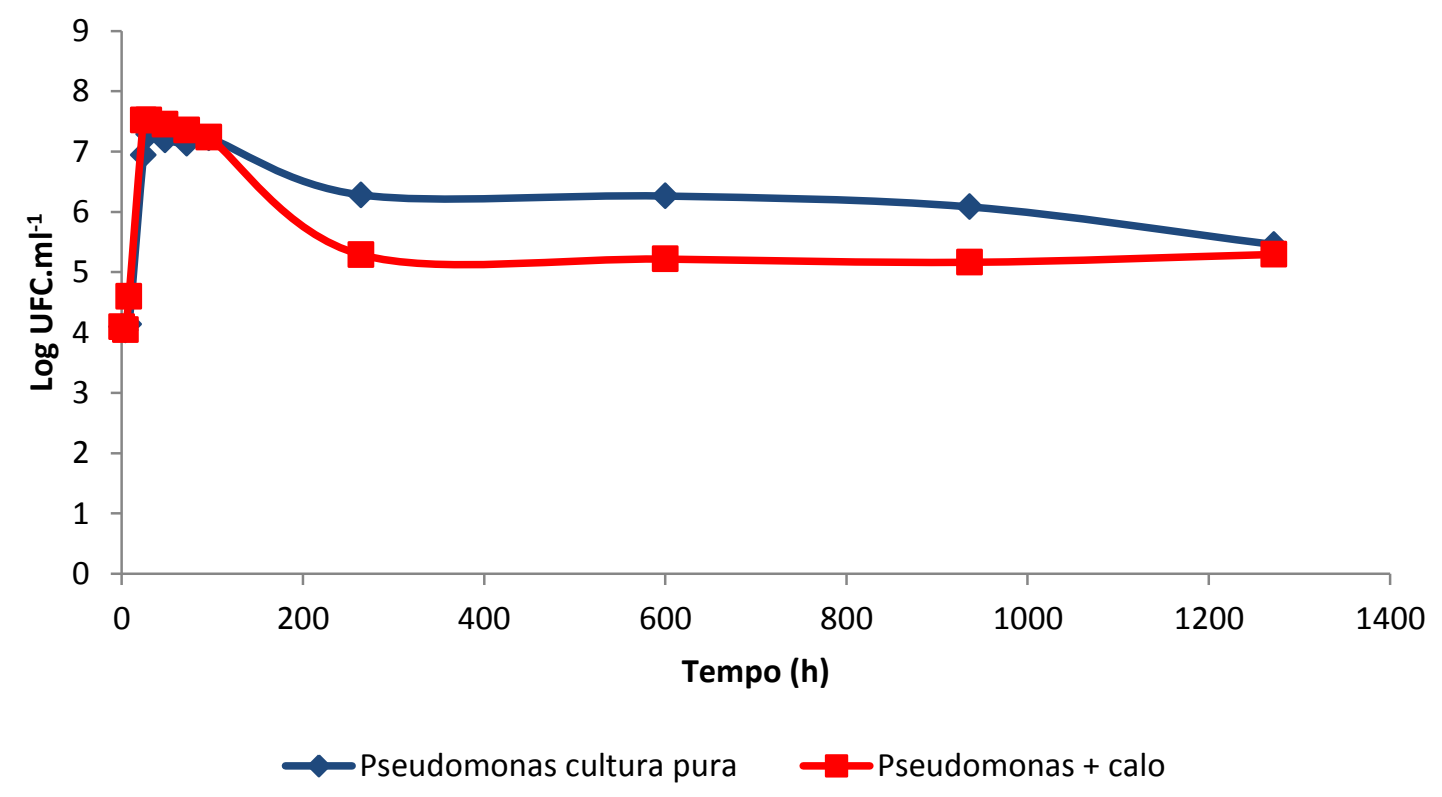

\subsubsection{Culturas mistas}

As figuras 8 e 9 mostram Pseudomonas sp. cultivada com Enterobacter sp. ou Pantoea sp., em ausência de calo. A curva "Pseudomonas cultura pura" é a mesma mostrada na figura 7. Cultivada com Enterobacter sp., a população de Pseudomonas sp. apresentou um tempo de geração de 79 minutos (tabela 4). Após 72 horas de cultivo a população bacteriana diminuiu gradualmente se estabilizando ao final do experimento. Houve diferença estatística 
entre as curvas "Pseudomonas cultura pura" e "Pseudomonas + Enterobacter" entre 4 e 8 horas (figura 9) quando a curva "Pseudomonas + Enterobacter" apresentou valores maiores e após às 96 horas de ensaio, quando a curva "Pseudomonas + Enterobacter" sofreu um queda de seus valores. Quando Pseudomonas sp. foi cultivada com Pantoea sp. apresentou um tempo de geração de 138 minutos (tabela 4). Após 264 horas não se detectou mais células viáveis de Pseudomonas sp.. Diferenças estatísticas entre as curvas "Pseudomonas cultura pura" e "Pseudomonas + Pantoea" foram encontradas após 96 horas de experimento, quando houve a extinção da população de Pseudomonas sp. na curva "Pseudomonas + Pantoea".

Figura 8 - Curvas de crescimento de Pseudomonas sp. ICB383 cultivada em ausência de calo (Pseudomonas cultura pura) e em mistura com Enterobacter sp. ICB113 (Pseudomonas + Enterobacter) e com Pantoea sp. ICB409 (Pseudomonas + Pantoea) sem a presença de calo.

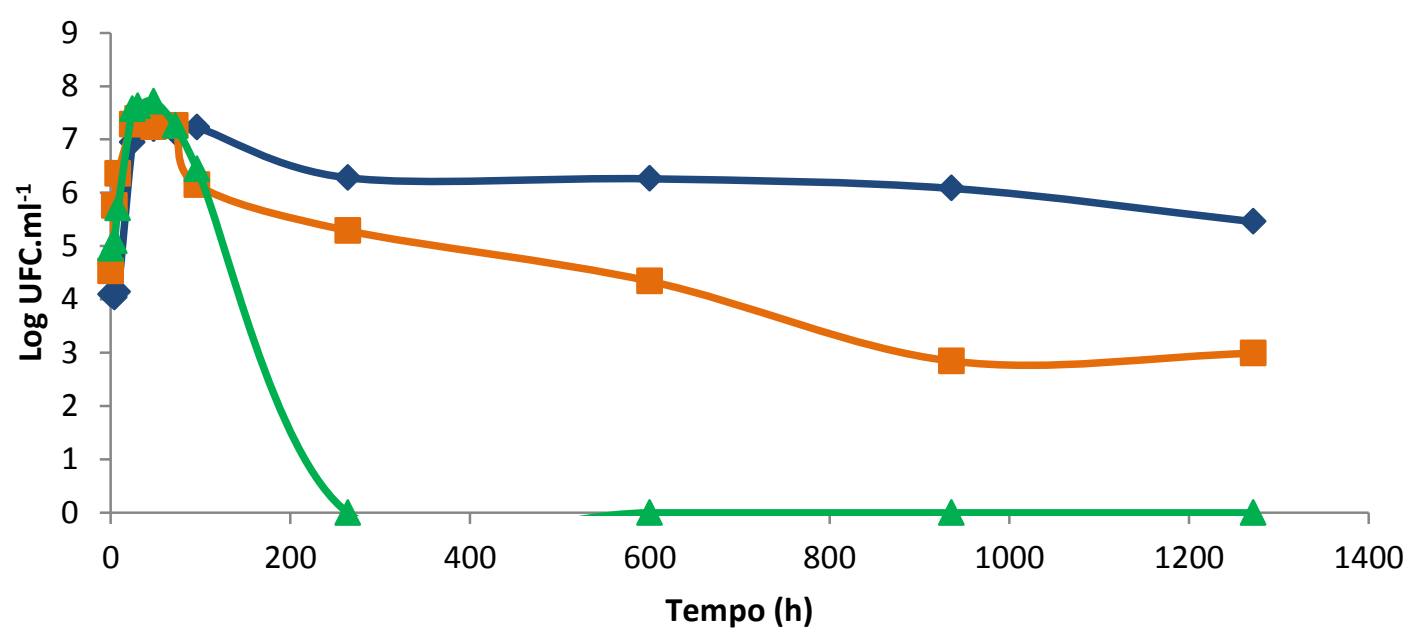

$\sim$ Pseudomonas cultura pura $\longrightarrow$ Pseudomonas + Enterobacter $\rightarrow$ Pseudomonas + Pantoea 
Figura 9 - Curvas de crescimento de Pseudomonas sp. ICB383 cultivada em ausência de calo (Pseudomonas cultura pura) e em mistura com Enterobacter sp. ICB113 (Pseudomonas + Enterobacter) e com Pantoea sp. ICB409 (Pseudomonas + Pantoea) sem a presença de calo.

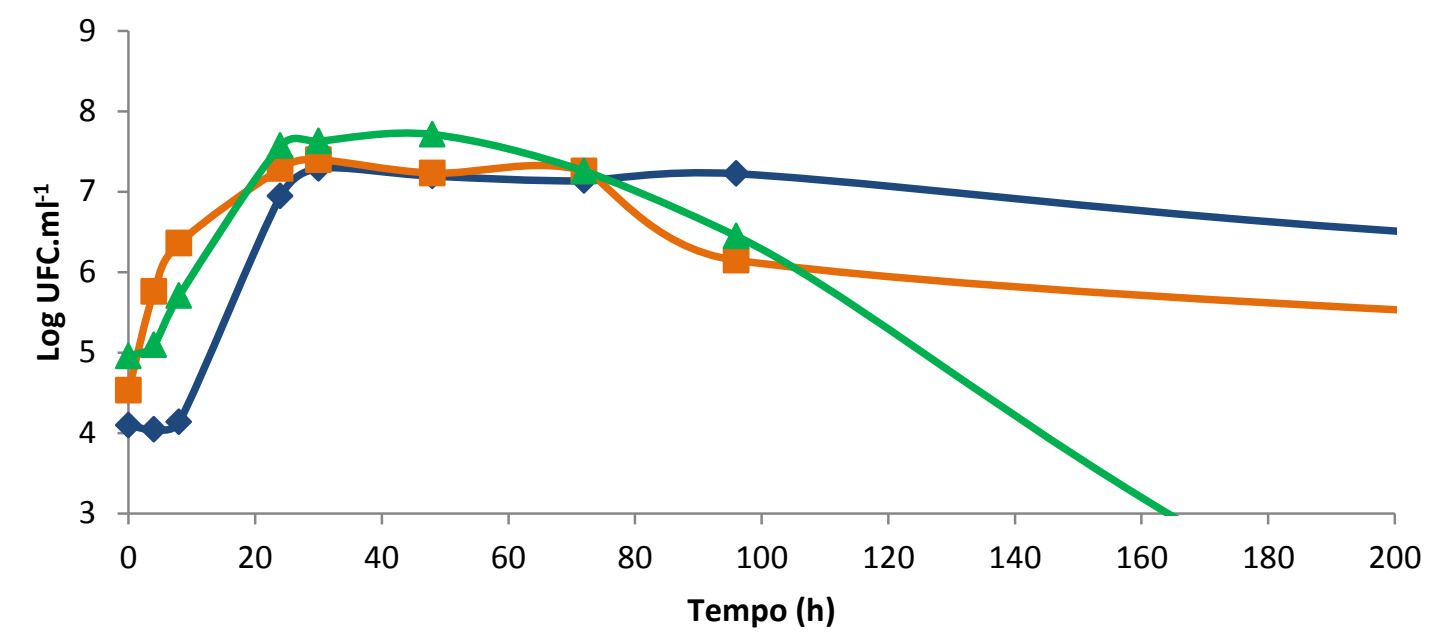

$\sim$ Pseudomonas cultura pura $\rightarrow$ Pseudomonas + Enterobacter $\rightarrow$ Pseudomonas + Pantoea

As figuras 10 e 11 mostram Pseudomonas sp. cultivada com Enterobacter sp. ou Pantoea sp., em presença de calo. A curva "Pseudomonas + calo" é a mesma mostrada na figura 7. Quando cultivada com Enterobacter sp. e calo, Pseudomonas sp. apresentou um tempo de geração de 77 minutos (tabela 4). Porém, após 8 horas de cultivo, células bacterianas viáveis de Pseudomonas sp. ICB383 não foram mais encontradas. Diferenças significativas entre as curvas "Pseudomonas + calo" e "Pseudomonas + Enterobacter + calo" foram encontradas a partir de 8 horas de cultivo devido a extinção da população de Pseudomonas sp. na curva "Pseudomonas + Enterobacter + calo". Quando Pseudomonas sp. foi cultivada conjuntamente com Pantoea sp. e calo, sua população apresentou um tempo de geração de 333 minutos (tabela 4). Após 24 horas de ensaio não se detectou mais a presença de Pseudomonas sp.. Diferenças estatísticas entre as curvas "Pseudomonas + calo" e "Pseudomonas + Pantoea + calo" foram encontradas após 24 horas de experimentodevido a extinção da população de Pseudomonas sp. na curva "Pseudomonas + Pantoea + calo". 
Figura 10 - Curvas de crescimento de Pseudomonas sp. ICB383 cultivada em presença de calo (Pseudomonas + calo) e em mistura com Enterobacter sp. ICB113 (Pseudomonas + Enterobacter + calo) e com Pantoea sp. ICB409 (Pseudomonas + Pantoea + calo) em presença de calo.

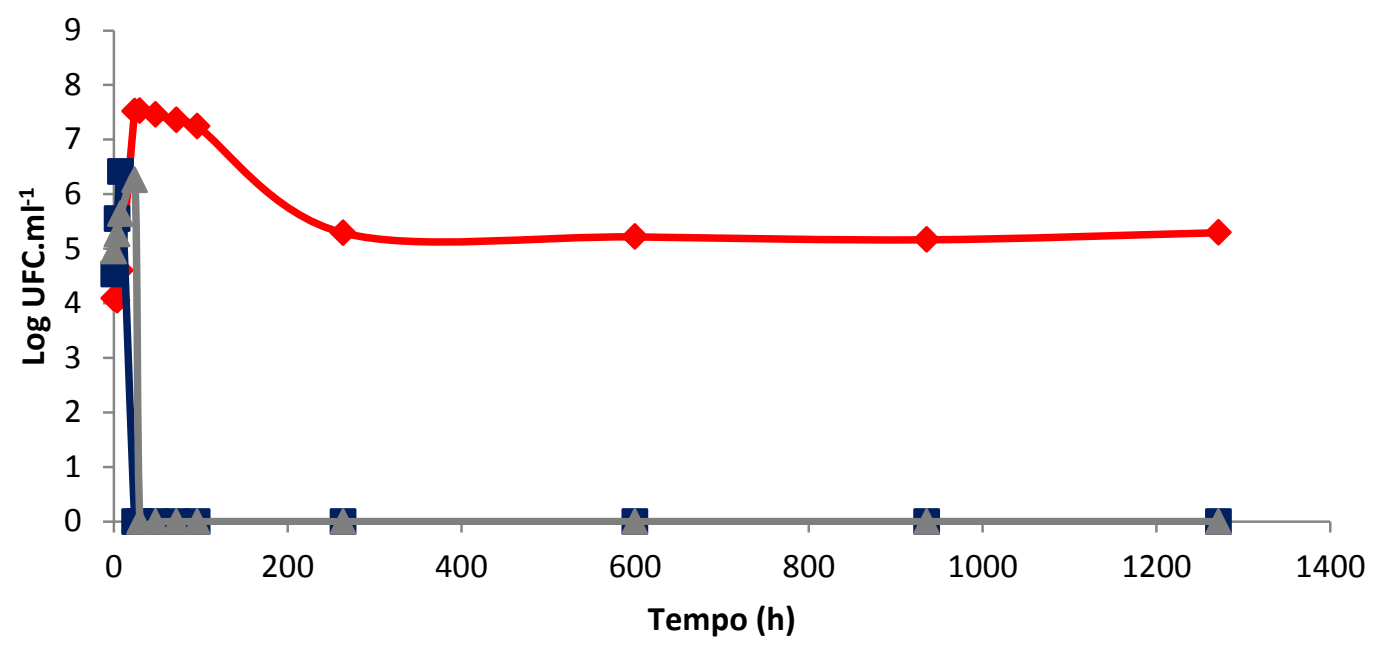

-Pseudomonas + calo $\_$Pseudomonas + Enterobacter + calo $\longrightarrow$ Pseudomonas + Pantoea + calo

Figura 11 - Curvas de crescimento de Pseudomonas sp. ICB383 cultivada em presença de calo (Pseudomonas + calo) e em mistura com Enterobacter sp. ICB113 (Pseudomonas + Enterobacter + calo) e com Pantoea sp. ICB409 (Pseudomonas + Pantoea + calo) em presença de calo.

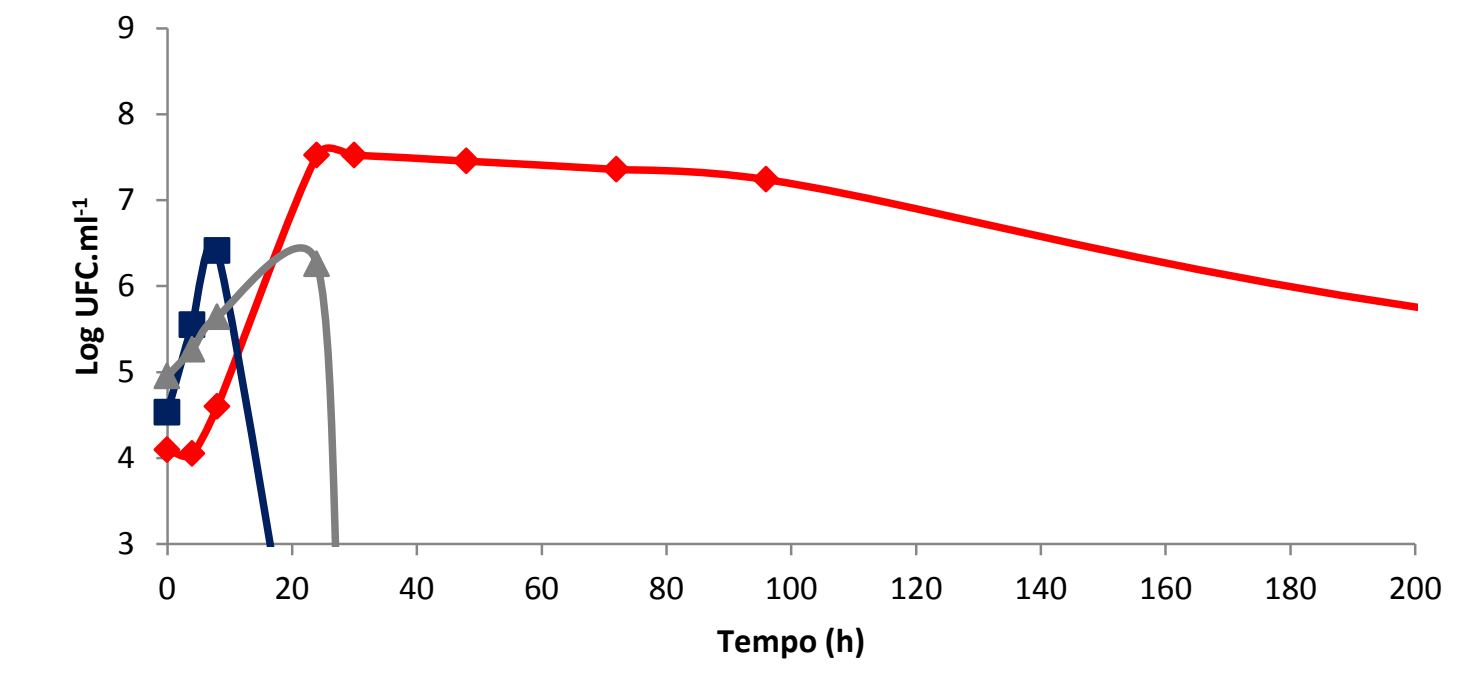

$\longrightarrow$ Pseudomonas + calo $\longrightarrow$ Pseudomonas + Enterobacter + calo $\longrightarrow$ Pseudomonas + Pantoea + calo

Para se analisar o que ocorreu quando s misturas foram cultivadas com ou sem calo foi viu-se a necessidade de se comparar as figuras 8 e 9 com as figuras 10 e 11 . Observou-se que a população de Pseudomonas sp. quando cultivada com Enterobacter sem calo, apresentou um tempo de geração de 79 minutos (tabela 4). Quando esta mistura foi cultivada com o calo, 
o tempo de geração de Pseudomonas sp. foi de 77 minutos (tabela 4) e suas células viáveis não foram mais detectada após 8 horas de cultivo. As curvas "Pseudomonas + Enterobacter" e "Pseudomonas + Enterobacter + calo" são diferentes estatísticamente a partir de 8 horasdevido a extinção da população de Pseudomonas sp. na curva "Pseudomonas + Enterobacter + calo". Quando Pseudomonas sp. foi cultivada com Pantoea sp. observou-se que a população de Pseudomonas sp. apresentou um tempo de geração de 138 minutos (tabela 4), porém quando a mistura foi cultivada com o calo, o tempo de geração de Pseudomonas sp. aumentou para 333 minutos (tabela 4). As curvas "Pseudomonas + Pantoea" e "Pseudomonas + Pantoea + calo" são diferentes significativamente entre 24 e 264 horas, período este em que somente havia células viáveis de Pseudomonas sp.na co-cultura com Pantoea sp..

\subsubsection{Pantoea sp. ICB409}

\subsubsection{Cultura simples}

A figura 12 mostra as curvas de crescimento de Pantoea sp. cultivada com ou sem o calo. Quando cultivada sem calo, observou-se um tempo de geração de 96 minutos (tabela 5). Após esta fase, a população começou a declinar, estabilizando após 1272 horas. Quando em co-cultura, a população bacteriana apresentou um tempo de geração de 107minutos (tabela 5). Após este período, ocorreu uma queda gradativa e constante que ocasionou a morte da população. A partir das 96 horas de experimento houve diferenças significativas entre as curvas cultura pura e co-cultura mostradas neste gráfico, quando a população de Pantoea sp. decaiu na cultura com o calo. 
Figura 12 - Curvas de crescimento de Pantoea sp. ICB409 cultivada com ou sem a presença de calo.

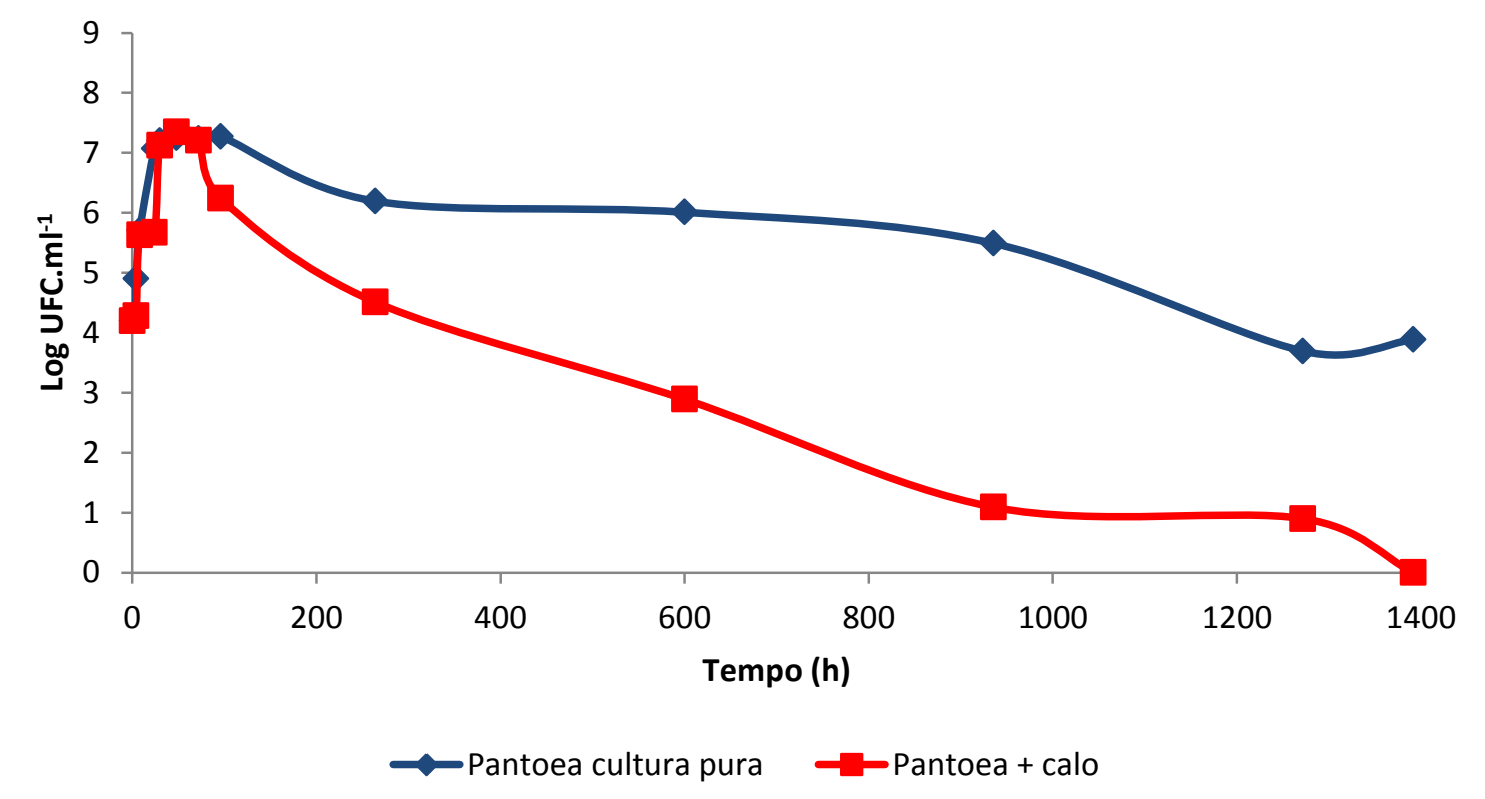

\subsubsection{Culturas mistas}

As figuras 13 e 14 mostram as curvas de crescimento de Pantoea sp. em mistura com Enterobacter sp. ou Pseudomonas sp., em ausência de calo. A curva "Pantoea cultura pura" foi descrita na figura 12 e utilizada neste gráfico somente para comparação. Quando Pantoea sp. foi cultivada em mistura com Enterobacter sp. em ausência de calo, (figura 13), apresentou inicialmente um tempo de geração de 144 minutos (tabela 5).Após esta fase, a população bacteriana sofreu uma queda gradual até o final do experimento. Quando Pantoea sp. foi cultivada com Pseudomonas sp. apresentou um tempo de geração de 207 minutos (tabela 5). Após a fase exponencial,apresentou um perfil semelhante ao das outras duas curvas, ou seja, queda gradual até o final do experimento. Não houve diferenças significativas entre as curvas apresentadas nas figuras 13 e 14 . 
Figura 13 - Curvas de crescimento de Pantoea sp. ICB409 cultivada em ausência de calo (Pantoea cultura pura) e em mistura com Enterobacter sp. ICB113 (Pantoea + Enterobacter) e com Pseudomonas sp. ICB383 (Pantoea + Pseudomonas) em ausência de calo.

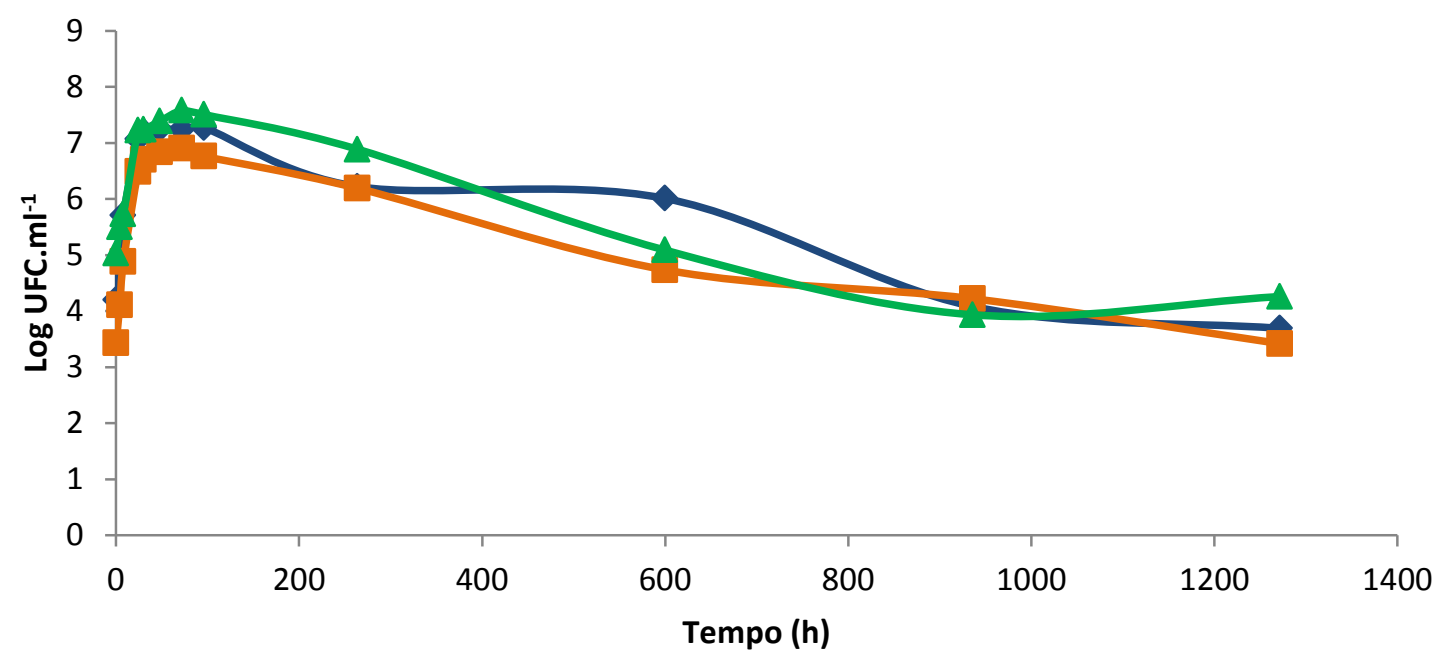

-Pantoea cultura pura $\quad \longrightarrow$ Pantoea + Enterobacter $\rightarrow$ Pantoea + Pseudomonas

Figura 14 - Curvas de crescimento de Pantoea sp. ICB409 cultivada em ausência de calo (Pantoea cultura pura) e em mistura com Enterobacter sp. ICB113 (Pantoea + Enterobacter) e com Pseudomonas sp. ICB383 (Pantoea + Pseudomonas) em ausência de calo.

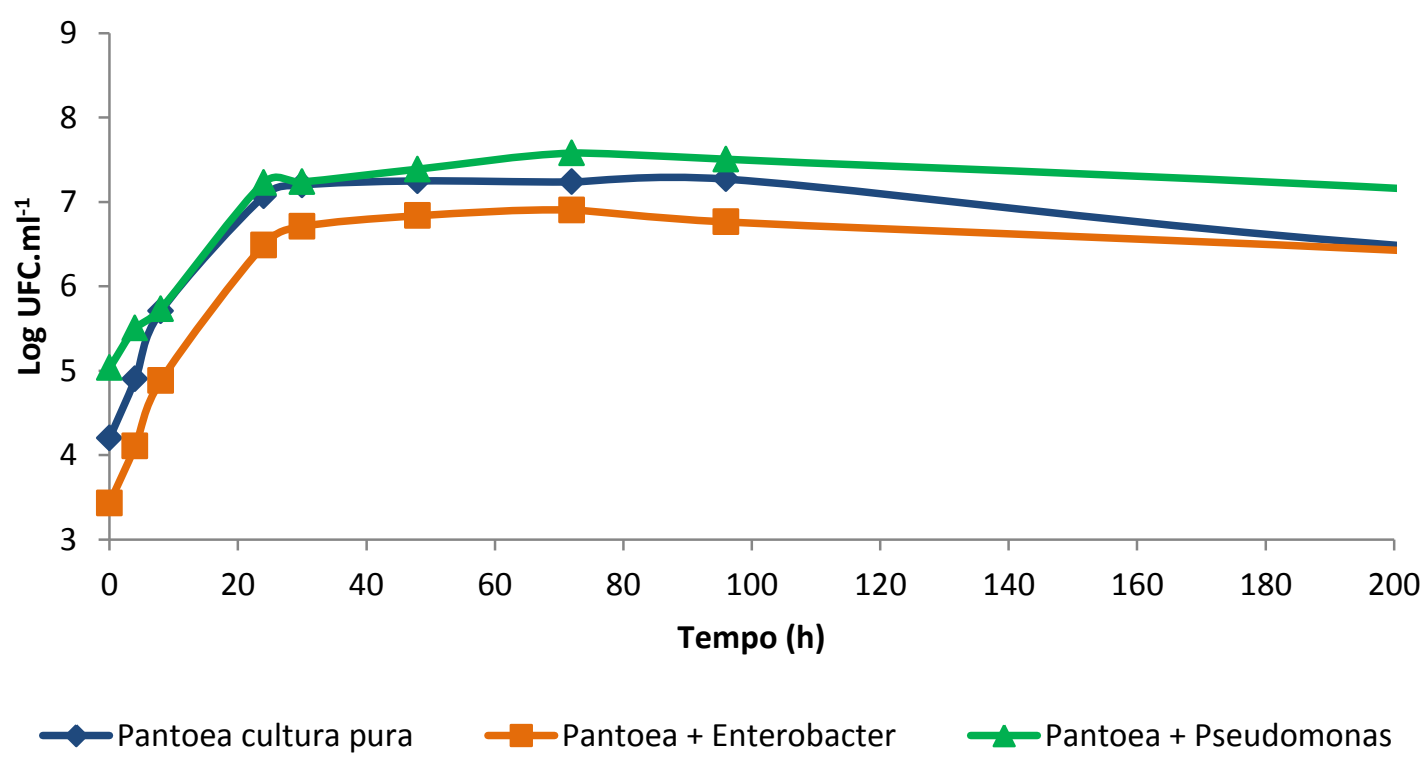

As figuras 15 e 16 mostram a população de Pantoea sp., quando em mistura com Enterobacter sp. ou Pseudomonas sp., em presença de calo. A curva "Pantoea + calo" foi descrita na figura 12. Quando Pantoea sp. foi cultivada conjuntamente com Enterobacter sp. e calo, apresentou um tempo de geração de 117 minutos (tabela 5). Depois deste período a 
população sofreu uma queda brusca, mas, após 96 horas, a população se estabilizou. Diferenças significativas foram encontradas entre as curvas "Pantoea + calo" e "Pantoea + Enterobacter + calo" a partir das 48 horas de ensaio. Entre 48 e 264 horas, a curva "Pantoea + Enterobacter + calo" apresentou menores valores, porém a partir de 600 horas, esta curva se estabilizou apresentando maiores valores que a curva "Pantoea + calo" que estava em declínio. Quando Pantoea sp. foi cultivada com Pseudomonas sp. e calo, a população de Pantoea sp. apresentou um tempo de geração de 91 minutos (tabela 5), mas,após 96 horas não foram mais encontradas células viáveis de Pantoea sp.. Os pontos das curvas "Pantoea + calo" e "Pantoea + Pseudomonas + calo" são diferentes significativamente a partir das 30 horas. Primeiramente está diferença foi entre 30 e 96 horas quando observou-se valores maiores na curva "Pantoea + Pseudomonas + calo" porém, após 96 horas, com a morte da população de Pantoea sp. a curva "Pantoea + calo" apresentou valores maiores.

Figura 15 - Curvas de crescimento de Pantoea sp. ICB409 cultivada em presença de calo $($ Pantoea + calo) e em mistura com Enterobacter sp. ICB113 (Pantoea + Enterobacter + calo) e com Pseudomonas sp. ICB383 (Pantoea + Pseudomonas + calo) em presença de calo.

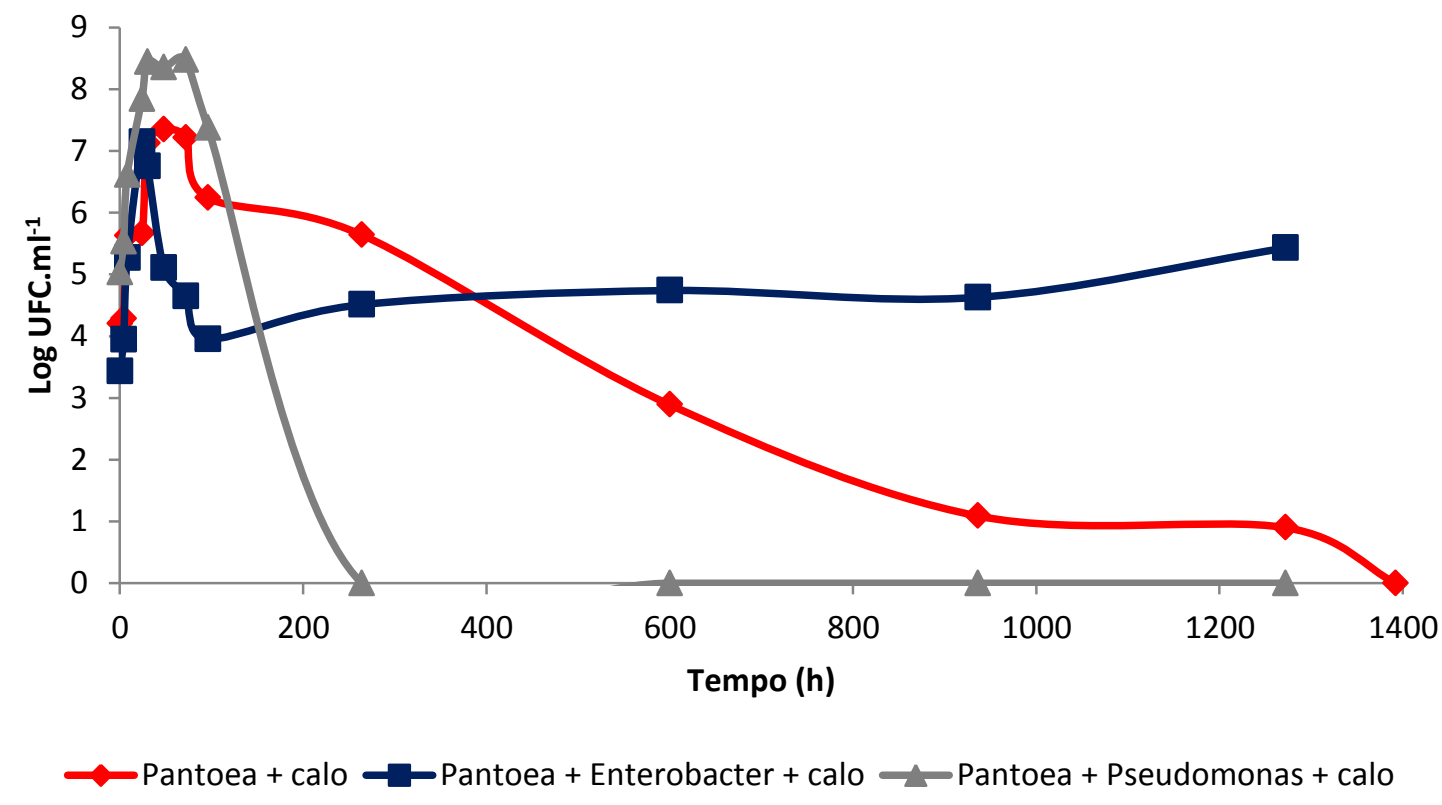


Figura 16 - Curvas de crescimento de Pantoea sp. ICB409 cultivada em presença de calo $($ Pantoea + calo) e em mistura com Enterobacter sp. ICB113 (Pantoea + Enterobacter + calo) e com Pseudomonas sp. ICB383 (Pantoea + Pseudomonas + calo) em presença de calo.

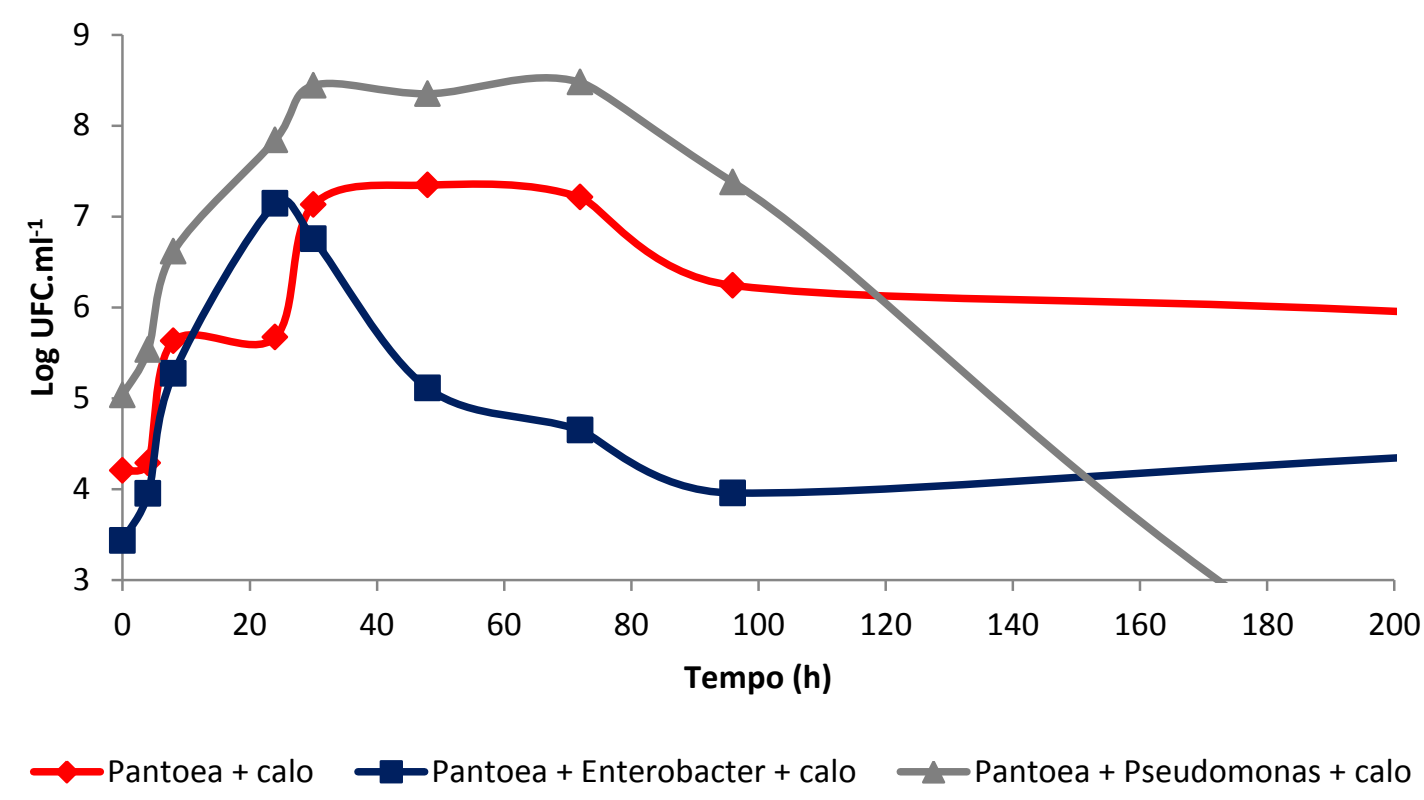

Para se analisar o que ocorreu quando as misturas foram cultivadas com ou sem calo, viu-se a necessidade de se comparar as figuras 13 e 14 com as figuras 15 e 16. Quando Pantoea sp. foi cultivada com Enterobacter sp., em ausência de calo, observou-se no crescimento de Pantoea sp. um tempo de geração de 144 minutos (tabela 5), após a fase exponencial houve queda seguida de estabilidade da população. Quando esta mistura foi cultivada com o calo, a população de Pantoea sp. apresentou um tempo de geração de 117 minutos (tabela 5), após a fase exponencial houve queda seguida de estabilidade da população. As curvas "Pantoea + Enterobacter" e "Pantoea + Enterobacter + calo" são diferentes entre 48 e 264 horas, quando observou-se valores maiores na curva "Pantoea + Enterobacter" e em 1272 horas, quando os maiores valores pertenciam à curva "Pantoea + Enterobacter + calo". Quando Pantoea sp. foi cultivada com Pseudomonas sp., em ausência de calo, a população de Pantoea sp. apresentou um tempo de geração de 207 minutos (tabela 5), sofreu uma queda gradual da população após a fase exponencial e estabilizou-se. Quando a mistura foi cultivada com calo, o tempo de geração de Pantoea sp. caiu para 91 minutos (tabela 5). Após 72 horas houve uma diminuição da população de Pantoea sp. que após 264 horas não foi mais detectada. As curvas "Pantoea + Pseudomonas" e "Pantoea + Pseudomonas + calo" são diferentes estatíticamente entre 30 e 48 horas quando houve um aumento da curva "Pantoea + Pseudomonas + calo" e após 264 horas quando houve a extinção da população de Pantoea sp. na mesma curva citada anteriormente. 
Tabela 3- Tempo de geração de Enterobacter sp. ICB113 em cultura pura e em cultura mista, em presença ou ausência de calo.

\begin{tabular}{cc}
\hline Curvas de crescimento & $\begin{array}{c}\text { Tempo de } \\
\text { geração }\end{array}$ \\
\hline Enterobacter cultura pura & $158 \mathrm{~min}$ \\
Enterobacter + calo & $147 \mathrm{~min}$ \\
Enterobacter + Pseudomonas & $97 \mathrm{~min}$ \\
$\begin{array}{c}\text { Enterobacter }+ \\
\text { Pseudomonas + calo } \\
\text { nterobacter }+ \text { Pantoea } \\
\text { Enterobacter }+ \text { Pantoea }+ \\
\text { calo }\end{array}$ & $80 \mathrm{~min}$ \\
\hline
\end{tabular}

Tabela 4- Tempo de geração de Pseudomonas sp. ICB383 em cultura pura e em cultura mista, em presença ou ausência de calo.

\begin{tabular}{cc}
\hline Curvas de crescimento & $\begin{array}{c}\text { Tempo de } \\
\text { geração }\end{array}$ \\
\hline Pseudomonas cultura pura & $103 \mathrm{~min}$ \\
Pseudomonas + calo & $84 \mathrm{~min}$ \\
Pseudomonas + Enterobacter & $79 \mathrm{~min}$ \\
$\begin{array}{c}\text { Pseudomonas + Enterobacter } \\
+ \text { calo }\end{array}$ & $77 \mathrm{~min}$ \\
$\begin{array}{c}\text { Pseudomonas + Pantoea } \\
\text { Pseudmonas + Pantoea }+ \\
\text { calo }\end{array}$ & $138 \mathrm{~min}$ \\
\hline
\end{tabular}

Tabela 5- Tempo de geração de Pantoea sp. ICB409 em cultura pura e em cultura mista, em presença ou ausência de calo.

\begin{tabular}{cc}
\hline Curvas de crescimento & $\begin{array}{c}\text { Tempo de } \\
\text { geração }\end{array}$ \\
\hline Pantoea cultura pura & $96 \mathrm{~min}$ \\
Pantoea + calo & $107 \mathrm{~min}$ \\
Pantoea +Pseudomonas & $207 \mathrm{~min}$ \\
$\begin{array}{c}\text { Pantoea }+ \text { Pseudomonas }+ \\
\text { calo }\end{array}$ & $91 \mathrm{~min}$ \\
$\begin{array}{c}\text { Pantoea }+ \text { Enterobacter } \\
\text { Pantoea }+ \text { Enterobacter }+ \\
\text { calo }\end{array}$ & $144 \mathrm{~min}$ \\
\hline
\end{tabular}




\subsection{Atividade da Nitrogenase}

\subsubsection{Culturas Simples}

\subsubsection{Enterobacter sp. ICB113}

As figuras 17 e 18 mostram as curvas de atividade da nitrogenase em função do tempo de Enterobacter sp, em presença ou ausência do calo. Quando em cultura pura, os valores oscilaram durante as primeiras 100 horas, o maior pico aconteceu com 4 horas de experimento atingindo 219,16 fmol.UFC ${ }^{-1} \cdot \mathrm{h}^{-1}$. Um novo pico de valor próximo ao primeiro foi observado em 72 horas $\left(217,32\right.$ fmol.UFC $\left.{ }^{-1} \cdot h^{-1}\right)$. Após este período, os valores permaneceram baixos e com 600 horas a atividade não foi mais detectada. Quando cultivada com o calo, a bactéria apresentou um pico, ao mesmo tempo da curva cultura pura, às 4 horas de experimento, atingindo o valor de 3069,74 fmol.UFC ${ }^{-1} \cdot \mathrm{h}^{-1}$. Seguiu-se uma queda acentuada, até não ser mais detectada com 600 horas de experimento. Diferenças significativas entre as curvas descritas na figura 2 foram observadas apenas entre 4 e 30 horas, quando os valores da curva "Enterobacter + calo" foram maiores.

Figura 17 - Curvas de atividade específica da nitrogenase de Enterobacter sp. ICB113 cultivada com ou sem a presença de calo.

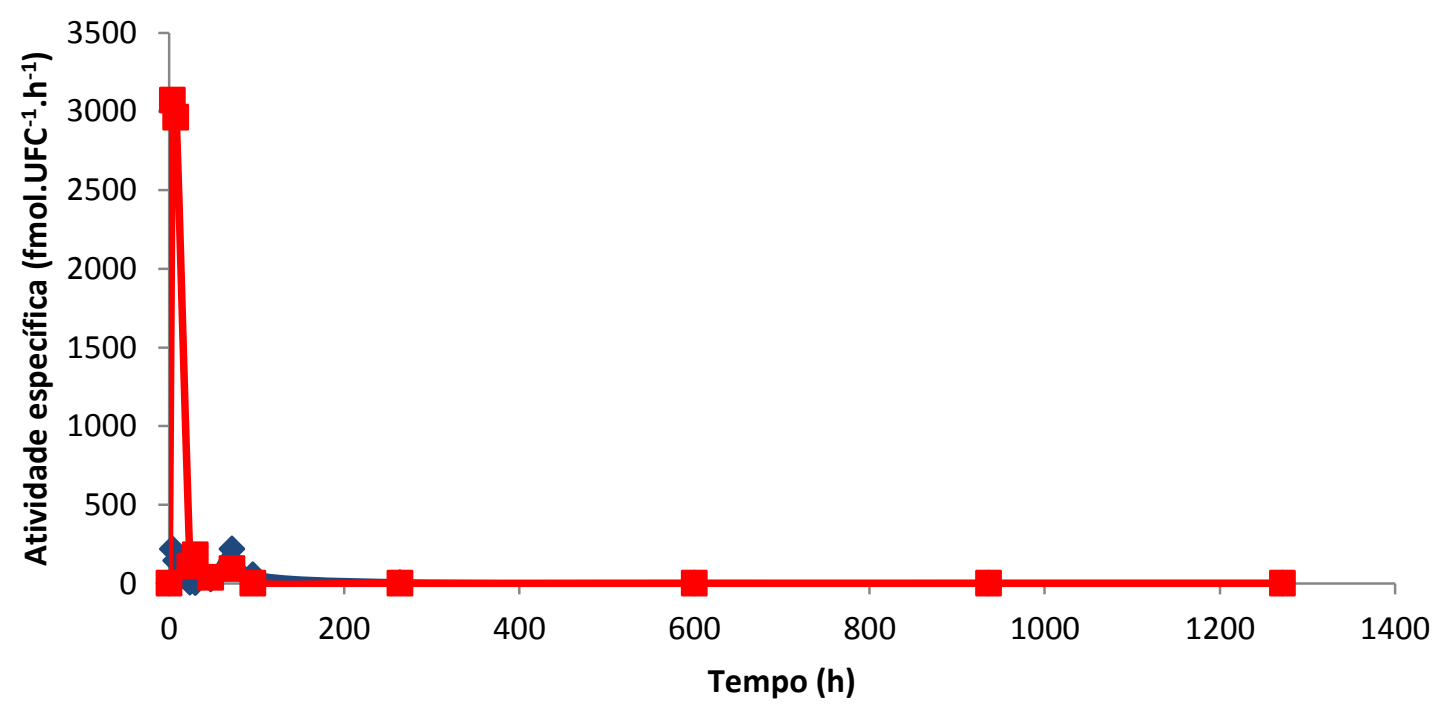

Enterobacter cultura pura Enterobacter + calo 
Figura 18 - Curvas de atividade específica da nitrogenase de Enterobacter sp. ICB113 cultivada com ou sem a presença de calo.

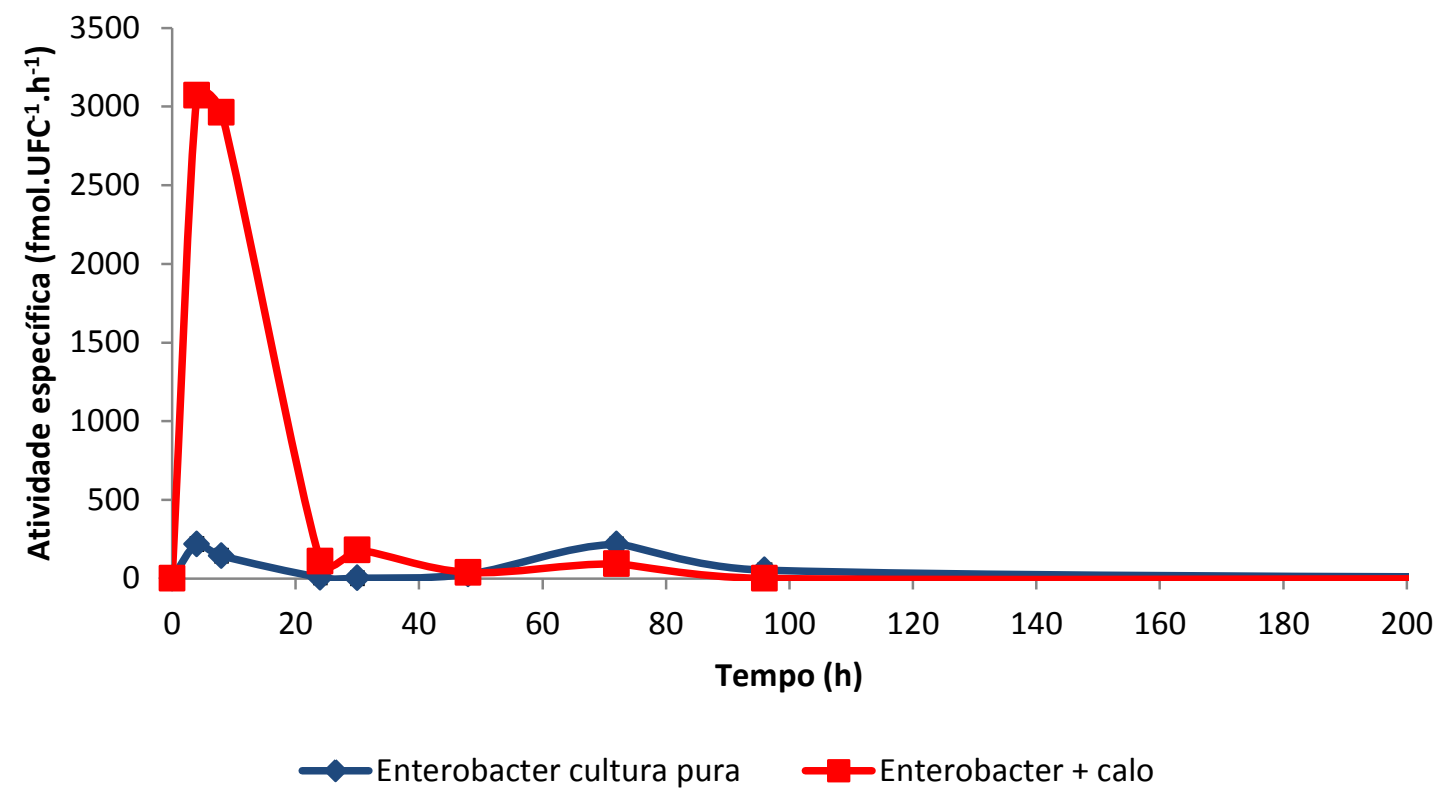

\subsubsection{Pseudomonas sp. ICB383}

As figuras 19 e 20 mostram os valores de atividade da nitrogenase de Pseudomonas sp. em função do tempo, na presença ou ausência de calo. Quando em cultura pura, a atividade da enzima apresentou o maior pico com 4 horas de experimento, atingindo 39529,44 fmol.UFC ${ }^{-1} \cdot h^{-1}$ seguida de queda apresentando valores baixos até o final do experimento. Quando cultivada com o calo, observou-se um pico com 8 horas de cultivo $(20499,18$ fmol.UFC $\left.{ }^{-1} \cdot h^{-1}\right)$. Um outro pico foi encontrado com 600 horas de cultivo, com o valor de 710,33 fmol.UFC ${ }^{-1} \cdot h^{-1}$ seguido de queda. Os pontos em que as curvas das figuras 19 e 20 são diferentes significativamente são o ponto das 4 horas de experimento, quando o valore da curva "Pseudomonas cultura pura" foi maior, e o ponto das 600 horas quando o valor da cocultura foi maior. 
Figura 19 - Curvas de atividade específica da nitrogenase de Pseudomonas sp. ICB383 cultivada com ou sem a presença de calo.

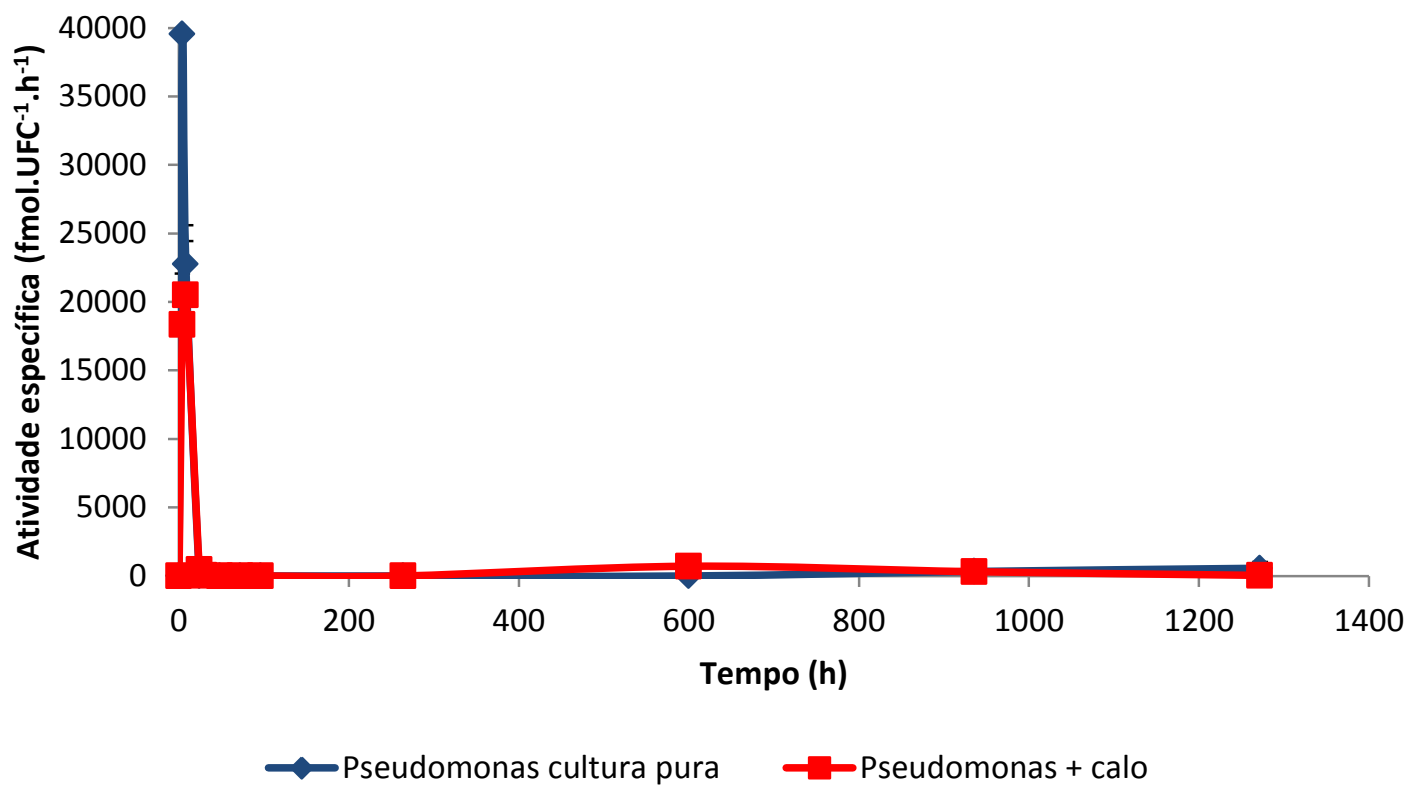

Figura 20 - Curvas de atividade específica da nitrogenase de Pseudomonas sp. ICB383 cultivada com ou sem a presença de calo.

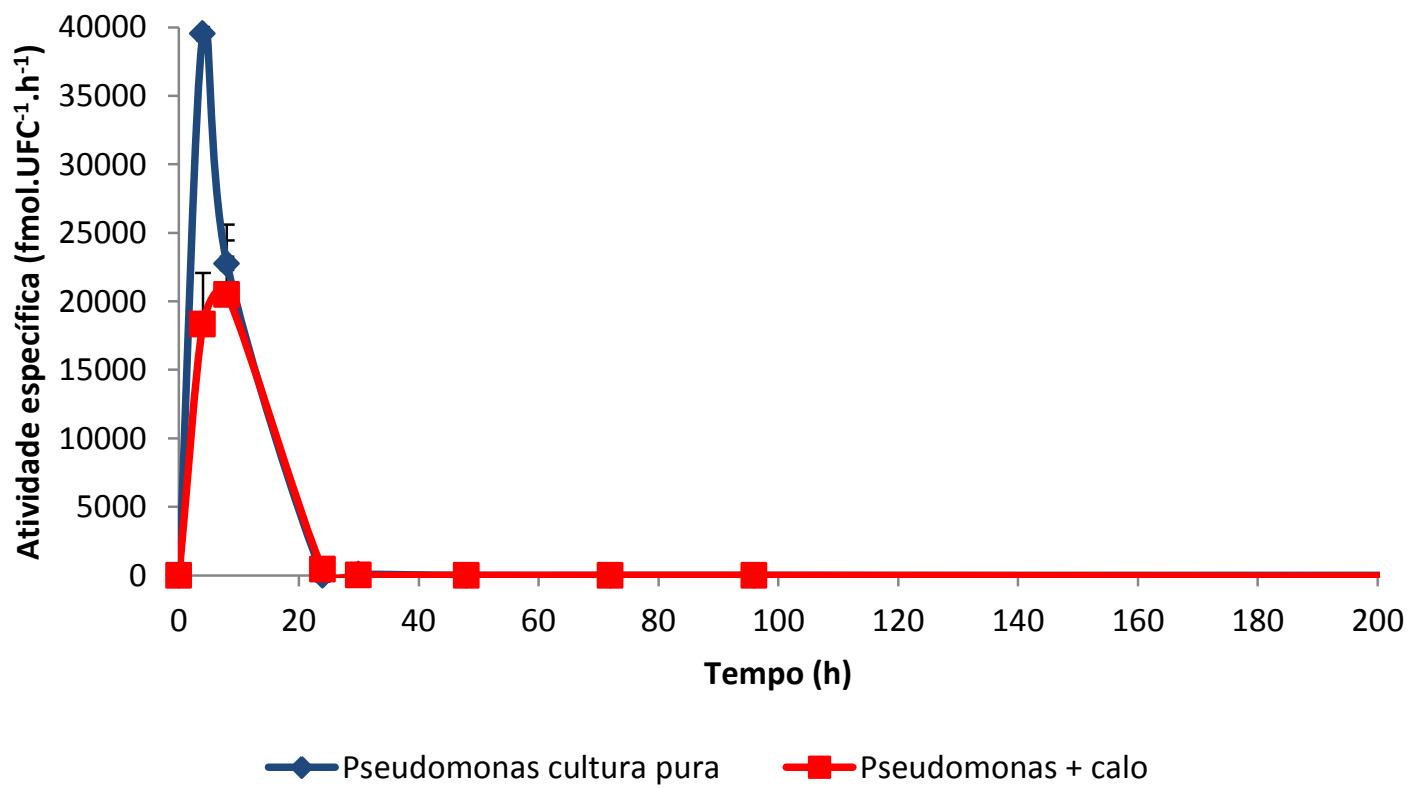

\subsubsection{Pantoea sp. ICB409}

As figuras 21 e 22 mostram as curvas de atividade da nitrogenase de Pantoea sp. em função do tempo, com ou sem a presença de calo. Quando em cultura pura, apresentou um pico de atividade de 1784,89 fmol.UFC ${ }^{-1} \cdot h^{-1}$ com 4 horas de cultivo; seguiu-se uma queda e após 264 horas não se detectou mais a atividade da enzima. Em co-cultura, apresentou um 
pico com 4 horas de cultivo, com o valor de 2337,60 fmol.UFC ${ }^{-1} \cdot \mathrm{h}^{-1}$, e igualmente à curva de cultura pura, não foi mais detectada a atividade da enzima após 264 horas. Os pontos diferentes significativamente entre as curvas das figuras 21 e 22 são entre 4 e 8 horas de experimento, quando os valores da curva "Pantoea + calo" foram maiores.

Figura 21 - Curvas de atividade específica da nitrogenase de Pantoea sp. ICB409 cultivada com ou sem a presença de calo.

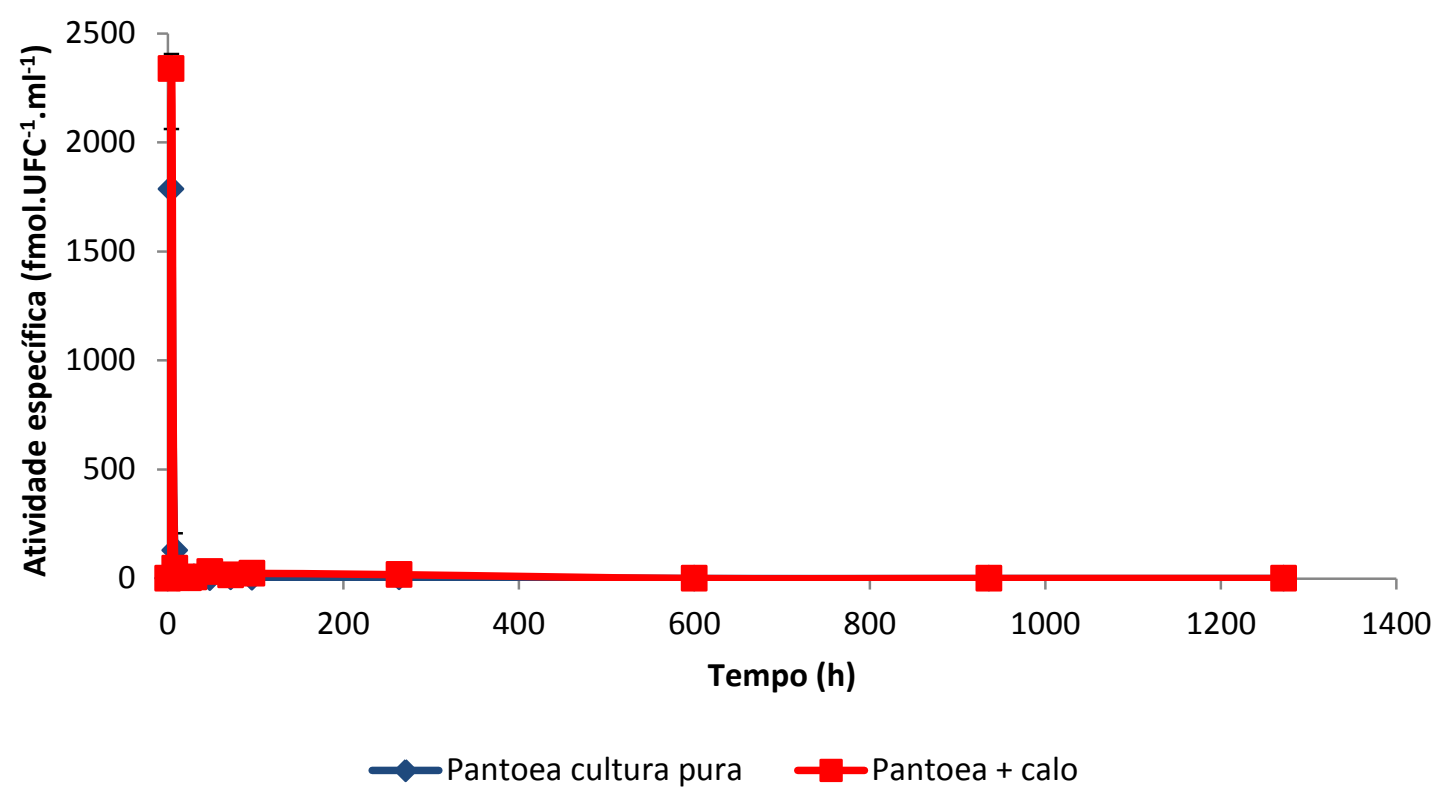

Figura 22 - Curvas de atividade específica da nitrogenase de Pantoea sp. ICB409 cultivada com ou sem a presença de calo.

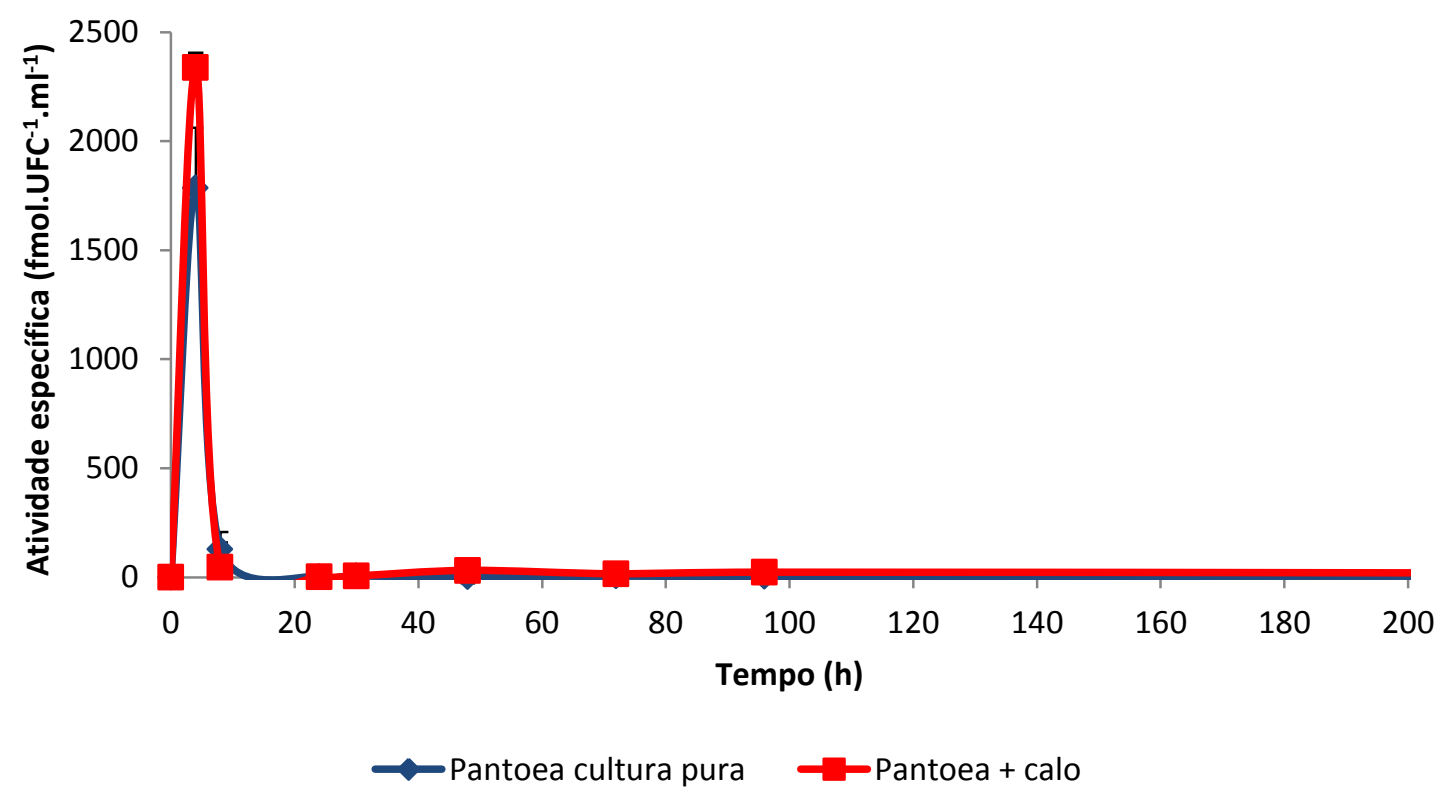




\subsubsection{Culturas Mistas}

Ao se analisar as medidas de atividade da nitrogenase nas culturas mistas não foi possível distinguir a quantidade atribuída a cada cultura, uma vez que as medidas são obtidas a partir de uma fase gasosa. Portanto, os valores obtidos foram considerados como pertencendo à mistura bacteriana.

4.2.2.1 Enterobacter sp. ICB113 + Pseudomonas sp. ICB383

As figuras 23 e 24 mostram as curvas de atividade da enzima nitrogenase da mistura Enterobacter sp. com Pseudomonas sp., em ausência de calo, em função do tempo. A curva "Enterobacter cultura pura" é a mesma mostrada na figura 17 e a curva "Pseudomonas cultura pura" é a mesma da figura 19.

Os valores da atividade da enzima apresentaram um pico inicial com 4 horas de experimento $\left(158,85 \mathrm{fmol} . \mathrm{UFC}^{-1} \cdot \mathrm{h}^{-1}\right)$ seguido por uma acentuada queda e novamente por um pico no ponto 264horas (figura 23) com valor de 411,09 fmol.UFC ${ }^{-1} \cdot \mathrm{h}^{-1}$, seguido de uma leve queda e por um pico de 350,00 fmol. $\mathrm{UFC}^{-1} \cdot \mathrm{h}^{-1}$ e novamente uma queda ao final do experimento. Diferenças estatísticas entre as curvas "Enterobacter cultura pura" e "Enterobacter + Pseudomonas" foram encontradas em 264 e 936 horas de experimento quando os valores de atividade da mistura superou os da cultura pura. Diferenças estatísticas entre as curvas "Pseudomonas cultura pura" e "Enterobacter + Pseudomonas" foram encontradas em 4, 8 e 24 horas quando os valores de atividade da cultura pura foram maiores que da mistura. 
Figura 23 - Curvas de atividade específica da nitrogenase da mistura bacteriana Enterobacter sp. ICB113 e Pseudomonas sp. ICB383em ausência de calo.

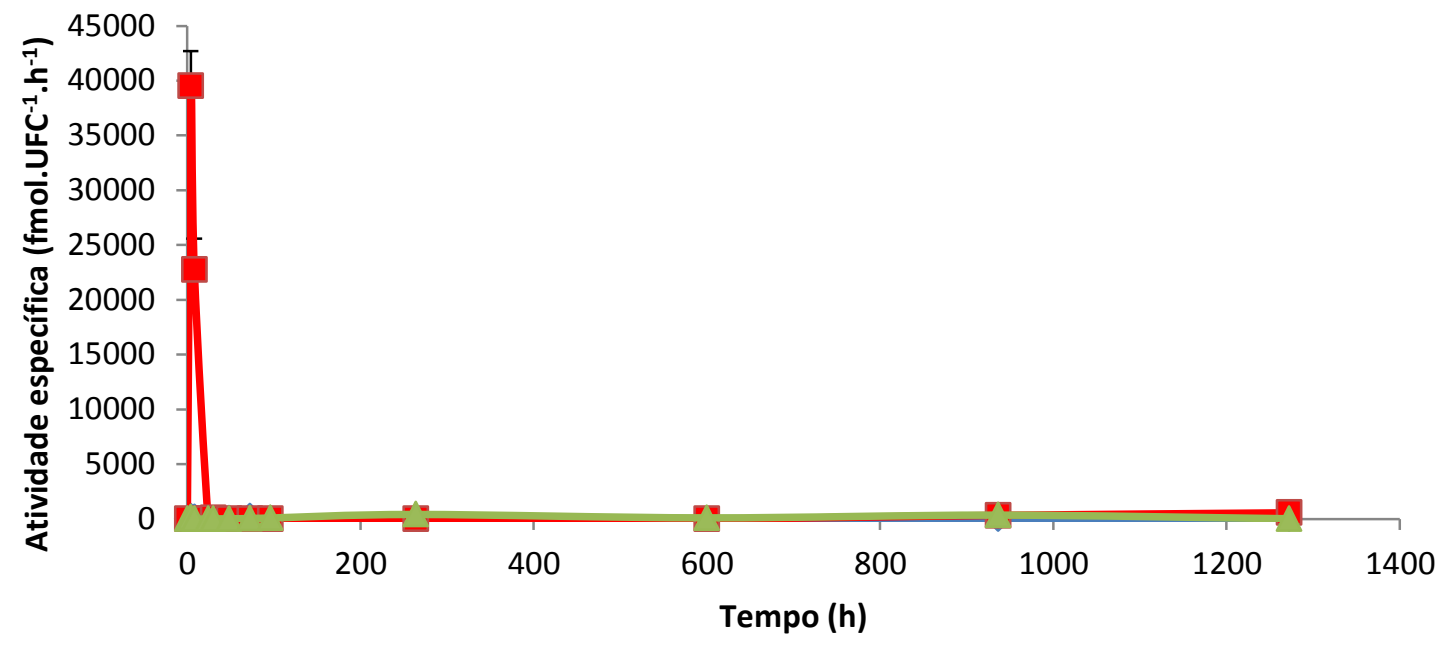

- Enterobacter cultura pura $\rightarrow$ Pseudomonas cultura pura $\rightarrow$ Enterobacter + Pseudomonas

Figura 24 - Curvas de atividade específica da nitrogenase da mistura bacteriana Enterobacter sp. ICB113 e Pseudomonas sp. ICB383em ausência de calo.

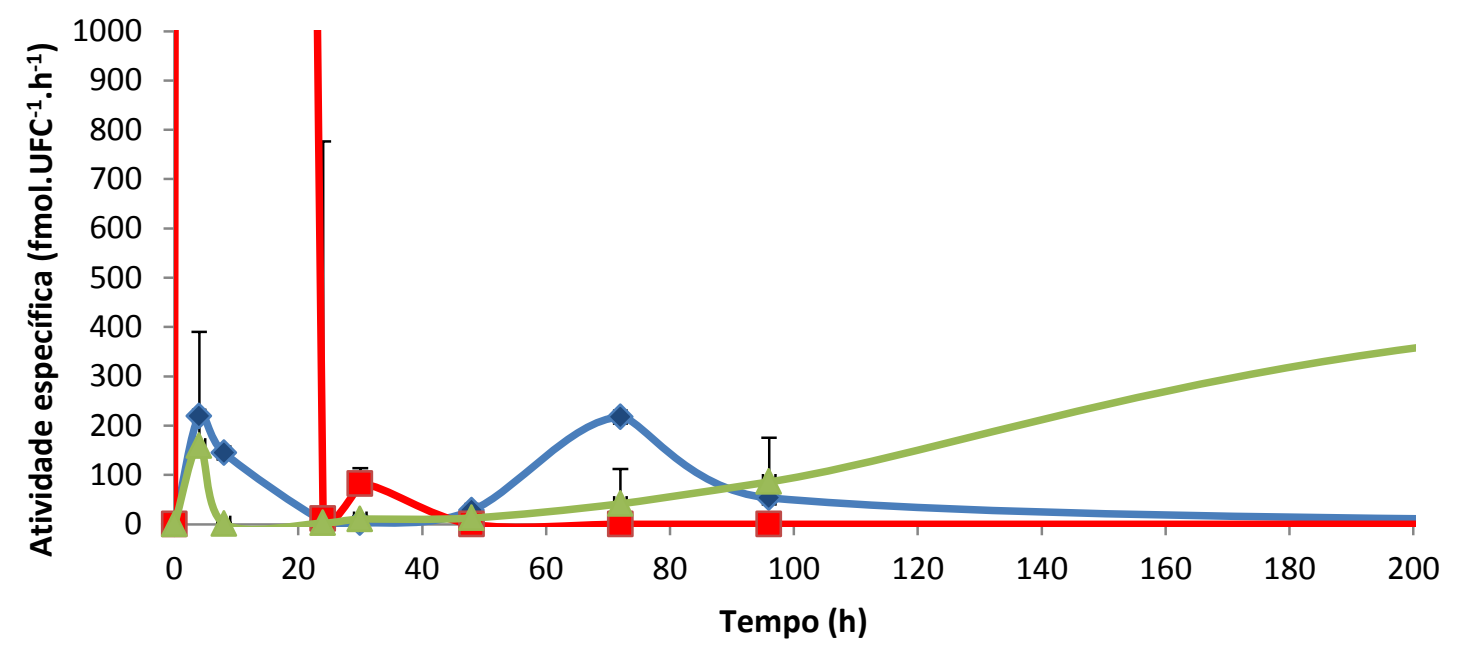

$\downarrow$ Enterobacter cultura pura $\_$Pseudomonas cultura pura $\longrightarrow$ Enterobacter + Pseudomonas

As figuras 25 e 26 mostram as curvas de atividade da enzima nitrogenase da mistura bacteriana Enterobacter sp. com Pseudomonas sp., em presença de calo. A curva "Enterobacter + calo" é a mesma mostrada na figura 17 e a curva "Pseudomonas + calo" é a mesma mostrada na figura 19.

Observou-se um pico em 4 horas de experimento no valor de 52,61 fmol. $\mathrm{UFC}^{-1} \cdot \mathrm{h}^{-1}$ seguido da queda dos valores, e após 264 horas, não foi mais detectada atividade da enzima. 
Diferenças significativas foram encontradas entre as curvas "Enterobacter + calo" e "Enterobacter + Pseudomonas + calo" entre 4, 8 e 30 horas quando os valores da curva "Enterobacter + calo" foram maiores que os da curva da mistura. Diferenças significativas foram encontradas entre as curvas "Pseudomonas + calo" e "Enterobacter + Pseudomonas + calo" entre 4 e 8 horas e em 600 horas quando os valores da curva "Pseudomonas + calo" foram superiores aos da mistura.

Figura 25 - Curvas de atividade específica da nitrogenase da mistura bacteriana Enterobacter sp. ICB113 e Pseudomonas sp. ICB383em presença de calo.

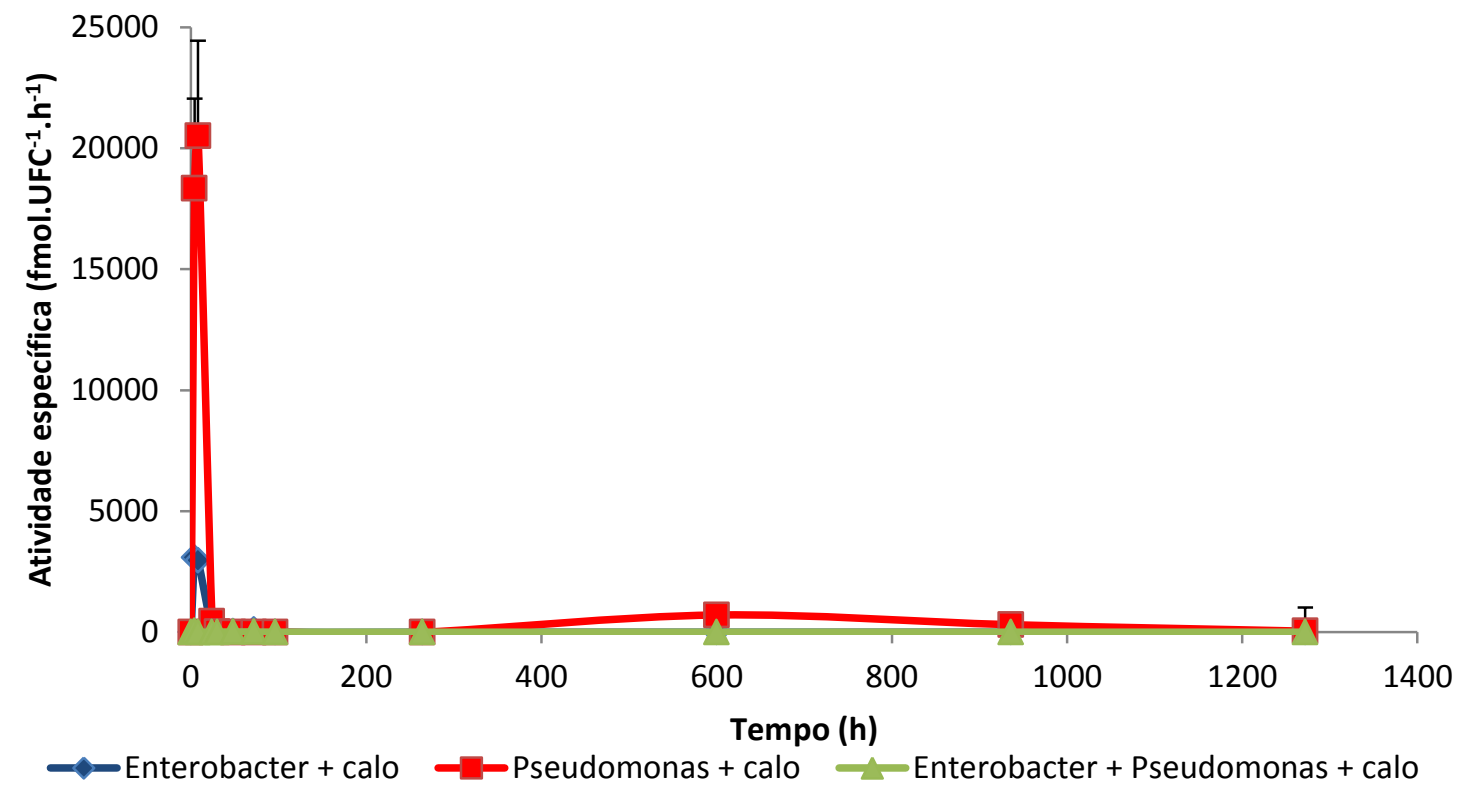


Figura 26 - Curvas de atividade específica da nitrogenase da mistura bacteriana Enterobacter sp. ICB113 e Pseudomonas sp. ICB383em presença de calo.

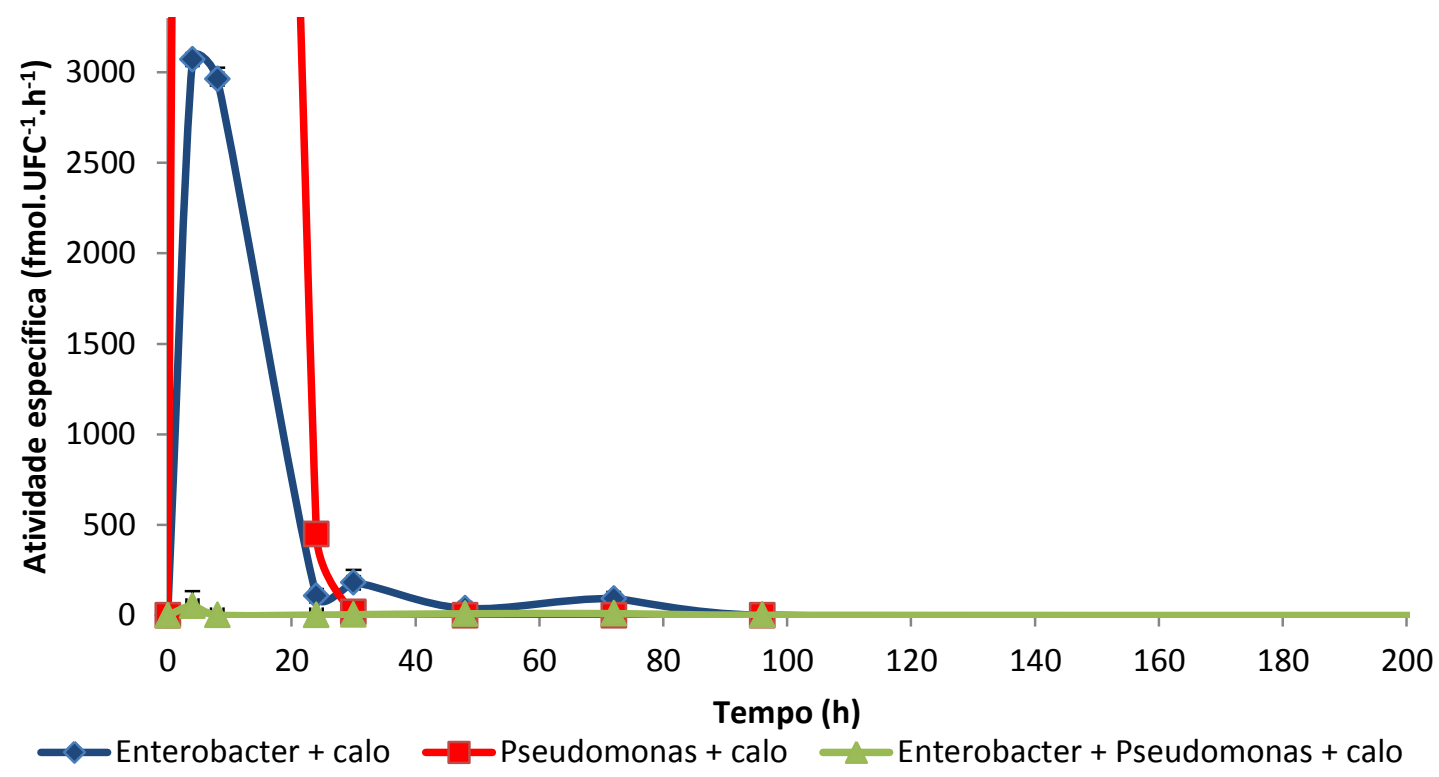

Para se analisar o que ocorreu quando a mistura foi cultivada com ou sem o calo, viuse a necessidade de se comparar as figuras 23 e 24 com as figuras 25 e 26 . Quando a mistura foi cultivada sem o calo, observou-se que três picos de atividade ao longo do ensaio. Porém, quando a mistura foi cultivada com o calo houve somente um pico às 4 horas de experimento $\left(52,61\right.$ fmol.UFC $\left.{ }^{-1} \cdot h^{-1}\right)$, logo após houve a diminuição dos valores que não foram mais detectados depois de 264 horas de cultivo. Diferenças significativas foram encontradas entre as curvas "Enterobacter + Pseudomonas" e "Enterobacter + Pseudomonas + calo" em 4 horas e a partir de 72 horas quando os valores da mistura cultivada sem o calo foram superiores.

\subsubsection{Enterobacter sp. ICB113 + Pantoea sp. ICB409}

As figuras 27 e 28 ilustram as curvas de atividade da nitrogenase da mistura bacteriana Enterobacter sp. e Pantoea sp., em ausência de calo, em função do tempo. A curva "Enterobacter cultura pura" é a mesma utilizada na figura 17 e a curva "Pantoea cultura pura" é a mesma descrita na figura 19. Houve um pequeno pico inicial $\left(96,29 \mathrm{fmol} \cdot \mathrm{UFC}^{-1} \cdot \mathrm{h}^{-1}\right)$ também com 4 h de cultivo, porém logo após houve uma queda que diminuiu os valores de atividade que voltou a aumentar após 600 horas de experimento, atingindo um pico em 1272 de experimento de 4571,58 fmol.UFC ${ }^{-1} \cdot \mathrm{h}^{-1}$. Houve diferença significativa entre as curvas "Enterobacter cultura pura" e "Enterobacter + Pantoea" em 72 horas quando o valor da curva 
"Enterobacter cultura pura" foi superior e a partir de 600 horas quando os valores da mistura foram maiores. Houve diferença significativa entre as curvas "Pantoea cultura pura" e “Enterobacter + Pantoea" em 4 horas de ensaio quando o valor da cultura pura foi maior e a partir de 600 horas quando os valores da mistura superaram os da cultura pura.

Figura 27 - Curvas de atividade específica da nitrogenase da mistura bacteriana Enterobacter sp. ICB113 e Pantoea sp. ICB409em ausência de calo.

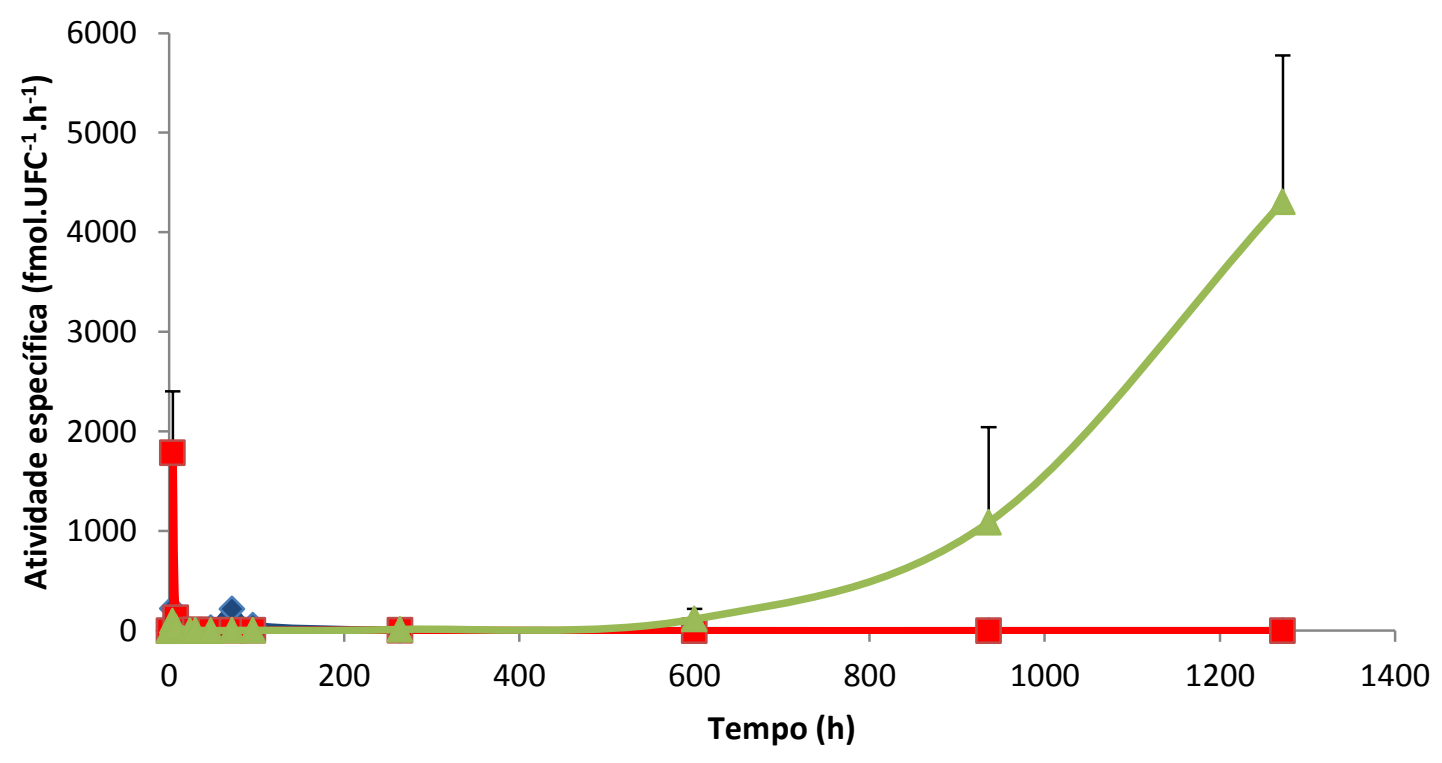

- Enterobacter cultura pura $\rightarrow$ Pantoea cultura pura $\rightarrow$ Enterobacter + Pantoea

Figura 28 - Curvas de atividade específica da nitrogenase da mistura bacteriana Enterobacter sp. ICB113 e Pantoea sp. ICB409em ausência de calo.

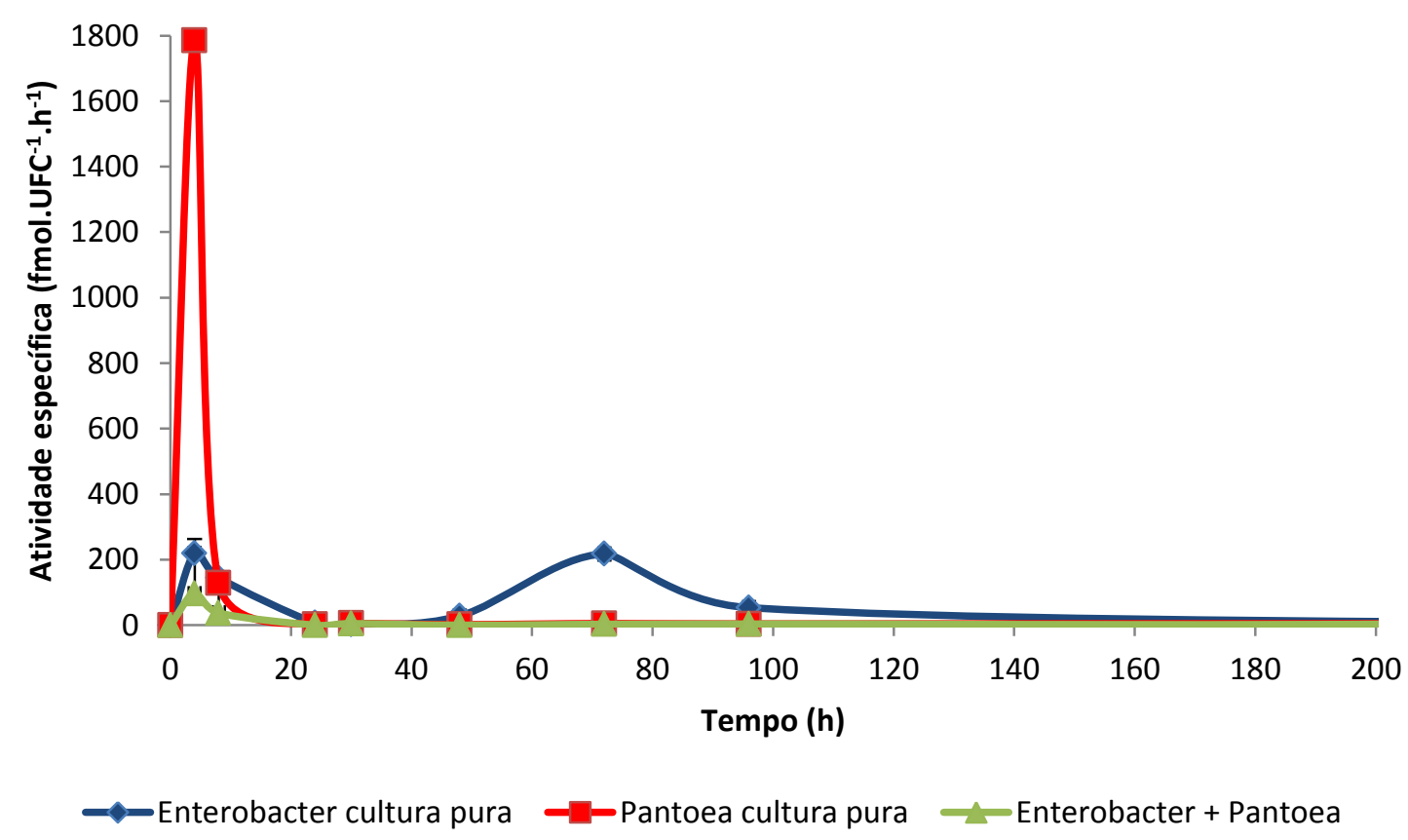


As figuras 29 e 30 mostram as curvas de atividade da enzima nitrogenase da mistura bacteriana Enterobacter sp. e Pantoea sp., em presença de calo, em função do tempo. A curva "Enterobacter + calo" é a mesma descrita na figura 17 e a curva "Pantoea + calo" é a mesma da figura 21. Observou-se um pico em 4 horas de experimento $\left(387,23\right.$ fmol.UFC $\left.{ }^{-1} \cdot h^{-1}\right)$, ocilando até às 96 horas de experimento, quando não foi mais detectada. Diferenças significativas foram encontradas entre as curvas "Enterobacter + calo" e "Enterobacter + Pantoea + calo" entre 4, 8 e 24 horas quando os valores da curva "Enterobacter + calo" foram superiores. Diferenças significativas foram encontradas entre as curvas "Pantoea + calo" e "Enterobacter + Pantoea + calo" somente em 4 horas de experimento quando o valor da curva "Pantoea + calo" foi superior.

Figura 29 - Curvas de atividade específica da nitrogenase da mistura bacteriana Enterobacter sp. ICB113 e Pantoea sp. ICB409em presença de calo.

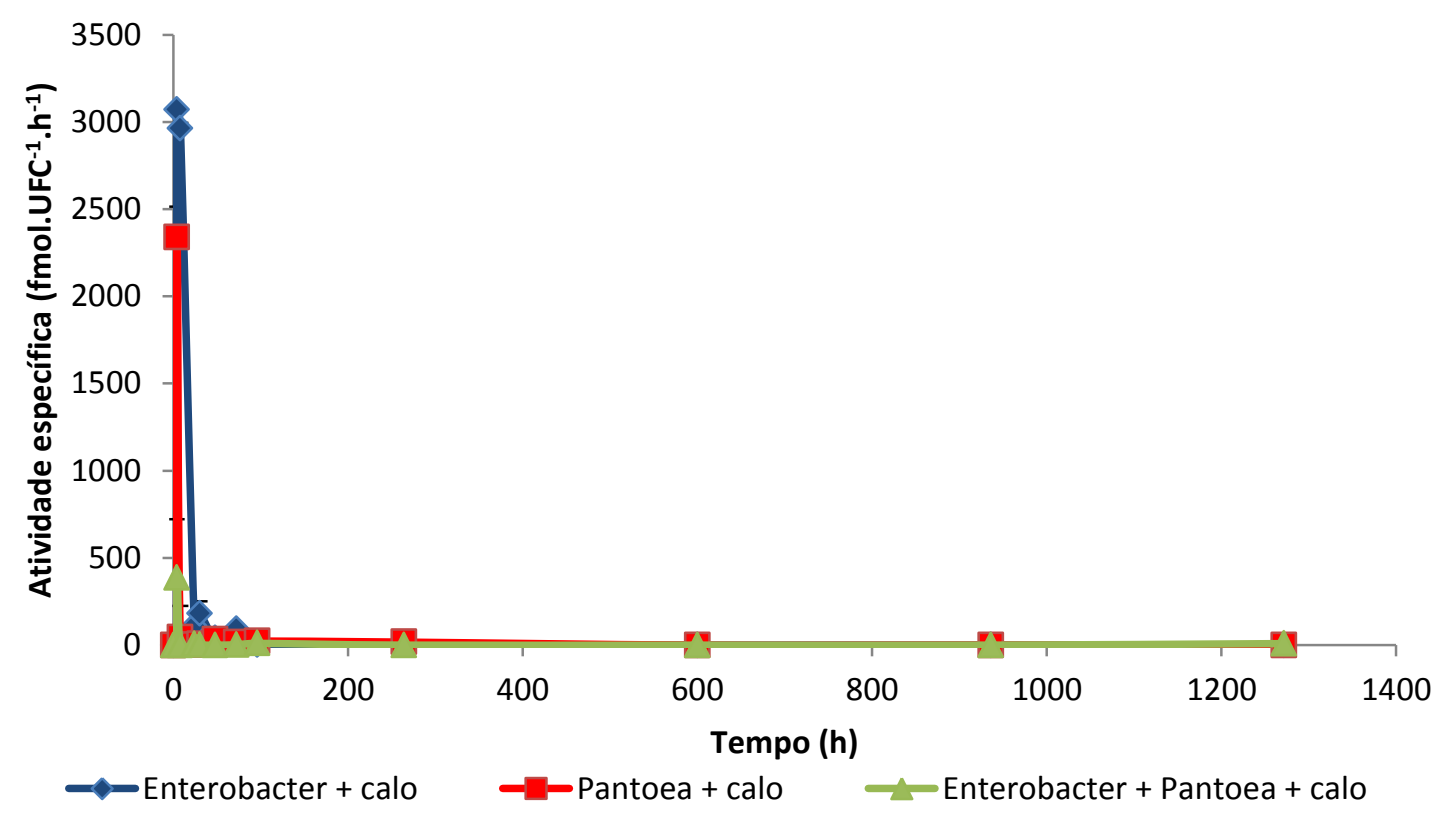


Figura 30 - Curvas de atividade específica da nitrogenase da mistura bacteriana Enterobacter sp. ICB113 e Pantoea sp. ICB409em presença de calo.

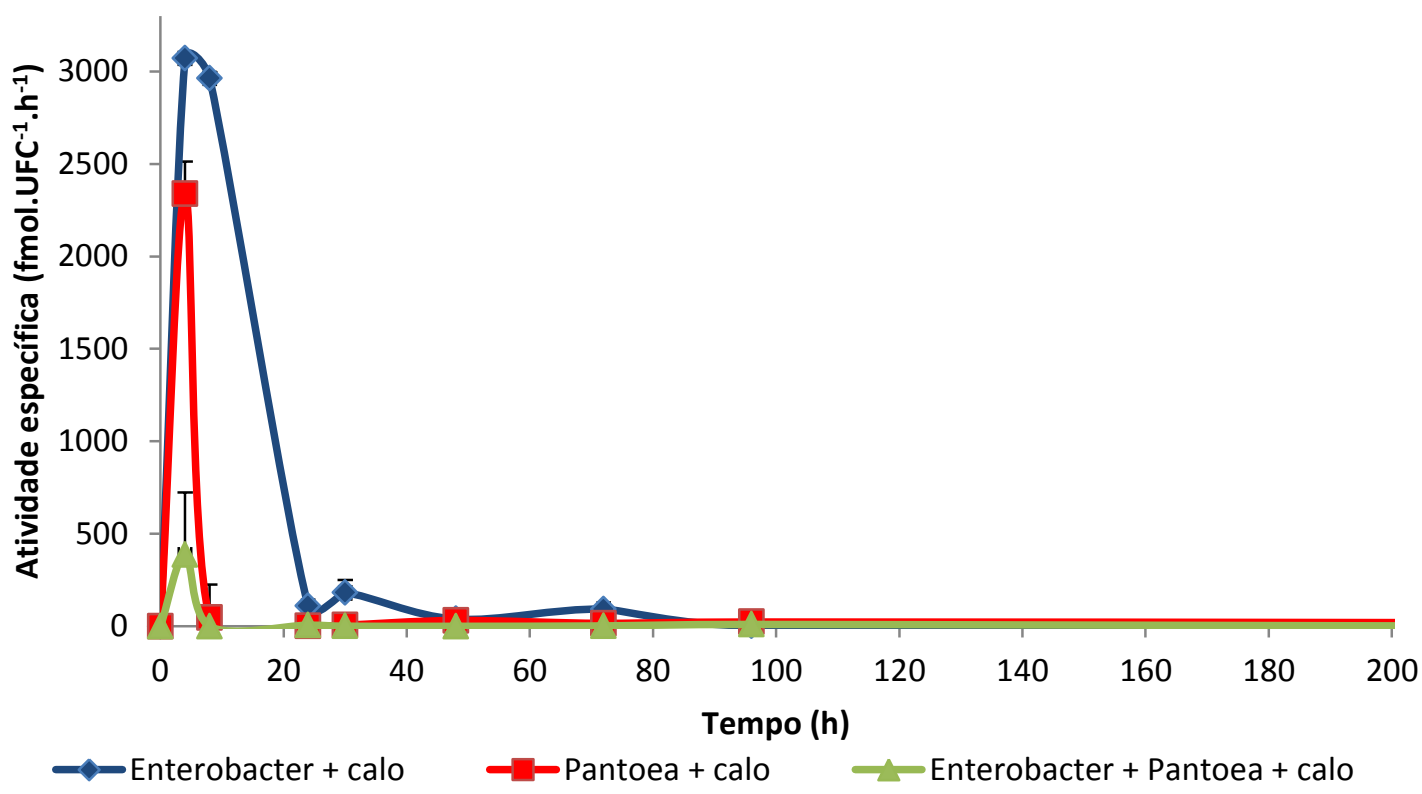

Para se analisar o que ocorreu quando a mistura foi cultivada com ou sem o calo, viuse a necessidade de se comparar as figuras 27 e 28 com as figuras 29 e 30. Quando a mistura foi cultivada sem calo, houve um pequeno pico com 4 horas de experimento $(96,29$ fmol.UFC $\left.{ }^{-1} \cdot h^{-1}\right)$ e em seguida a diminuição destes valores, porém após 600 horas, houve um aumento na atividade da enzima que se manteve em ascensão até o final do ensaio. A mistura cultivada com o calo, apresentou também um pico em 4 horas de experimento $(387,23$ fmol.UFC ${ }^{-1} \cdot h^{-1}$ ), os valores oscilaram até 96 horas quando não foi mais detectada. Houve diferença significativa entre as curvas "Enterobacter + Pantoea" e "Enterobacter + Pantoea + calo" em 4 horas de ensaio quando o valor da atividade da mistura cultivada com o calo foi maior e a partir de 600 horas quando os valores de atividade da mistura cultivada sem o calo foi maior.

\subsubsection{Pseudomonas sp. ICB383+ Pantoea sp. ICB409}

As figuras 31 e 32 ilustram as curvas de atividade da enzima nitrogenase da mistura Pseudomonas sp. e Pantoea sp. em ausência de calo, em função do tempo. A curva "Pseudomonas cultura pura" foi descrita na figura 19 e a curva "Pantoea cultura pura" é a mesma descrita na figura 21. Os valores de atividade da nitrogenase permaneceram baixos durante as primeiras 600 horas de experimento, quando houve um pico de 53,16 fmol.UFC ${ }^{-}$ 
${ }^{1} \cdot \mathrm{h}^{-1}$, porém, após este pico, não se detectou mais a presença da atividade da enzima. Houve diferença estatística entre as curvas "Pseudomonas cultura pura" e "Pseudomonas + Pantoea" entre 4 e 8 horas de cultivo quando a curva da cultura pura apresentou valores maiores que a curva da mistura e em 600 horas quando o valor de atividade da mistura foi maior. Houve diferença estatística entre as curvas "Pantoea cultura pura" e "Pseudomonas + Pantoea" entre 4 e 30 horas quando os valores da cultura pura foram maiores e em 600 horas quando o valor da atividade da mistura foi superior.

Figura 31 - Curvas de atividade específica da nitrogenase da mistura bacteriana Pseudomonas sp. ICB383e Pantoea sp. ICB409em ausência de calo.

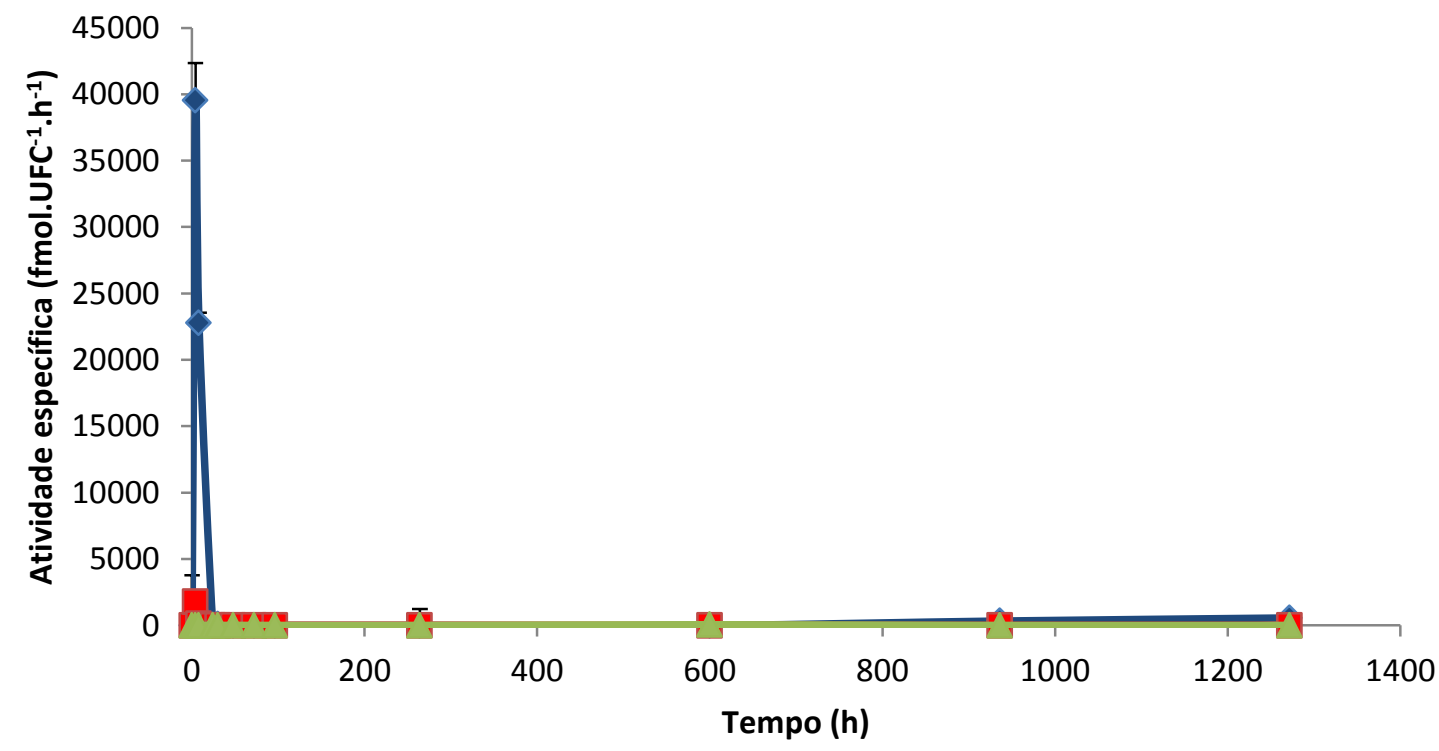

$\longrightarrow$ Pseudomonas cultura pura $\_$Pantoea cultura pura $\rightarrow$ Pseudomonas + Pantoea 
Figura 32 - Curvas de atividade específica da nitrogenase da mistura bacteriana Pseudomonas sp. ICB383e Pantoea sp. ICB409em ausência de calo.

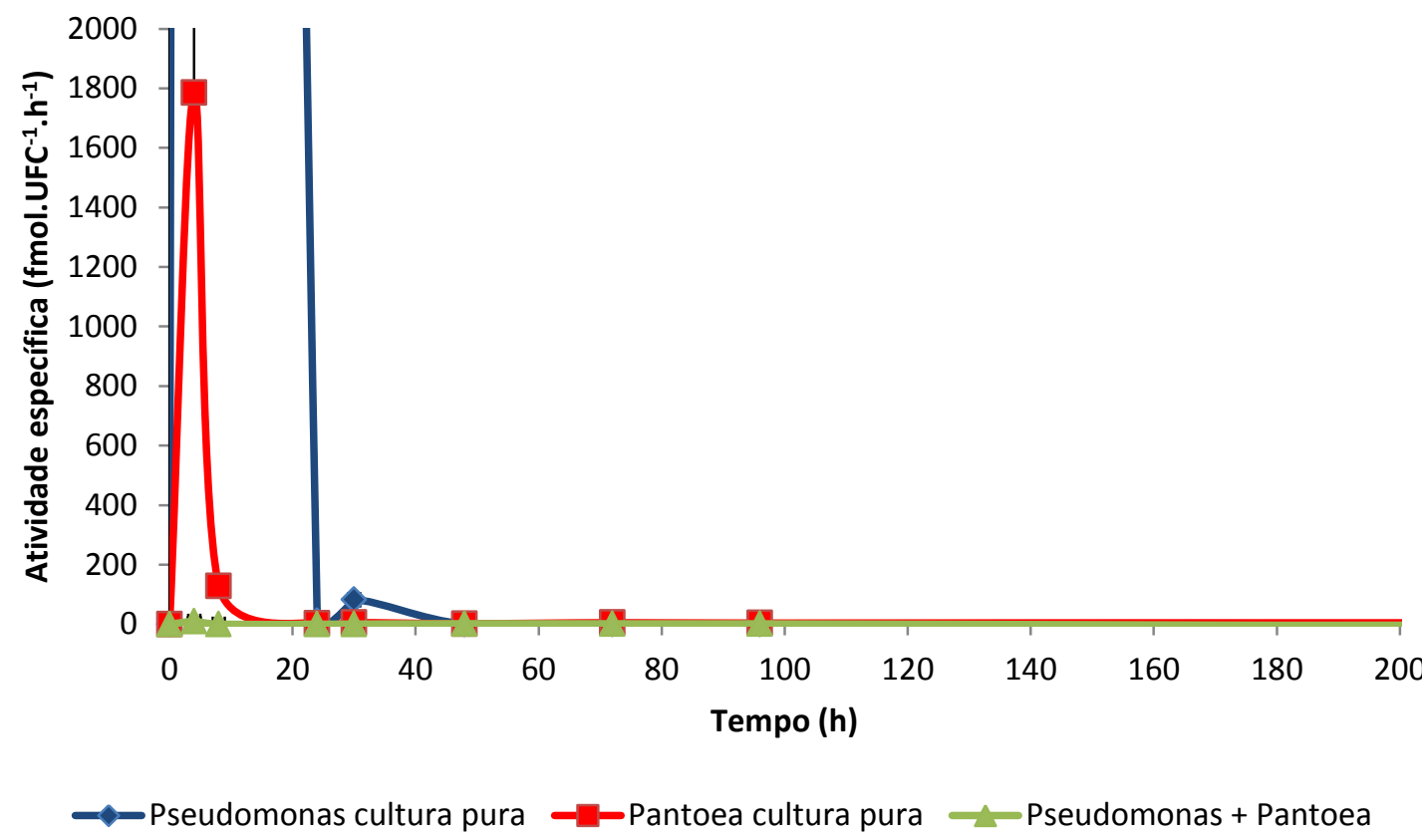

As figuras 33 e 34 mostram as curvas de atividade da enzima nitrogenase da mistura bacteriana Pseudomonas sp. e Pantoea sp. em co-cultura com o calo, em função do tempo. A curva "Pseudomonas + calo" foi descrita na figura 19 e a curva "Pantoea + calo" foi descrita na figura 21. A atividade da mistura bacteriana apresentou um pico em 24 horas de ensaio $\left(156,27\right.$ fmol.UFC $\left.{ }^{-1} \cdot h^{-1}\right)$, após este pico, os valores foram decaindo e após 96 horas não foi mais detectado. Diferenças estatísticas foram encontradas entre as curvas "Pseudomonas + calo" e "Pseudomonas + Pantoea + calo" entre 4 e 8 horas e em 600 horas quando os valores da curva "Pseudomonas + calo" foram maiores. Diferenças estatísticas foram encontradas entre as curvas "Pantoea + calo" e "Pseudomonas + Pantoea + calo" às 4 horas quando o valor da curva "Pantoea + calo" foi maior e em 24 horas quando o valor de atividade da mistura foi maior. 
Figura 33 - Curvas de atividade específica da nitrogenase da mistura bacteriana Pseudomonas sp. ICB383e Pantoea sp. ICB409em presença de calo.

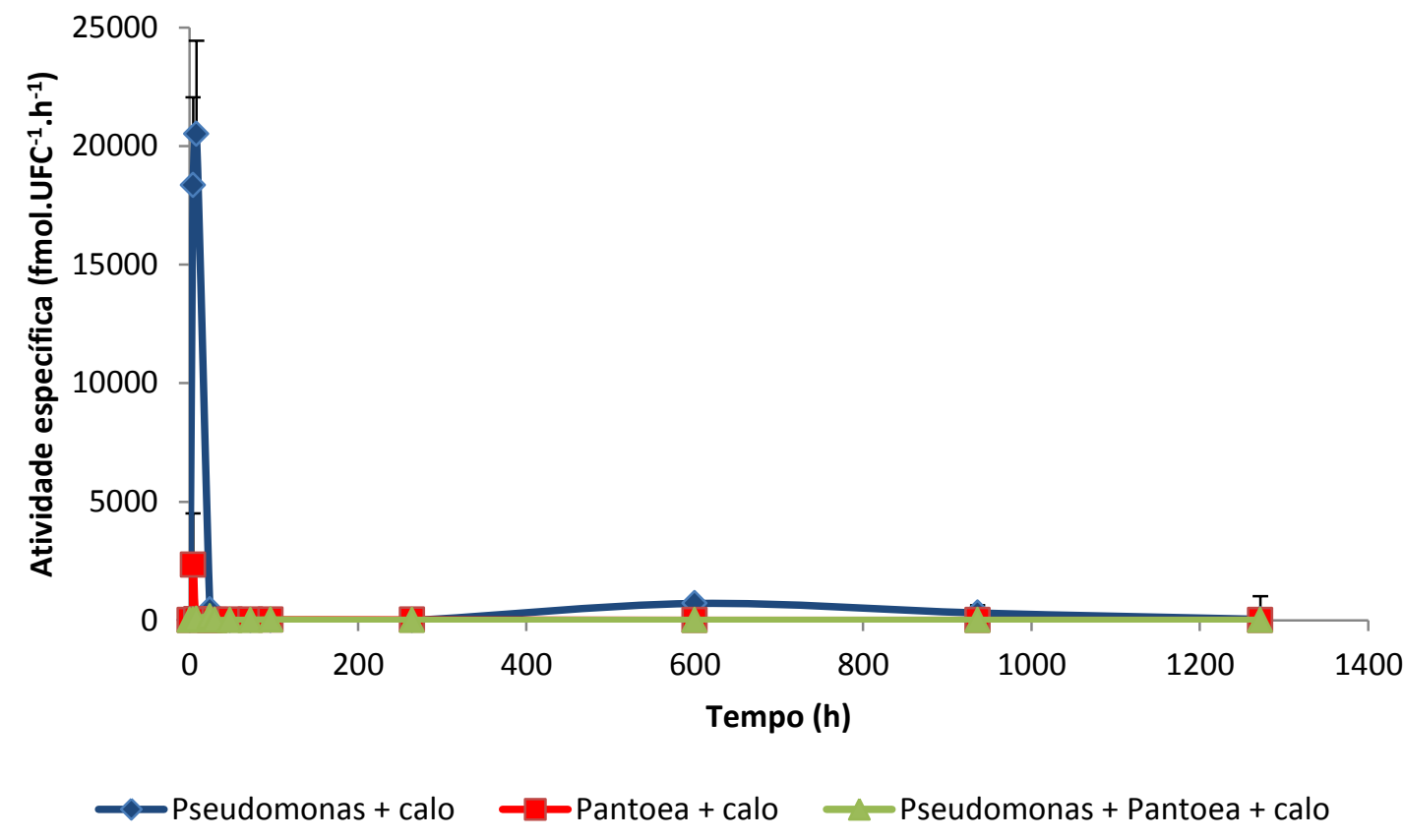

Figura 34 - Curvas de atividade específica da nitrogenase da mistura bacteriana Pseudomonas sp. ICB383 e Pantoea sp. ICB409em presença de calo.

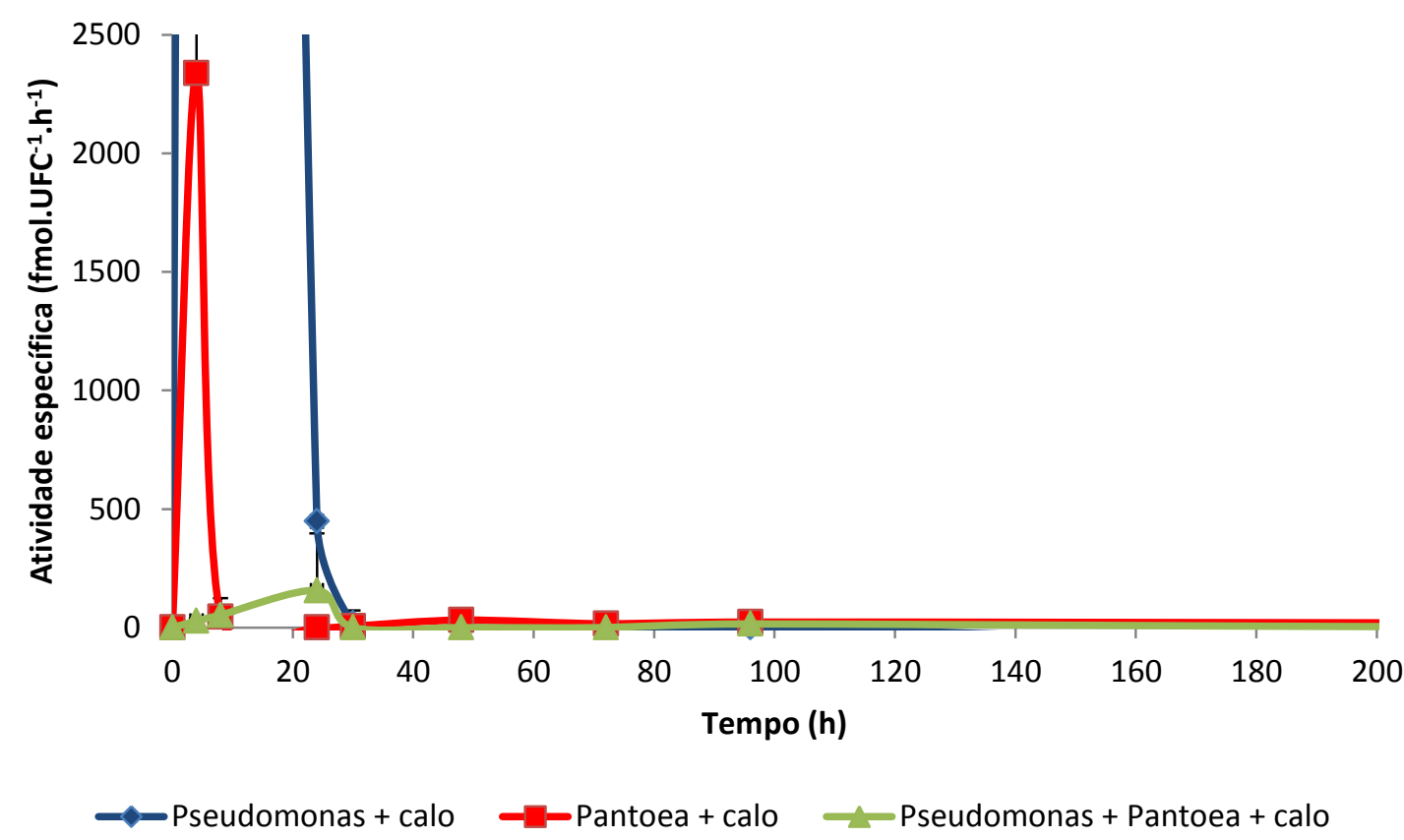

Para se analisar o que ocorreu quando a mistura foi cultivada com ou sem o calo, viuse a necessidade de se comparar as figuras 31 e $32 \mathrm{com}$ as figuras 33 e 34 . Quando a mistura foi cultivada sem o calo, apresentou somente um pico com 600 horas de experimento $(53,16$ fmol.UFC $\left.{ }^{-1} \cdot h^{-1}\right)$, e após este pico, apresentou valores menores até o final do experimento. Quando a mistura foi cultivada com o calo, houve um pico às 24 de ensaio $\left(156,27\right.$ fmol.UFC $^{-}$ 
$\left.{ }^{1} \cdot \mathrm{h}^{-1}\right)$, mas após 96 horas não se detectou mais a atividade da enzima. Houve diferenças significativas entre as curvas "Pseudomonas + Pantoea" e "Pseudomonas + Pantoea + calo" às 24 horas quando o valor de atividade da mistura cultivada com o calo foi maior e em 600 horas quando o valor de atividade foi maior na mistura cultivada sem o calo.

\subsection{Conteúdo Proteico dos Calos}

As figuras a seguir (35 a 40) mostram o conteúdo proteico dos calos em função do tempo, cultivados em meio MS (CN), em meio MSM (SN) e em meio MSM em co-cultura com as bactérias em cultura simples e em cultura mista. As curvas $\mathrm{CN}$ e $\mathrm{SN}$ nas figuras 35 a 40 são as mesmas e foram utilizadas para se comparar o crescimento do calo em meio com nitrogênio combinado $(\mathrm{CN})$ e em meio sem nitrogênio combinado (SN) ambas em ausência de bactéria.

O conteúdo proteico dos calos em meio contendo nitrogênio $(\mathrm{CN})$ apresentou, durante o experimento, um aumento significativo de $17 \%$, comparando-se o maior com o menor valor encontrado. Em contrapartida, os calos cultivados em meio que não continha nitrogênio (SN), não apresentaram variação em seu conteúdo proteico.

\subsubsection{Culturas Simples}

As figuras 35, 36 e 37 mostram as curvas controle (CN e $\mathrm{SN})$ e a curva de conteúdo proteico dos calos cultivados com Enterobacter sp., Pseudomonas sp. e Pantoea sp. respectivamente. Na figura 35, não houve variação no conteúdo do calos durante todo o experimento, não havendo diferenças significativas da curva "Enterobacter +calo" em relação à curva SN. Na figura 36, quando em co-cultura, o calo apresentou um incremento proteico de $18 \%$ em relação ao tempo inicial, porém, não houve diferenças significativas entre as curvas "Pseudomonas sp. + calo" e SN. Na figura 37, houve um decréscimo de $36 \%$ ao final do experimento em relação ao valor inicial $\left(\mathrm{T}_{0}\right)$. Não houve diferenças significativas entre as curvas "Pantoea + calo" e SN. 
Figura 35 - Curvas de conteúdo proteico do calo em co-cultura com Enterobacter sp. ICB113 (Enterobacter + calo), em meio MS completo (CN) e em meio MSM (SN).

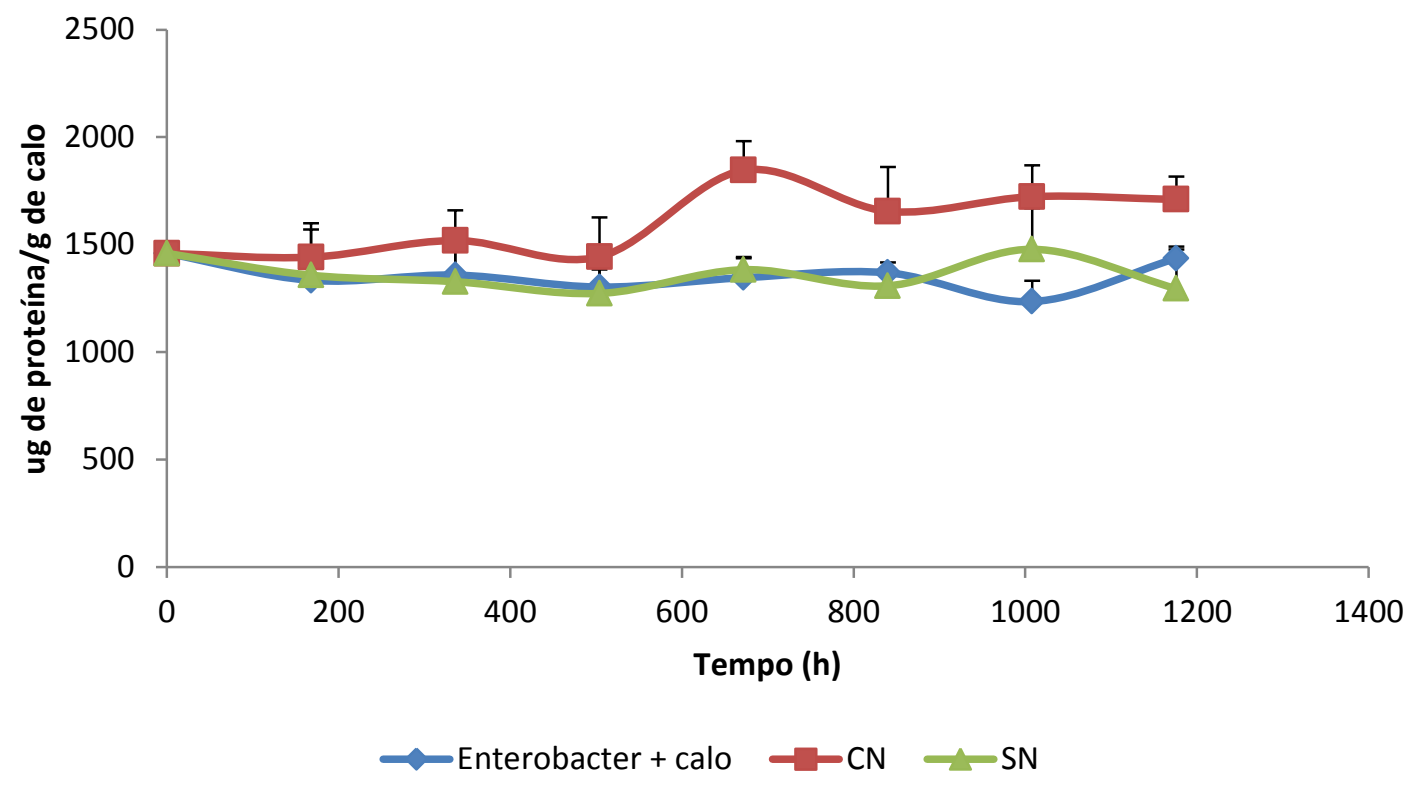

4.3.1.2 Pseudomonas sp. ICB383

Figura 36 - Curvas de conteúdo proteico do calo em co-cultura com Pseudomonas sp. ICB383 (Pseudomonas + calo), em meio MS com nitrogênio $(\mathrm{CN})$ e em meio $\operatorname{MSM}(\mathrm{SN})$.

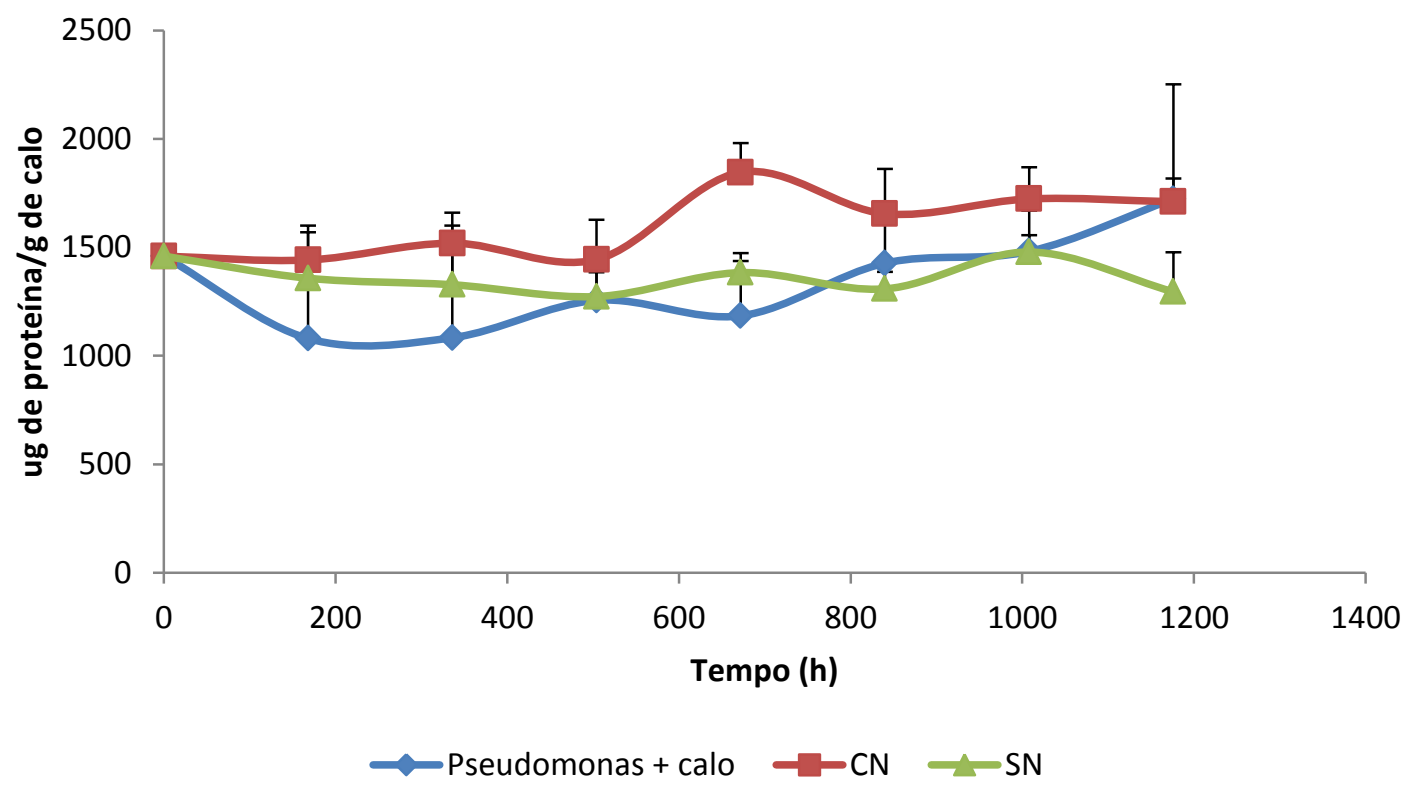




\subsubsection{Pantoea sp. ICB409}

Figura 37 - Curvas de conteúdo proteico do calo em co-cultura com Pantoea sp. ICB409 $($ Pantoea + calo), em meio MS com nitrogênio $(\mathrm{CN})$ e em meio MSM (SN).

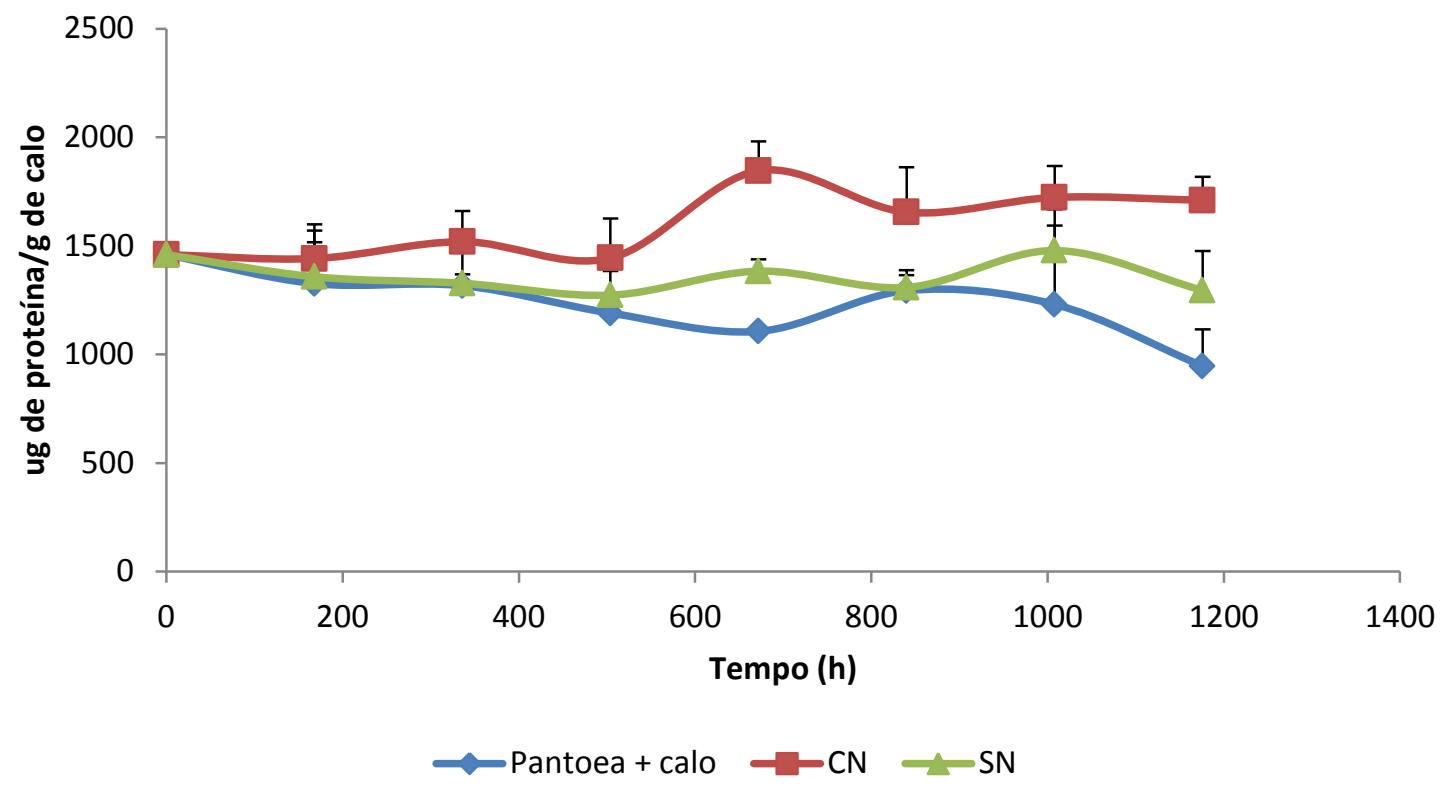

\subsubsection{Culturas Mistas}

As figuras 38, 39 e 40 mostram as curvas controle ( $\mathrm{CN}$ e $\mathrm{SN})$ e a curva de conteúdo proteico dos calos cultivados com as misturas Enterobacter sp. + Pseudomonas sp., Enterobacter sp. + Pantoea sp. e Pseudomonas sp. + Pantoea sp. respectivamente. Na figura 38, quando os calos foram cultivados com a mistura de Pseudomonas sp. e Enterobacter sp. em meio MSM não houve variação significativa do conteúdo proteico dos calos. Não houve diferenças significativas entre as curvas "Entrobacter + Pseudomonas + calo" e SN. Na figura 39, a curva de co-cultura permaneceu praticamente constante durante todo o experimento. Não houve diferenças significativas entre as curvas "Enterobacter + Pantoea + calo" e a curva SN. Na figura 40, houve um decréscimo de $42 \%$ no conteúdo proteico dos calos na curva co-cultura que se estabilizou após 168 horas, porém, não houve diferenças significativas entre as curvas SN e "Pseudomonas + Pantoea + calo". 
Figura 38 - Curvas de conteúdo proteico do calo em co-cultura com a mistura Enterobacter sp. ICB113 e Pseudomonas sp. ICB383 (Enterobacter + Pseudomonas + calo), em meio MS com nitrogênio $(\mathrm{CN})$ e em meio MSM (SN).

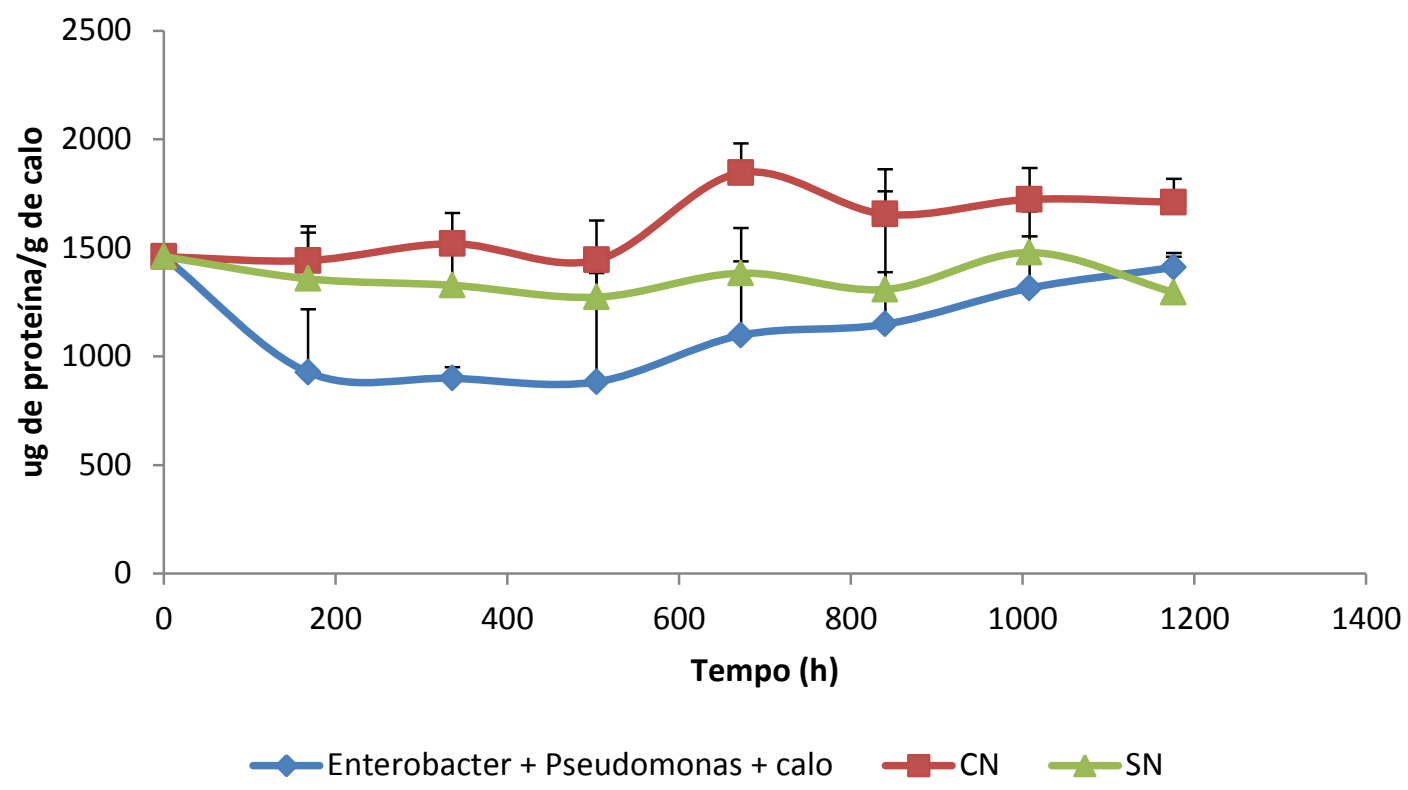

\subsubsection{Enterobacter sp. ICB113 + Pantoea sp. ICB409}

Figura 39 - Curvas de conteúdo proteico do calo em co-cultura com a mistura Enterobacter sp. ICB113 e Pantoea sp. ICB409 (Enterobacter + Pantoea + calo), em meio MS com nitrogênio $(\mathrm{CN})$ e em meio MSM (SN).

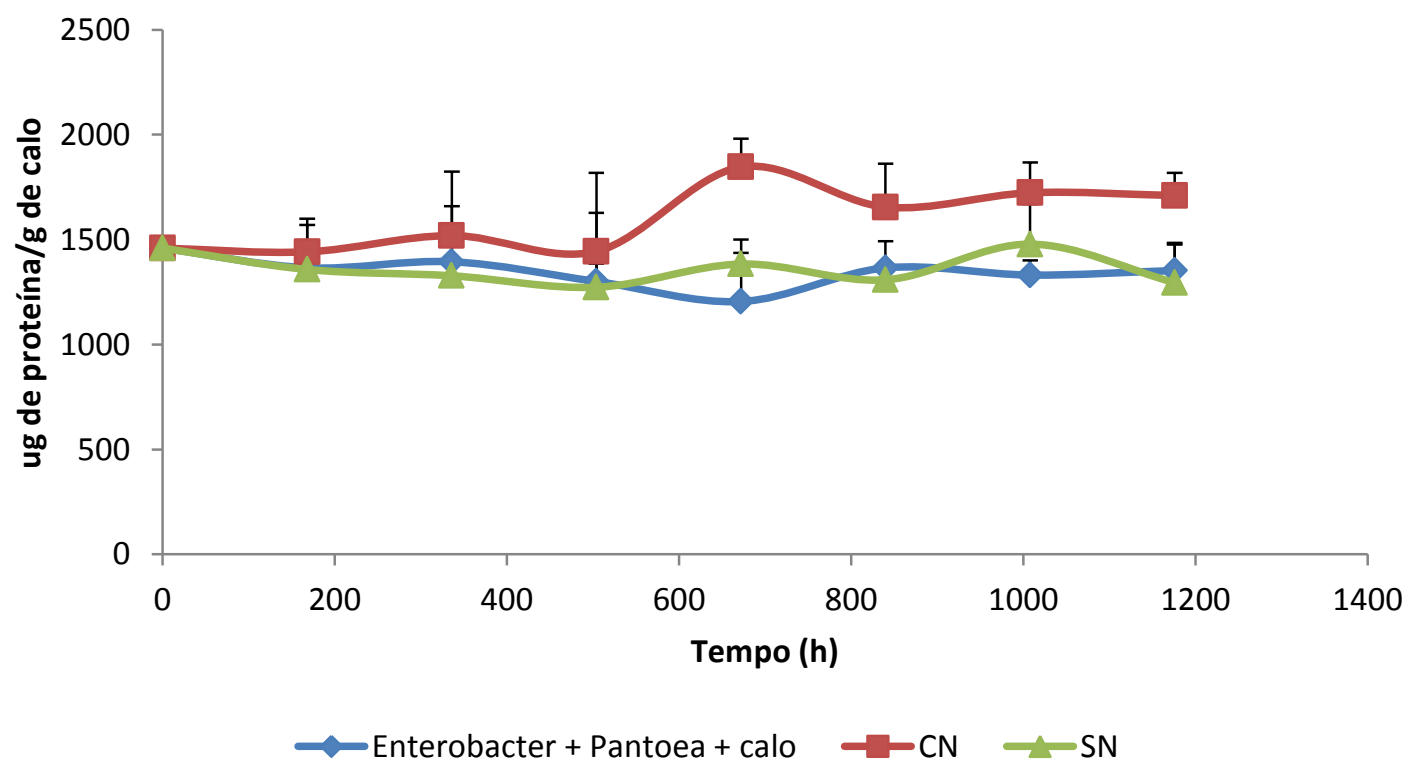


Figura 40 - Curvas de conteúdo proteico do calo em co-cultura com a mistura Pseudomonas sp. ICB383e Pantoea sp. ICB409(Pseudomonas + Pantoea + calo), em meio MS com nitrogênio $(\mathrm{CN})$ e em meio MSM (SN).

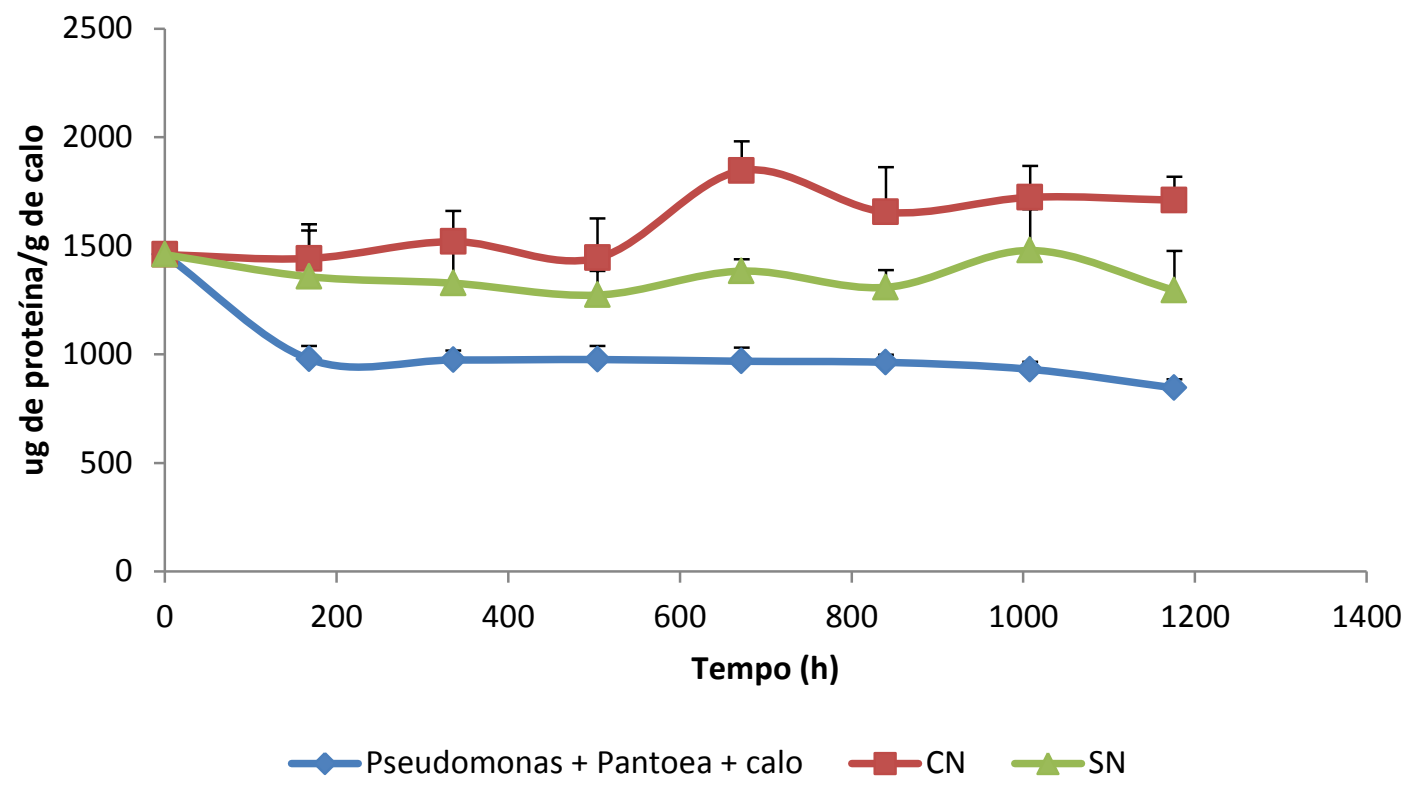

\subsection{Conteúdo de ON e EROS nos calos em presença de bactérias}

\subsubsection{ON}

As figuras a seguir (41 a 46) mostram o conteúdo intra e extracelular de óxido nitrico (ON) das suspensões de células de cana-de-açúcar, em função do tempo. As curvas "Controle intracelular" e "Controle extracelular" nestas figuras, são as mesmas e foram utilizadas para se comparar a variação do conteúdo de ON nas suspensões somente com o fluoróforo, com as suspensões acrescidas do fluoróforo mais a(s) bactéria(s).

\subsubsection{Culturas Simples}

As figuras 41, 42 e 43 mostram as curvas controle e as curvas onde a suspensão foi acrescida de cultura bacteriana contendo Enterobacter sp., Pseudomonas sp. e Pantoea sp. respectivamente. $\mathrm{Na}$ figura 41, ambas as curvas de conteúdo de $\mathrm{ON}$ da co-cultura tanto intracelular, quanto extra, não sofreram variação ao longo do tempo. Porém ambas são diferentes significativamente em relação aos seus respectivos controles, sendo que a curva 
"Enterobacter + calo (intracelular)" apresentou maiores valores que a curva controle, por outro lado, a curva "Enterobacter + calo (extracelular)" apresentou valores menores que seu respectivo controle.Na figura 42, ambas as curvas de co-cultura apresentaram valores constantes de ON e não houve diferença significativa entre as curvas de co-cultura e seus respectivos controles. Na figura 43, a curva de co-cultura intracelular não sofreu variação ao longo do tempo, por outro lado, a cuva de conteúdo extracelular sofreu uma leve queda no decorrer do experimento. Ambas as curvas são diferentes de seus respectivos controles, uma vez que as duas foram maiores que seus controles.

\subsection{Enterobacter sp. ICB113}

Figura 41 - Conteúdo intra e extracelular de ON das suspensões celulares cultivadas com Enterobacter sp. ICB113.

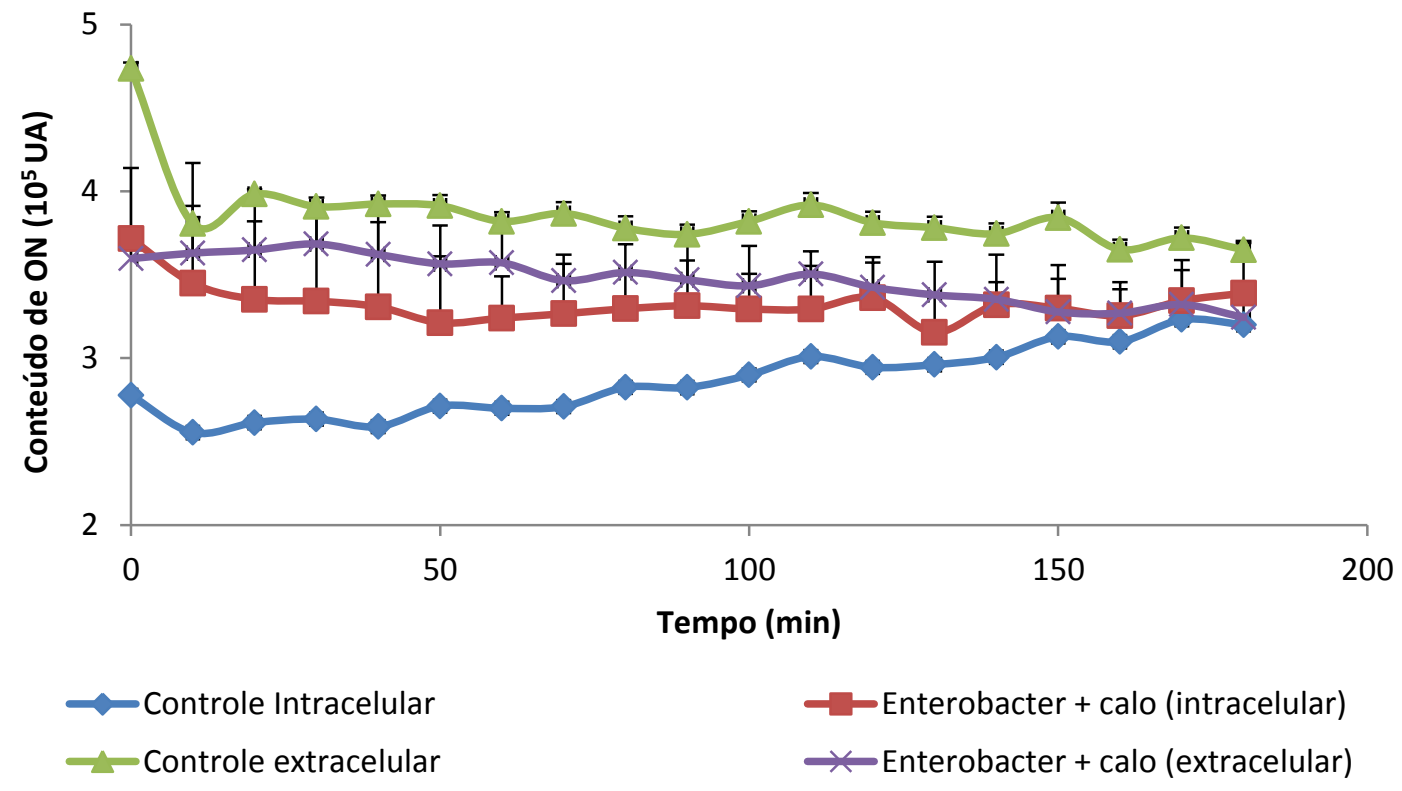

UA= Unidades de Absorbância 


\subsection{Pseudomonas sp. ICB383}

Figura 42 -Conteúdo intra e extracelular de $\mathrm{ON}$ das suspensões celulares cultivadas com Pseudomonas sp. ICB383.

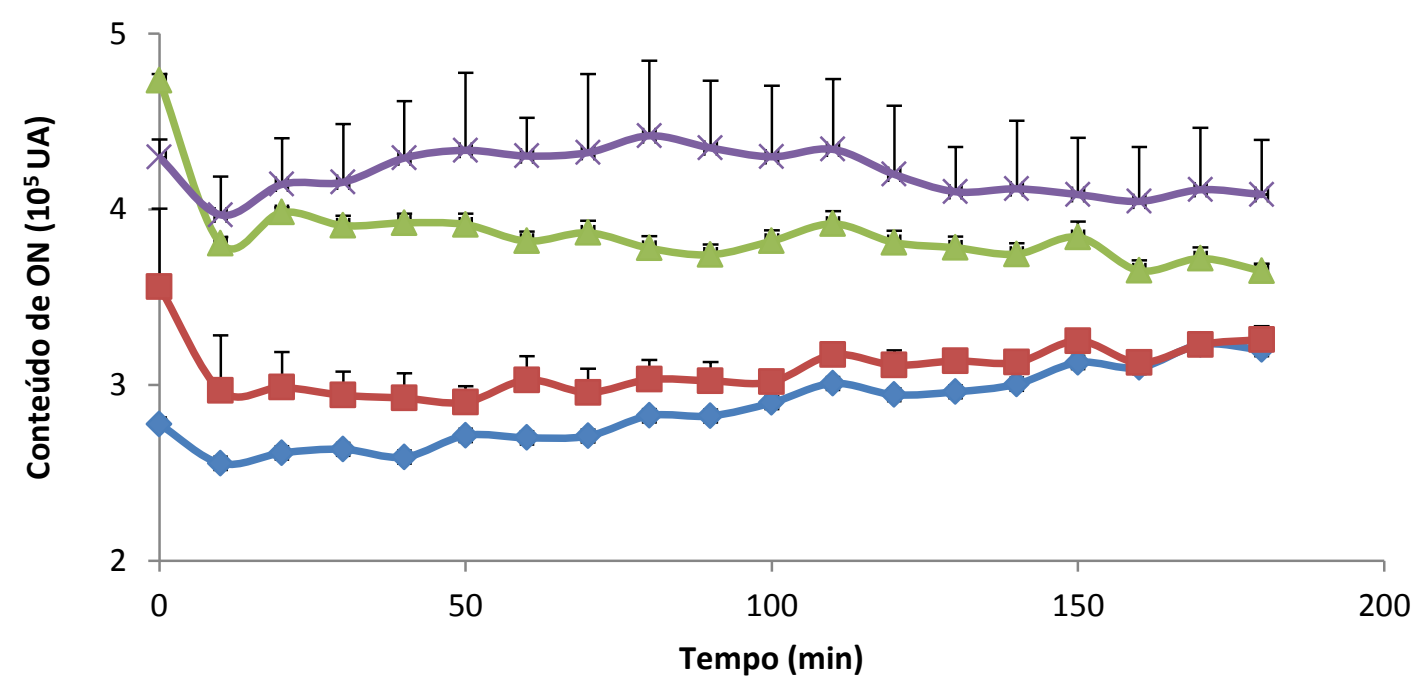

- Controle intracelular - Controle extracelular

-Pseudomonas + calo (intracelular)

$\leftarrow$ Pseudomonas + calo (extracelular)

$\mathrm{UA}=$ Unidades de Absorbância

\subsection{Pantoea sp. ICB409}

Figura 43 - Conteúdo intra e extracelular de $\mathrm{ON}$ das suspensões celulares cultivadas com Pantoea sp. ICB409.

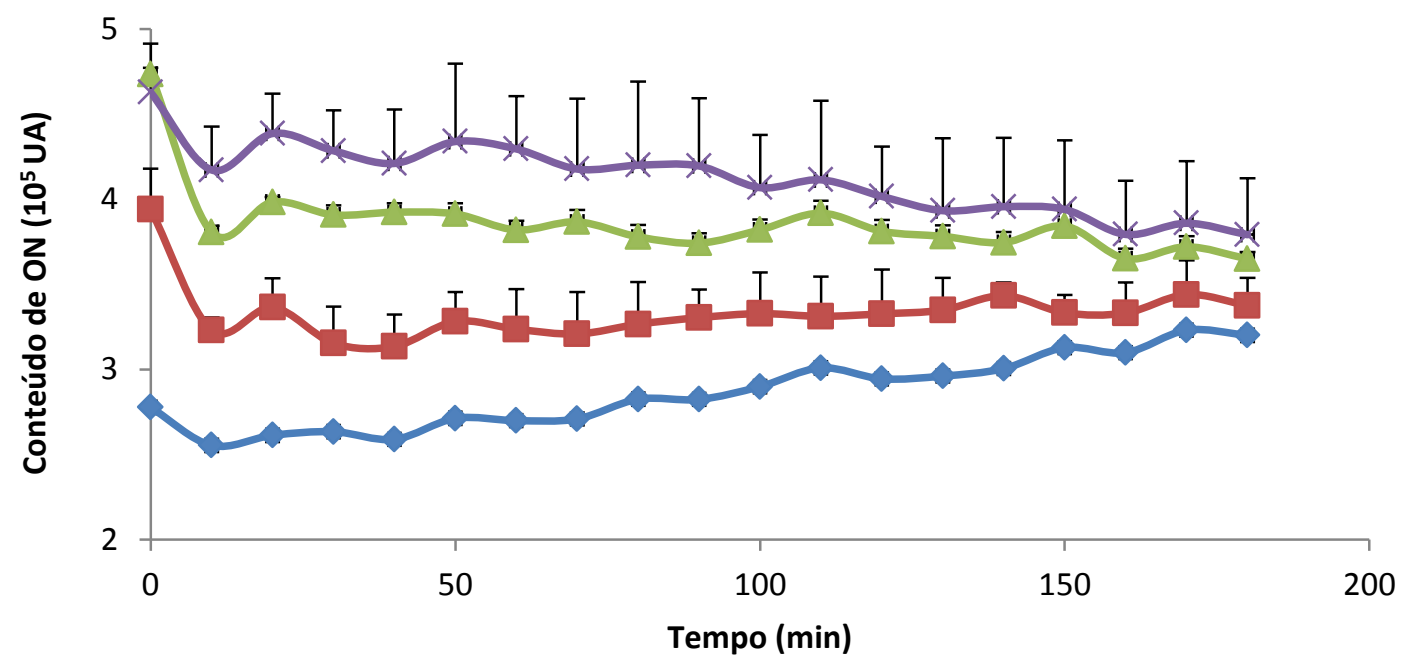

$\sim$ Controle intacelular

- Pantoea + calo (intracelular)

- Controle extracelular

$\because$ Pantoea + calo (extracelular)

UA= Unidades de Absorbância 


\subsubsection{Culturas Mistas}

As figuras 44, 45 e 46 mostram as curvas de conteúdo de ON controle e as curvas onde a suspensão foi acrescida de cultura bacteriana contendo as misturas Enterobacter sp. + Pseudomonas sp., Enterobacter sp. + Pantoea sp. e Pseudomonas sp. + Pantoea sp. respectivamente. $\mathrm{Na}$ figura 44 , em ambas as curvas de conteúdo de $\mathrm{ON}$ da co-cultura tanto intra, quanto extracelular, não sofreram variação ao longo do tempo e ambas são significativamente iguais aos seus respectivos controles. Na figura 45 , as duas curvas de cocultura (intra e extracelular) não sofreram variação de seus valores ao longo do tempo. Somente a curva "Enterobacter + Pantoea + calo (extracelular)" é diferente significativamente em relação ao seu controle, apresentando valores menores que o controle. $\mathrm{Na}$ figura 46, as curvas da co-cultura intra e extracelular apresentaram-se constantes ao longo do ensaio. Porém somente a curva de co-cultura de conteúdo de ON extracelular é diferente significativamente de seu respectivo controle, apresentando valores menores.

\subsection{Enterobacter sp. ICB113 + Pseudomonas sp. ICB383}

Figura 44 - Conteúdo intra e extracelular de ON das suspensões celulares cultivadas com Enterobacter sp. ICB113 e Pseudomonas sp. ICB383.

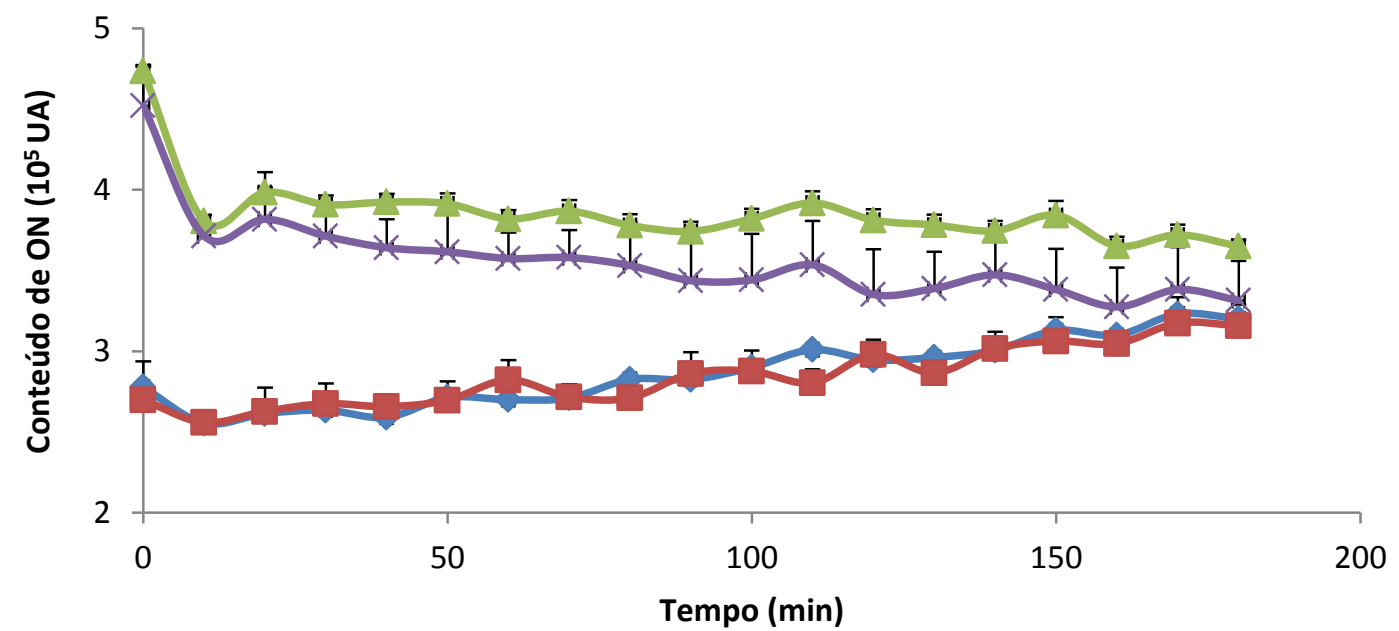

Controle intracelular

Enterobacter + Pseudomonas + calo (intracelular)

- Controle extracelular

* Enterobacter + Pseudomonas + calo (extracelular)

$\mathrm{UA}=$ Unidades de Absorbância 
Figura 45 - Conteúdo intra e extracelular de ON das suspensões celulares cultivadas com Enterobacter sp. ICB113 e Pantoea sp. ICB409.

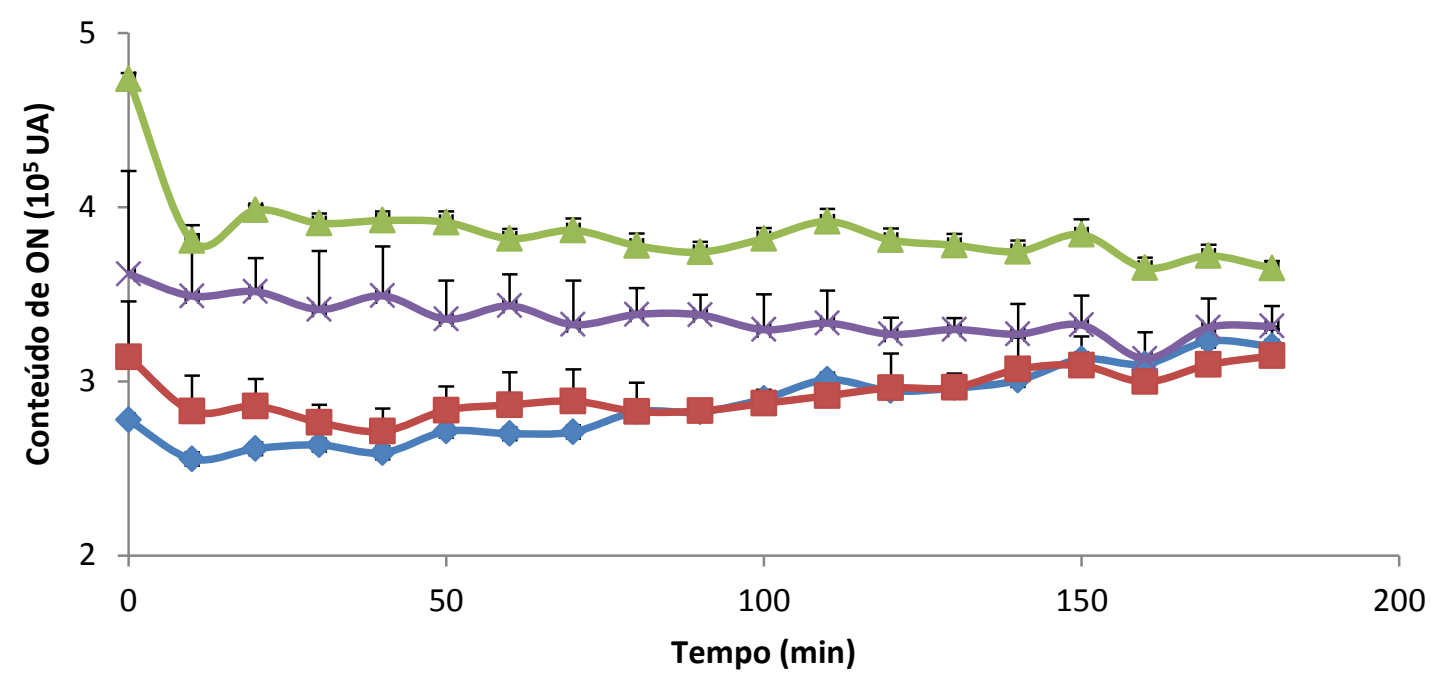

Controle intracelular

Enterobacter + Pantoea + calo (intracelular)

- Controle extracelular

$\times$ Enterobacter + Pantoea + calo (extracelular)

UA= Unidades de Absorbância

\subsection{Pseudomonas sp. ICB383 + Pantoea sp. ICB409}

Figura 46 - Conteúdo intra e extracelular de $\mathrm{ON}$ das suspensões celulares cultivadas com Pseudomonas sp. ICB383 e Pantoea sp. ICB409.

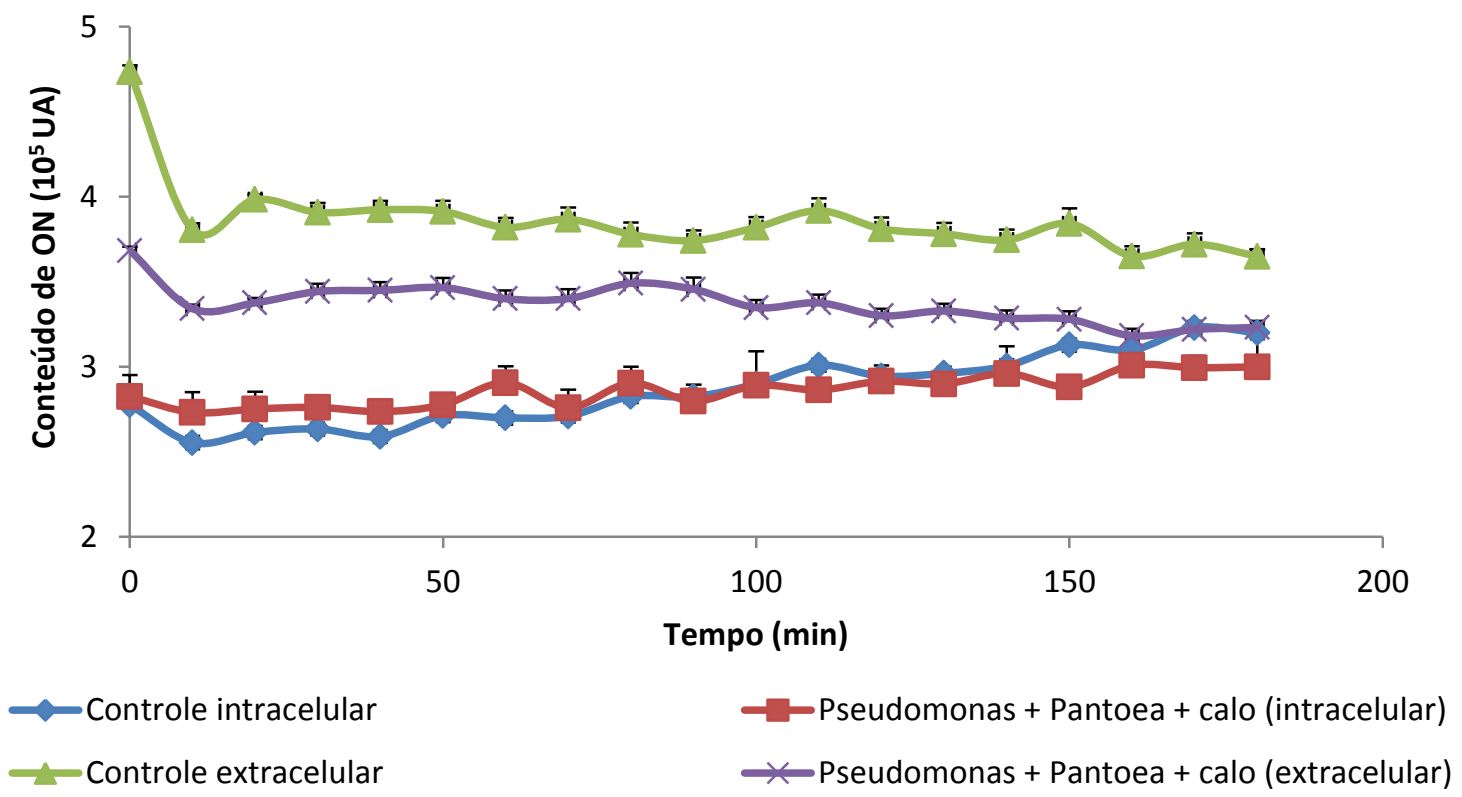

UA= Unidades de Absorbância 


\subsubsection{EROs}

As figuras a seguir (47 a 52) mostram o conteúdo intra e extracelular de espécies reativas de oxigênio (EROs) das suspensões de células de cana-de-açúcar em função do tempo. A curva "Controle" utilizada nestas figuras é a mesma e foi utilizada para se comparar a variação do conteúdo de EROs nas suspensões somente com o fluoróforo, com as suspensões acrescidas do fluoróforo mais a(s) bactéria(s).

\subsubsection{Culturas Simples}

As figuras 47, 48 e 49 mostram a curva controle e as curvas onde a suspensão foi acrescida de cultura bacteriana contendo Enterobacter sp., Pseudomonas sp. e Pantoea sp. respectivamente. Na figura 47, o perfil da curva de co-cultura foi muito semelhante ao da curva controle, assim, não houve diferenças significativas entre as curvas. Na figura 48, a curva de co-cultura sofreu um aumento ao longo do tempo que foi significativamente diferente de seu controle. Na figura 49, a curva de co-cutura apresentou um aumento de seus valores ao longo do tempo. Houve diferença significativa entre a curva de co-cultura e a controle. 
Figura 47 - Conteúdo de EROs das suspensões celulares cultivadas com Enterobacter sp. ICB113.

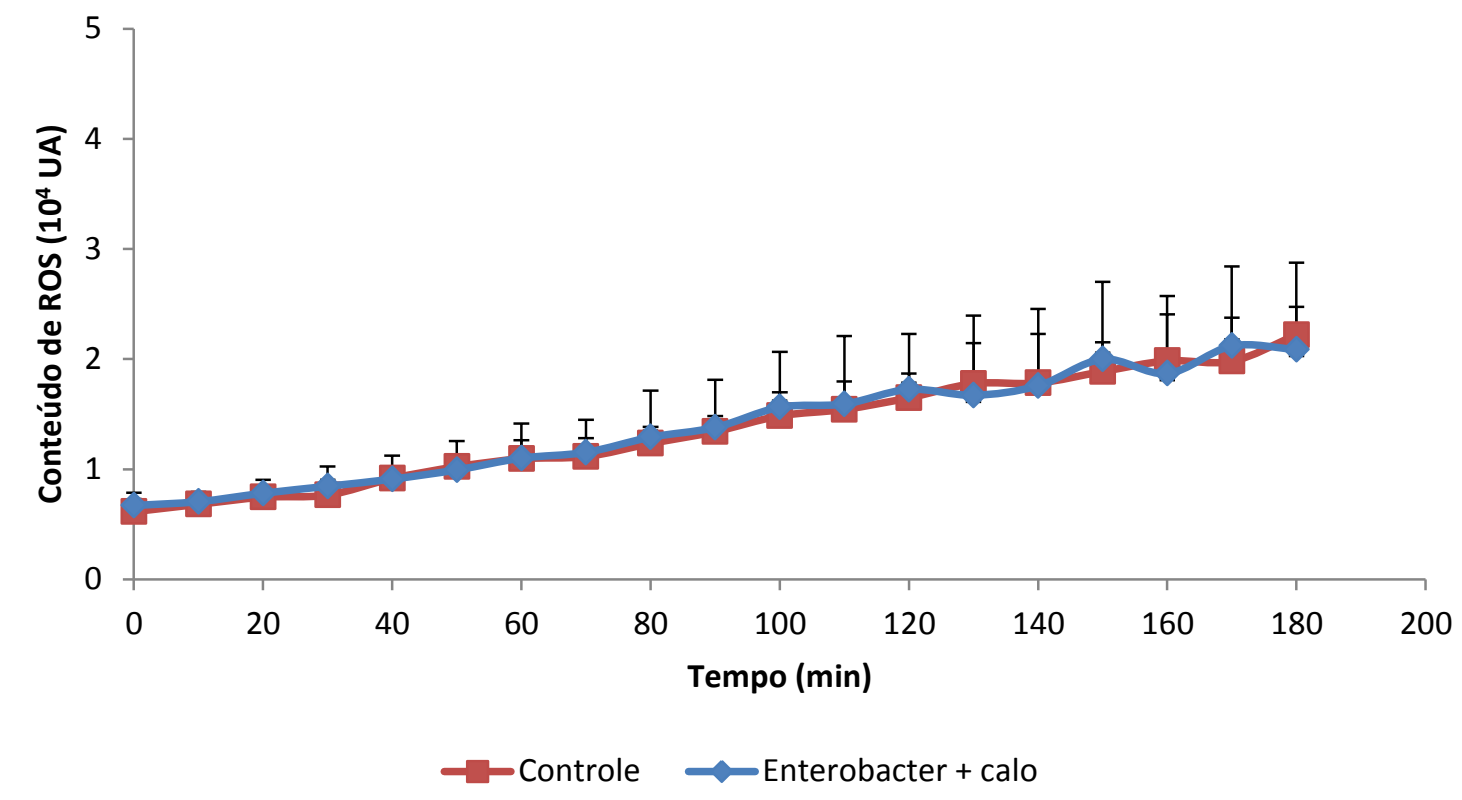

UA= Unidades de Absorbância

\subsection{Pseudomonas sp. ICB383}

Figura 48 - Conteúdo de EROs das suspensões celulares cultivadas com Pseudomonas sp. ICB383.

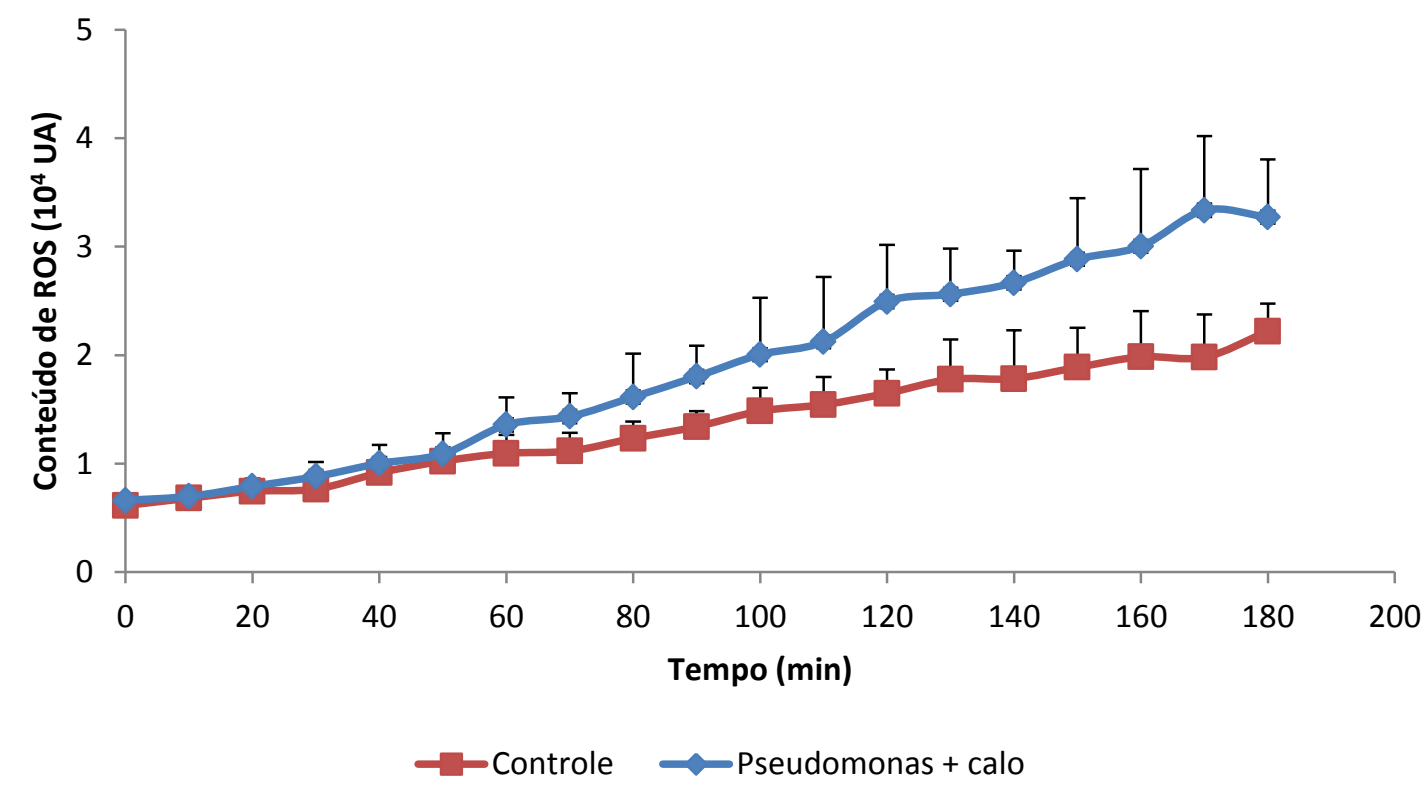

UA= Unidades de Absorbância 
Figura 49 - Conteúdo de EROs das suspensões celulares cultivadas com Pantoea sp. ICB409.

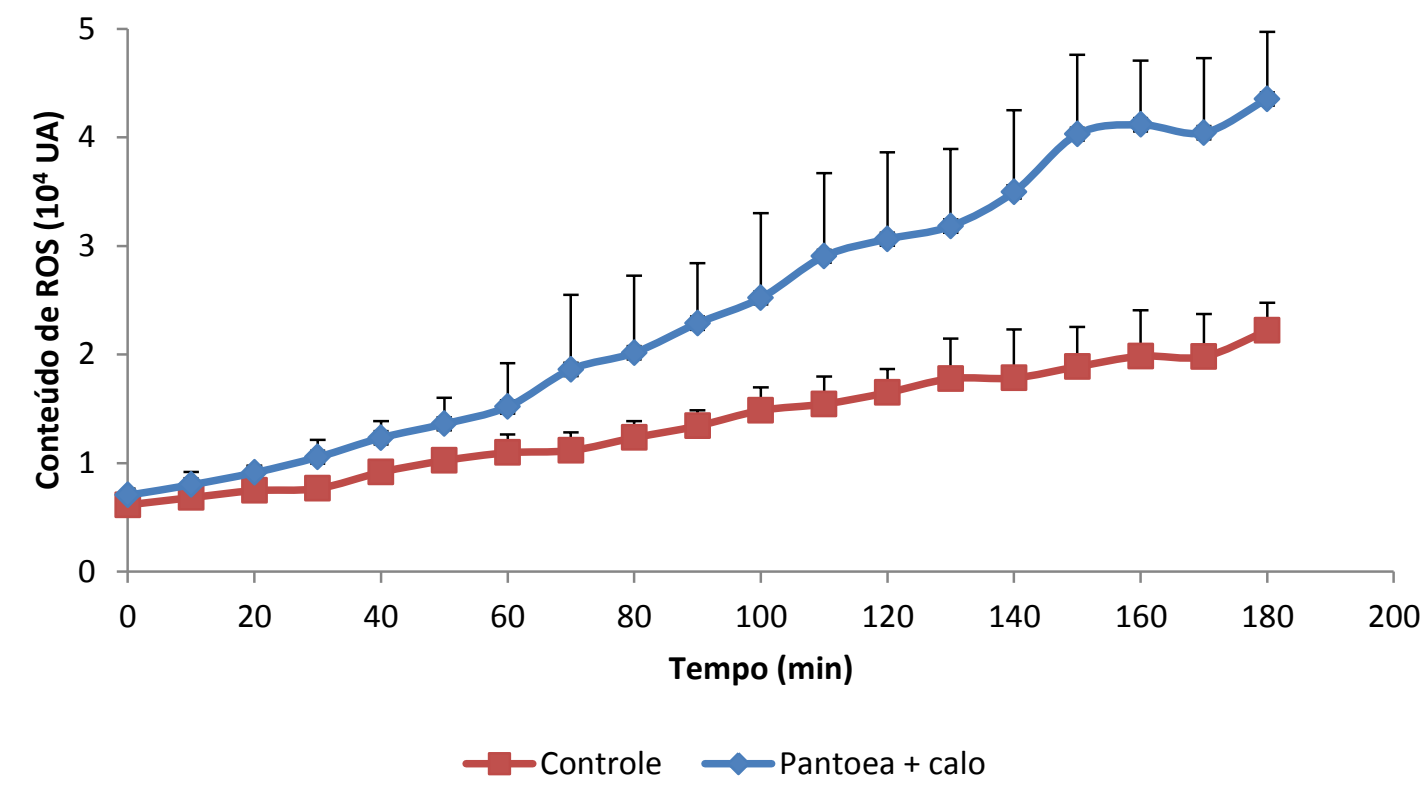

UA= Unidades de Absorbância

\subsubsection{Culturas Mistas}

As figuras 50, 51 e 52 mostram a curva de conteúdo de EROs controle e as curvas onde a suspensão foi acrescida de cultura bacteriana contendo as misturas Enterobacter sp. + Pseudomonas sp., Enterobacter sp. + Pantoea sp. e Pseudomonas sp. + Pantoea sp. respectivamente. Na figura 50, a curva de co-cultura sofreu um aumento de seus valores ao longo do tempo, sendo diferente significativamente de seu controle. Na figura 51, houve um aumento no conteúdo de EROs ao longo do tempo na curva de co-cultura, que foi diferente significativamente do controle. Na figura 52, a curva de co-cultura apresentou este mesmo perfil onde houve um aumento no conteúdo de EROs, sendo diferente significativamente em relação ao controle. 
Figura 50 - Conteúdo de EROs das suspensões celulares cultivadas com Enterobacter sp. ICB113 e Pseudomonas sp. ICB383.

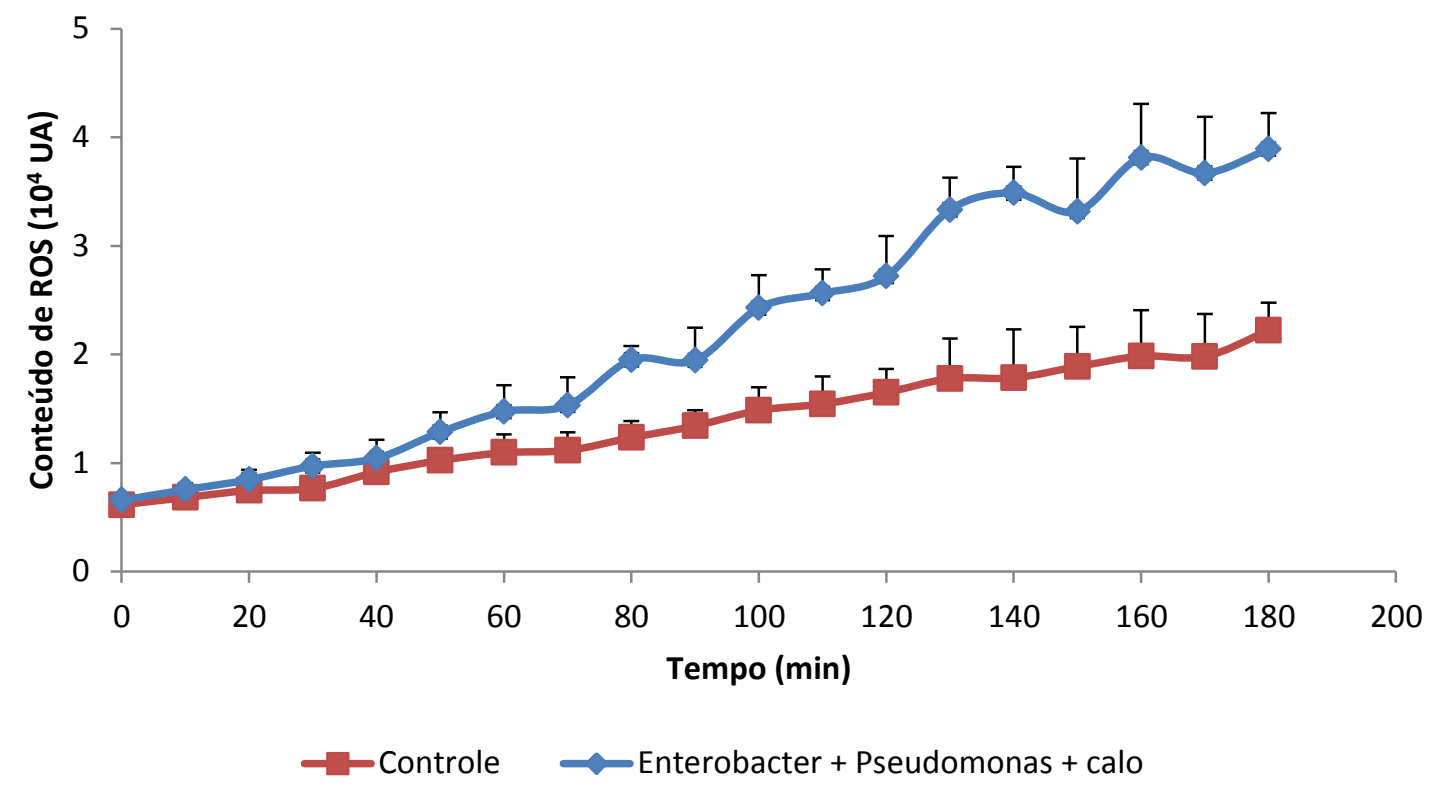

UA= Unidades de Absorbância

4.4.2.2.2 Enterobacter sp. ICB113+ Pantoea sp. ICB409

Figura 51 - Conteúdo de EROs das suspensões celulares cultivadas com Enterobacter sp. ICB113 e Pantoea sp. ICB409.

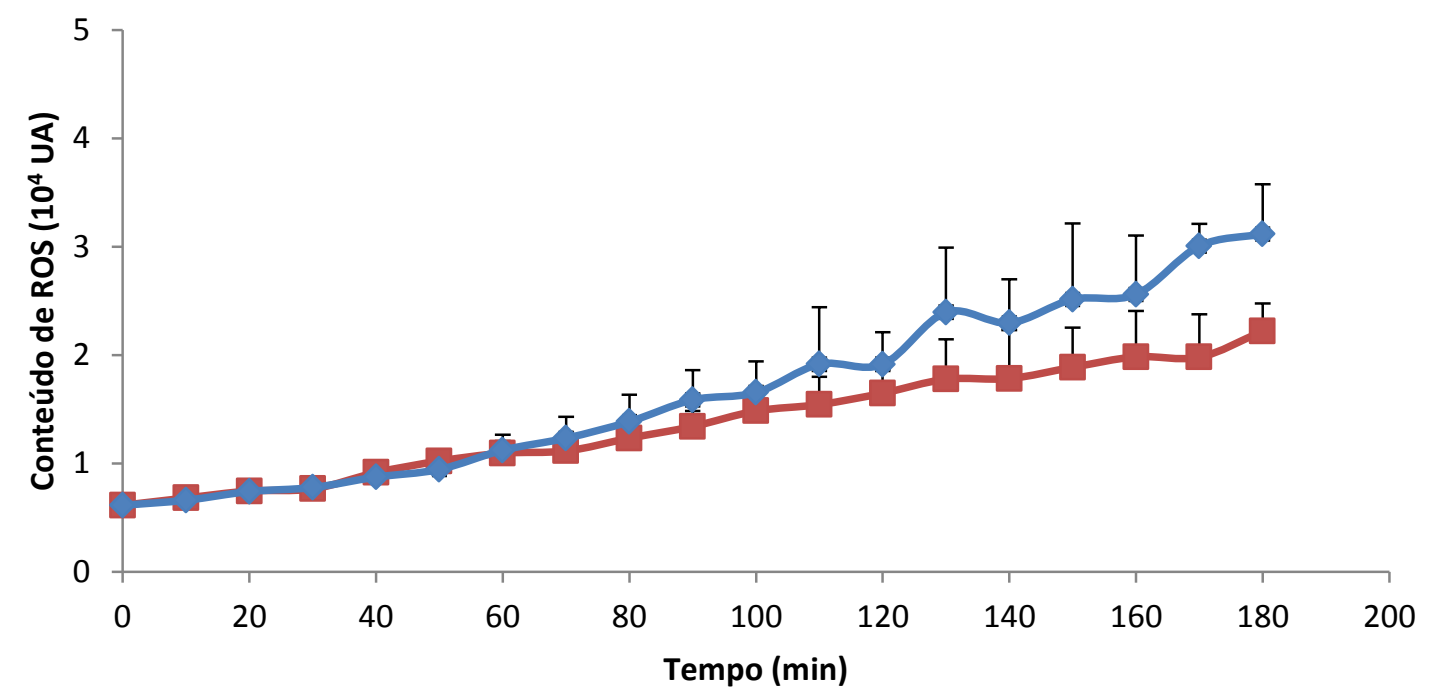

- Controle $\_$Enterobacter + Pantoea + calo

UA= Unidades de Absorbância 
4.4.2.2.3 Pseudomonas sp. ICB383 + Pantoea sp. ICB409

Figura 52 - Conteúdo de EROs das suspensões celulares cultivadas com Pseudomonas sp. ICB383 e Pantoea sp. ICB409.

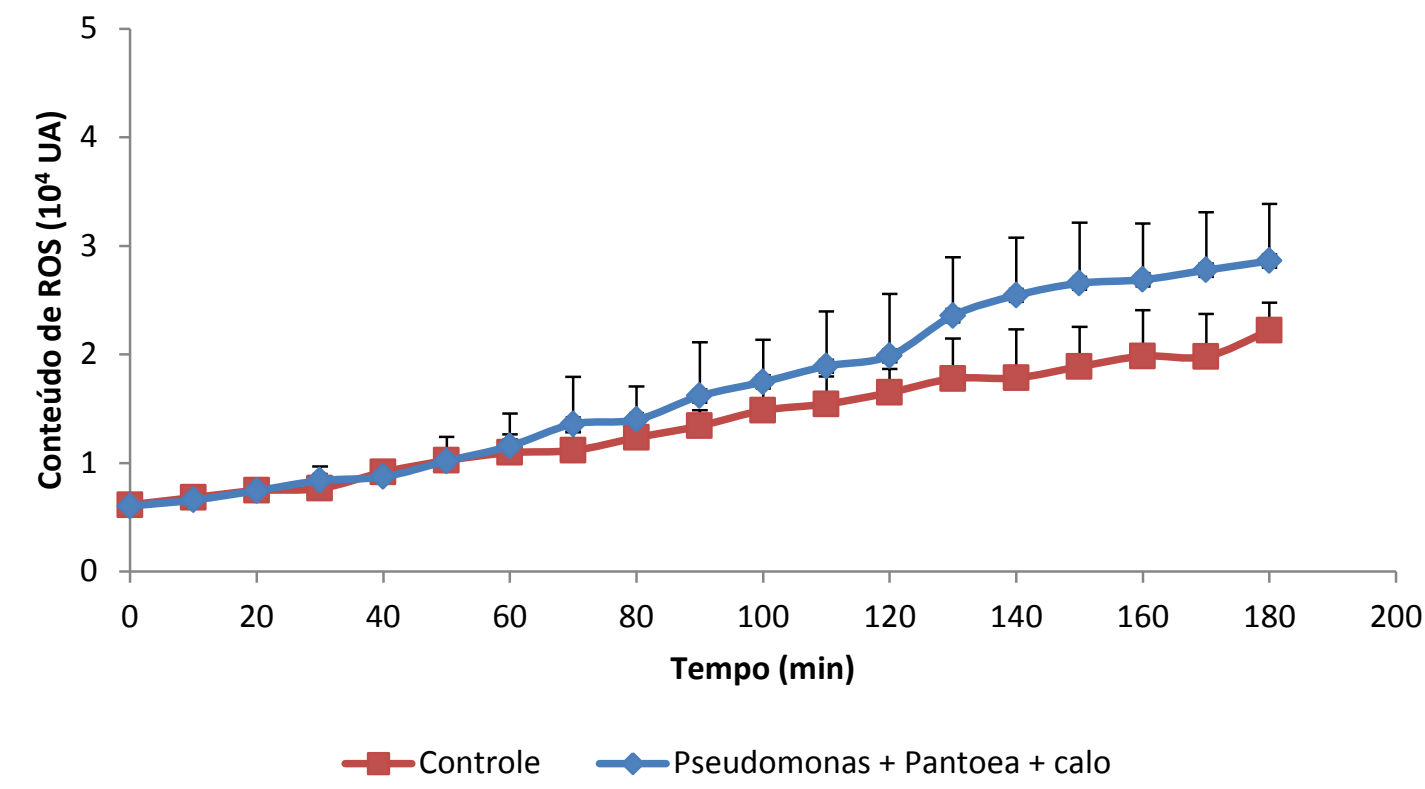

UA= Unidades de Absorbância 


\section{DISCUSSÃO}

\subsection{Crescimento bacteriano}

Os resultados obtidos neste trabalho para as curva de crescimento contendo uma única bactéria, mostraram que a presença do calo estimulou o crescimento de Enterobacter sp. ICB113 durante a fase exponencial, o que acarretou, em uma diminuição do tempo de geração (figura 2 e tabela 3). O número populacional continuou elevado ao atingir a fase estacionária (até 936 horas). Por outro lado, nesta mesma fase, as curvas de Pseudomonas sp. ICB383 (figura 7) e Pantoea sp. ICB409 (figura 12) apresentaram o efeito contrário, as populações foram inibidas e, no caso de Pantoea sp., todas as células bacterianas foram eliminadas ao final do experimento. Estes dados indicam que substâncias estimulantes ou inibitórias devem ter sido liberadas pelos calos quando em contato com diferentes microrganismos, porém, não há dados na literatura que corroborem este fato. O estímulo ou inibição ocorre devido a uma interação planta-bactéria, ou seja, o tipo de efeito é específico entre determinada espécie de planta com determinada espécie bacteriana.

A partir destes dados, acredita-se que o calo reconheceu Enterobacter sp. como uma bactéria benéfica, enquanto Pseudomonas sp. e Pantoea sp. foram reconhecidas como uma possível patógena, pois inibiu parcialmente o crescimento de Pseudomonas sp.e eliminou totalmente Pantoea sp.. Esta bactéria. em cultura pura, na ausência de calo , também sofreu uma queda na população durante a fase estacionaria (figura 12). Este fato pode ter ocorrido devido ao meio utilizado (MSM) ter-se tornado inadequado para o cultivo da linhagem em questão.

Para o estabelecimento de co-culturas que envolvessem calos, foi feita a opção pelo meio MSM (seção 3.2.2), apropriado para o desenvolvimento de células vegetais, porém sem nitrogênio combinado, que permite que a bactéria busque uma nova fonte de nitrogênio $\left(\mathrm{N}_{2}\right.$ atmosférico) e realize a fixação biológica de nitrogênio. Esta escolha foi feita porque as bactérias deste trabalho foram isoladas em meio de composição mais simples que o meio MSM, que inclusive também era destituído de fonte de $\mathrm{N}$ combinado. Assim, o meio MSM poderia ser apropriado para o cultivo tanto de células vegetais como dos microrganismos. No entanto, se realmente foi o meio de cultura que causou a morte de parte da população bacteriana, provavelmente foi devido carência de determinados nutrientes necessários para a manutenção da viabilidade de toda a população durante a fase estacionária. 
A inibição das populações de Pseudomonas sp. e Pantoea sp. em presença de calo (figuras 7 e 12) ocorreu imediatamente após o término da fase exponencial, ou seja, houve uma demora no desencadeamento ou na efetividade da(s) substância(s) liberadas pelo calo nesta associação. Esta demora no desencadeamento da resposta de defesa do calo pode ter ocorrido devido ao tempo necessário para o reconhecimento do microrganismo e, a partir disto, expressar os genes e respectiva(s) via(s) de defesa. O reconhecimento entre planta e organismos se dá pelas MAMPs (microbe-associated molecular patterns), entre eles está o LPS (lipopolissacarídeo) presentes nas bactérias Gram-negativas, que são reconhecidas pelos receptores altamente conservados PRRs (patterns recognition receptors) presentes nas plantas (O’BRIEN et al., 2012). As substâncias envolvidas nestas vias de defesa precisam estar em uma concentração adequada para que sejam eficazes na eliminação do patógeno. Este fato é demonstrado por Arencibia et al. (2006), que analisou a transcrição de genes ligados à sinalização de defesa entre planta (cana-de-açúcar) e bactéria (Xanthomonas albilineans) e mostrou que, três dias depois da inoculação, a transcrição destes genes foi fortemente observada. Entre os produtos destes genes, 26\% eram de vias de sinalização de etileno, que é expresso quando Induced Systemic Resistance (ISR) está ativa. O etileno e o ácido jasmônico são fitormônios e estão envolvidos no desencadeamento de ISR (COMPANT et al., 2005). Iniguez et al. (2004) também evidenciaram demora no desencadeamento da resposta de defesa. Plantas de Medicago truncatula cultivadas em meio suplementado com 1aminocyclopropane-1-carboxylic acid (ACC) molécula precursora do etileno, foram inoculadas com K. pneumoniae 342 (Kp342) e Salmonella enterica 14028; foi observado que a inibição da colonização nas raízes e hipocótilo só foi significante após 96 horas. Este fato foi corroborado quando as plantas foram cultivadas com 1-methylcyclopropene (1-MCP), inibidor do etileno e assim, observaram um aumento na colonização por estas mesmas bactérias.

Analisando-se o crescimento dos isolados, quando combinados com outras bactérias, observou-se que Pseudomonas sp. não sobreviveu nos ensaios em co-cultura com o calo, em ambas as misturas, com Pantoea sp. ou com Enterobacter sp. (figura 10). Os experimentos realizados com mistura de bactérias em co-culturas com calos foram ilustrativos e evidenciaram que o isolado Pseudomonas sp. é um fraco competidor em relação às outras duas linhagens. Experimentos de competição entre bactérias endofíticas Pantoea sp e Ochrobactrum sp inoculadas em arroz mostraram diferenças de competências de colonização entre as bactérias. A colonização de Ochrobactrum $s p$ foi severamente inibida quando as duas 
bactérias foram inoculadas em mesmo número populacional. Este fato implica que algumas linhagens são mais agressivas, com maior poder competitivo (VERMA et al., 2004). Plantas de tomate (Solanum lycopersicum) inoculadas simultaneamente com os microrganismos Fusarium oxysporum e Rhizobium etli, em seções separadas de raízes, resultaram numa diminiução de aproximadamente $37 \%$ da colonização da raíz por Rhizobium etli após quatro semanas da inoculação. Isto mostra que, na natureza, para se estabelecer nas plantas é preciso enfrentar uma gama de microrganismos que também competem por espaço e alimento (MARTINUZ; SHOUTEN; SIKORA, 2012) e a "força" da competição é bastante variável e pouco previsível.

Plantas micropropagadas de cana-de-açúcar foram inoculadas com diferentes misturas bacterianas para o estudo da capacidade de colonização de cada um dos isolados. Os resultados mostraram diferenças na colonização das plantas de cada espécie bacteriana. Azospirillum amazonense, após 120 horas da inoculação, apresentou predominância numérica em relação às outras espécies presentes na mistura: Gluconacetobacter diazotrophicus, Herbaspirillum seropedicae, H. rubrisubalbicans e Burkholderia tropica. Porém, quando A. amazonense foi inoculada em associação apenas com B. tropica, foi encontrada em menor densidade. (OLIVEIRA et al., 2009). Não houve nenhuma explicação, por parte dos autores que justificasse os resultados.

Pantoea sp. em cultura mista com Pseudomonas sp. ou com Enterobacter sp., em ausência de calo (figura 13), não apresentou diferenças significativas em comparação com a cultura pura. Pode-se inferir a partir disto, que Pseudomonas sp. e Enterobacter sp. não exerceram nenhum efeito sobre a população de Pantoea sp.. No entanto, efeito contrário foi observado, uma vez que, Pantoea sp. eliminou Pseudomonas sp. (figura 8) quando em mistura e inibiu parcialmente a população Enterobacter sp. (figura 3). Um controle das células vegetais na forma de calo ficou evidenciado na mistura Pseudomonas sp. com Pantoea sp. (figuras 10 e 15) quando ambas as linhagens foram eliminadas. Sabe-se que, em ambos os gêneros, são encontradas muitas espécies fitopatogênicas. Pantoea stewartii subespécie stewartii é uma bacteria entérica que primariamente infectava milho doce. Estudos com esta linhagem têm fornecido informações úteis sobre como esta bactéria se estabelece no xilema e incita a doença em seu hospedeiro (ROPER, 2011). Pseudomonas syrinagae é um patógeno hemibiotrófico que causa uma variedade de doenças em diversas plantas (STEVEN; DONG, 2008). Estes dados são corroborados nos ensaios que envolveram estes gêneros bacterianos em cultura com o calo (figuras 7 e 12) e a mistura deles com calo (figuras 10 e 
15). Quando em cultura simples com o calo, o crescimento Pseudomonas sp. ICB383 foi parcialmente inibido e o de Pantoea sp.ICB409 apresentou inibição total. Quando cultivadas juntas, em presença do calo, houve a inibição total do crescimento das duas bactérias, mostando que existe uma resposta do calo diante a presença de bactérias patogênicas. Esta resposta foi "mais forte" quando as duas bactérias foram cultivadas juntas. Observou-se também uma diminuição do tempo em que ambas as bactérias permaneceram viáveis.

A comunicação química entre as bactérias, quorum-sensing (QS), tanto para organismos benéficos quanto para patógenos é necessária para que a comunidade bacteriana consiga agir de maneira coordenada, obtendo assim, vantagens na adaptação a um novo nicho, vantagens competitivas sobre outras espécies, expressão de fatores de virulência, etc. $\mathrm{O}$ quorum-sensing de Erwinia carotovora é importante para que haja a produção de um antibiótico de amplo espectro, que proporciona vantagens na competição com outras bactérias e consequentemente, o sucesso na colonização do hospedeiro (BARRAS; VAN GIJSEM; CHATTERJEE, 1994). Por outro lado, a produção da molécula sinal AHL (N-acylhomoserine-lactone) no QS pode ser reconhecida pela planta que irá controlar ou exterminar o microrganismo ali presente, através do desencadeamento de algum mecanismo de defesa ou secretando substâncias que mimetizam o AHL. Moléculas de AHL foram reconhecidas por Medicago truncatula ocasionando um acúmulo de 7\% de proteínas em todo o vegetal. Nas proteínas recuperadas das raízes, $25 \%$ delas tinham funções na resposta de defesa da planta. Ainda persistem muitas duvidas sobre quando a planta percebe e responde a AHL (BAUER; MATHESIUS, 2004). P. stewartii subespécie stewartii produz grandes quantidades da molécula sinal AHL tornando-se um organismo excelente para se estudar a regulação de genes controlados pela interação planta-patógeno (ROPER, 2011).

Na cultura mista de Pseudomonas sp. e Enterobacter sp., com calo, (figura 5 e 10) a população de Pseudomonas sp. apresentou o menor tempo de geração observado (tabela 4). Neste caso, pode-se inferir que este aumento na taxa de multiplicação da bactéria foi devido à competição entre os gêneros. Para muitas espécies bacterianas, a combinação entre uma rápida taxa de crescimento e uma grande população, evidencia mutações raras (ao acaso) que podem conferir vantagens na adaptação de novos nichos e consequentemente uma vantagem na competição (HIBBING et al., 2009). Porém, por mais que Pseudomonas sp. tenha “tentado" aumentar sua população, não obteve êxito, pois, houve também um controle do crescimento da bactéria quando em contato com o calo, observou-se também que, enquanto Pseudomonas sp. foi eliminada, Enterobacter sp. sofreu inibição parcial de sua população, 
por parte do calo, na fase estacionária. Nesta situação, teve-se presente uma bactéria que acredita-se ser benéfica e outra um possível patógeno. Neste caso, a(s) substância(s) liberada(s) pelo calo, também afetou o crescimento de Enterobacter sp..

A pergunta que surge é: qual das vias de defesa será expressa neste caso? São crescentes, na literatura, artigos que afirmam que as duas vias induced systemic resistance (ISR) e systemic acquired resistance (SAR) não agem independentemente. Há uma interação entre as vias que pode ser sinérgica ou antagonista (KUNKEL; BROOKS, 2002). Dependendo do tipo de invasor, a planta parece ser capaz de ativar a via apropriada ou a combinação das vias (PIETERSE; VAN LOON, 1999). Patógenos de plantas são divididos em dois grupos: biotróficos, organismos que necessitam de células vivas para suprir sua demanda nutricional e os necrotróficos que danificam os tecidos de plantas através de toxinas e enzimas que degradam a parede celular. Porém, outro grupo chamado de hemibiotróficos foi encontrado. Nestes, uma fase inicial de biotrofia é seguida por uma necrotrófica; acredita-se que Pseudomonas syringae seja um microrganismo hemibiotrófico (BARNA et al., 2012). Spoel e Dong (2008) afirmam que, dependendo do tipo do patágeno (biotrófico ou necrotrófico) uma via será expressa. A resistência mediada por ácido salicílico (SAR) é efetiva contra patógenos biotróficos, enquanto que respostas de defesa mediada por ácido jasmônico ou etileno (ISR) são predominantemente contra patógenos necrotróficos e insetos herbívoros. Porém alguns patógenos podem induzir a produção de multiplas moléculas sinais e hormônios como o ácido salicílico e ácido jasmônico.

Nas figuras 10 e 11 notou-se que, em presença de Enterobacter sp., o calo eliminou rapidamente a população de Pseudomonas sp. que não sobreviveu após 8 horas de cultivo. Fica claro o papel de Enterobacter sp., uma vez que Pseudomonas sp., apenas em cultura com o calo, sofreu uma inibição parcial, mas não foi completamente eliminada. Muitos estudos têm sido realizados com a utilização de uma bactéria benéfica auxiliando na diminuição da susceptibilidade de plantas a doenças causadas por outras bactérias, fungos e até nematóides. Arencibia et al. (2006) inocularam, em cana-de-açúcar, uma suspensão de Gluconacetobacter diazotrophicus (endofítica) e após sete dias, inocularam nestas mesmas plantas, Xanthomonas albilineans (patogênica). Os dados mostraram um determinado número de plantas doentes. Quando a ordem de inoculação das duas bactérias foi invertida, o número de plantas doentes aumentou. Estes dados levaram à conclusão de que G. diazotrophicus deixou a planta em estado de "alerta", quando inoculada primeiramente, ou seja, o mecanismo de defesa agiu mais rapidamente quando a bactéria endofítica foi inoculada primeiro. No presente trabalho 
observou-se também o efeito contrário, quando uma bactéria considerada benéfica (Enterobacter $\mathrm{sp}$ ) auxiliou na manutenção da população de uma bactéria considerada como outro possível patógeno (Pantoea sp.). Na mistura Enterobacter sp. ICB383 e Pantoea sp. ICB409, em presença do calo (figura 15), observou-se que a população de Pantoea sp. ICB409 manteve-se constante entre 96 e 1272 horas, enquanto que a população de Enterobacter sp. foi parcialmente inibida após 24 horas de ensaio (figura 5). Aparentemente a presença de uma bactéria benéfica diminuiu a eficácia da(s) substâcia(s) liberadas contra a possível patogênica, que, conseguiu manter-se viável até o final do ensaio. Por outro lado, a bactéria benéfica sofreu os efeitos destas substâncias e cresceu menos do que quando em cultura pura. Estes dados de manutenção da população de Pantoea sp. foram reforçados pela análise do conteúdo de EROs nos calos (seção 5.4), pois, a presença de Enterobacter sp. ICB383 na mistura com Pantoea sp. ICB409 (figura 51) diminuiu o conteúdo de EROs quando se comparado com o da cultura simples de Pantoea sp. ICB409 (figura 49).

\subsection{Atividade específica da nitrogenase}

A interpretação dos dados de atividade especifica da nitrogenase foi muito complexa, considerando-se que os valores obtidos neste trabalho sofreram grandes oscilações e que quase não existem, na literatura, dados que avaliem a influência da associação de bactérias com calo ou planta na atividade da enzima nitrogenase.

As figuras 17 e 18 evidenciam estimulo da atividade da enzima pelo calo durante a fase logarítmica de crescimento (de 4 a 8 horas) de Enterobacter sp. em cultura simples. Nota-se que, quando comparada com esta mesma cultura sem o calo, em ambas as situações, a atividade cessou em 600 horas. Este mesmo efeito ocorreu na cultura simples de Pantoea sp. (figuras 21 e 22): um aumento significativo da atividade da nitrogenase em presença do calo às 8 horas de cultivo (fase exponencial) em comparação com a cultura pura, provavelmente sob efeito do calo, que, após 264 horas cessou. O resultado encontrado é coerente com os dados de crescimento (figura 12), pois, após a fase exponencial, houve uma inibição do crescimento que culminou na eliminação de Pantoea sp.. A fixação de nitrogênio pela bactéria é muito dispendiosa energeticamente e neste momento, provavelmente a necessidade de se obter nitrogênio foi substituída pela produção de outras moléculas atuantes no combate à expulsão e/ou morte, mantendo assim, a população viável. A mesma bactéria em cultura pura manteve a atividade da nitrogenase também até 264 horas quando, coincidentemente, a 
população começou a diminuir. Pode-se inferir que, a manutenção da atividade da nitrogenase foi vital para Pantoea sp, pois em ambas as condições, com e sem calo, houve a interrupção da atividade da nitrogenase concomitante com a queda da população. É interessante notar que as condições de carência de N-combinado também são impostas ao calo, porém este consegue manter as atividades de defesa e se sobrepor à bactéria. Berg et al., (1980) observaram o mesmo efeito na atividade da nitrogenase de Azospirillum brasilense quando este foi cultivado com calos de cana-de-açúcar. Os autores observaram que, em presença do calo, a bactéria apresentou um pico da atividade da enzima quatro vezes maior, que em sua ausência. O período em que houve este pico de atividade foi durante a fase de crescimento exponencial, fato que também foi observado neste trabalho. Porém, os autores, não explicaram como a associação com o calo aumentou a atividade da enzima da bactéria.

Pseudomonas sp. (figuras 19 e 20), apresentou o efeito contrário das outras duas linhagens. Durante a fase exponencial, houve uma inibição da atividade quando a bactéria foi cultivada com o calo. Porém, às 600 horas de cultivo houve um estímulo na atidade na cocultura. Os estímulos ou inibições sofridos pela nitrogenase foram diferentes do efeito do calo nas analises de crescimento, pois, a atividade foi estimulada ou inibida pontualmente. Poucos pontos foram encontrados onde houve um estímulo da atividade específica da nitrogenase pelo calo. Na literatura, além do trabalho citado (BERG et al., 1980) não existem estudos que mostrem a interação calo-bactéria e a influência desta interação na atividade da nitrogenase para que se possa comparar com os dados obtidos aqui. Na maioria dos trabalhos encontrados, a interação planta-bactéria foi realizada com plantas adultas ou plântulas micropropagadas. James et al. (1994) verificaram que em plantas maduras de cana-de açúcar, os vasos xilemáticos são um local apropriado para a realização da fixação de $\mathrm{N}_{2}$ de Acetobacter diazotrophicus, pois, aí existe uma baixa concentração de $\mathrm{O}_{2}$ uma vez que, a enzima nitrogenase é inibida permanentemente quando se liga ao oxigênio. Devido a isto, muitas bactérias possuem mecanismos de proteção à nitrogenase contra sua inativação pelo $\mathrm{O}_{2}$. Azotobacter vinelandii sintetiza uma capa de polissacarídeo que impede que em altas concentrações de $\mathrm{O}_{2}$ a nitrogenase seja inativada (SOTO-URZÚA; BACA, 2001). O fato das bactérias diazotróficas preferirem locais com baixa pressão de $\mathrm{O}_{2}$ explica o porquê microrganismos endofíticos fixadores de nitrogênio enfrentam muitos desafios para se estabelecer nos hospedeiros. Na associação de plantas leguminosas e Rhizobium, a formação dos nódulos propicia um local apropriado para a fixação do nitrogênio gerando vantagens 
tanto para o microrganismo quanto para a planta, pois, há uma transferência do nitrogênio fixado pela bactéria para o vegetal (LODWIG; POOLER, 2003).

Como poderá ser visto mais adiante, neste trabalho foi determinado o conteúdo de EROs nos calos. Na figura 48, pode-se observar um aumento na produção destas substâncias pelo calo, ao longo do tempo, em co-cultura com Pseudomonas sp. ICB383. Segundo Imalay (2003) o íon superóxido $\left(\mathrm{O}_{2}{ }^{-}\right)$e peróxido de hidrogênio $\left(\mathrm{H}_{2} \mathrm{O}_{2}\right)$ são capazes de inativar irreversivelmente enzimas que contenham o cluster $[4 \mathrm{Fe}-4 \mathrm{~S}]$, presente na estrutura da nitrogenase. Este pode ser um dos motivos que fez com que ocorresse uma queda nos valores de atividade da nitrogenase de Pseudomonas sp. em co-cultura com o calo. Valores altos de EROs também foram observados na co-cultura de calo com Pantoea sp. ICB409, porém, ocorreu o efeito contrário, houve um estímulo na atividade em 8 horas de cultivo. Possivelmente esta linhagem de Pantoea sp. possui algum mecanismo de proteção da enzima, como dito anteriormente, contra os efeitos danosos das espécies reativas de oxigênio. Esta proteção só foi eficiente até às 264 horas de ensaio, pois uma possível elevação da concentração de EROs ocasionou inativação da enzima.

Pseudomonas sp. e Pantoea sp. em co-cultura, apresentaram a nitrogenase ativa até às 96 horas de cultivo (figuras 33 e 34). Este curto período de atividade é coerente com os dados de crescimento bacteriano, porque após 24 horas Pseudomonas sp. não estava mais viável e a população de Pantoea sp.,foi eliminada após 96 horas. Esta mesma mistura, na ausência do calo, mostrou atividade baixa até 600 horas de ensaio quando houve uma tendência do aumento dos valores até o final do experimento. Neste caso, a atividade é atribuída a Pantoea sp., uma vez que a viabilidade de Pseudomonas sp. não foi mais detectada após 264 horas. Pode-se inferir então, que a liberação de alguma(s) substância(s) por Pseudomonas sp., anterior à sua morte ou até mesmo na lise das células bacterianas, tenha(m) estimulado a atividade da enzima de Pantoea sp.. Esta conclusão pode ser tirada, pois, Pantoea sp. em cultura pura, apresentou atividade de redução do acetileno até 264 horas. Holguin e Bashan (1996) realizaram culturas mistas da diazotrófica Azospirillum brasilense Cd com Staphylococcus sp., em meio isento de nitrogênio combinado, e verificaram que A. brasilense Cd fixou mais nitrogênio, sem o aumento da população, quando cultivado com a outra bactéria. Isto ocorreu, provavelmente, pela liberação de ácido aspártico por Staphylococcus sp.. Os autores confirmaram tal fato quando o dialisado de Staphylococcus sp., foi colocado na cultura de $A$. brasilense Cd e houve uma maior fixação de nitrogênio por esta bactéria. Este dialisado foi analisado e foi encontrada uma grande quantidade de ácido aspártico na amostra. 
A atividade de redução de acetileno nas raízes de cevada foi significantemente maior quando Azospirillum lipoferum 137 e Agrobacterium radiobacter 10 foram inoculados juntos. Utilizando-se da técnica de ${ }^{15} \mathrm{~N}$, os autores observaram que esta mistura incrementou o acúmulo de nitrogênio na planta. Também concluiram que a inoculação destas culturas em conjunto, forneceu maior balanço nutricional às plantas. Sabe-se que nas raízes, a tomada de nitrogênio e fósforo é o principal mecanismo de interação planta-bactéria (BELIMOV; KOJEMIAKOV; CHUVARLIYEVA，1994). Resultados semelhantes foram obtidos neste trabalho, com a mistura Pseudomonas sp. e Enterobacter sp., na ausência do calo (figuras 23 e 24), que apresentaram a enzima ativa durante todo o tempo de ensaio. Não se pode inferir se somente uma ou as duas bactérias estão com a enzima ativa, uma vez que, ambas estão vivas na cultura. Nota-se que a interação bactéria-bactéria não foi negativa quando se analisou a atividade da enzima. Na mesma mistura, em co-cultura com o calo, a atividade não foi mais detectada após 264 horas de cultivo. Neste caso, após 8 horas, células viáveis de Pseudomonas sp. não estavam mais presentes, portanto, a atividade encontrada das 24 às 264 horas era de Enterobacter sp..Vê-se aqui, que a presença do calo levou a uma menor duração da atividade de Enterobacter sp., pois, quando esta bactéria foi cultivada em cultura simples com o calo, exibiu atividade até 600 horas.

A mistura Enterobacter sp. com Pantoea sp. cultivada sem o calo, (figuras 27 e 28) apresentou dados de difícil interpretação, uma vez que houve um aumento da atividade da enzima após 600 horas de cultivo. Observou-se também, uma inibição do pico de atividade em 4 horas de ensaio, quando se comparou a atividade da mistura com as das culturas puras. Ao analisar as populações das duas linhagens, notou-se que a população de Enterobacter sp. ICB113 (figura 3) foi inibida pela outra linhagem durante todo o ensaio, enquanto que, não se observou efeito no crescimento da população de Pantoea sp. ICB409 por Enterobacter sp. ICB113 (figura 13). Não se pode tirar muitas conclusões em relação à atividade da nitrogenase desta mistura, uma vez que, ambas as bactérias permaneceram vivas e a atividade perdurou ao longo do ensaio. Uma conclusão que pode ser tirada é que o cultivo conjunto destas bactérias, ocasionou um aumento na duração da atividade das duas linhagens, pois, quando em cultura pura Enterobacter sp. ICB113 apresentou atividade até 600 horas e Pantoea sp. ICB409 até 264 horas, enquanto que, as duas bactérias em mistura, sem o calo, apresentaram atividade presente até o final do ensaio. 
Durante a fase exponencial, as bactérias produzem um grande número de proteínas que são utilizadas no crescimento. Nos dados aqui obtidos, observou-se que os picos de atividade da enzima nitrogenase se concentraram nesta fase (figuras 17, 19, 21, 24, 26 e 28).

\subsection{Conteúdo proteico dos calos}

As analises de conteúdo proteico dos calos foram realizadas para se verificar se o nitrogênio reduzido pelas bactérias, durante a fixação biológica de nitrogênio (FBN), foi transferido para as células vegetais. O nitrogênio combinado é incorporado em proteínas, ácidos nucleicos, e outras moléculas nitrogenadas; portanto, quanto maior a atividade da enzima, mais nitrogênio fixado e poderia haver a transferência de compostos nitrogenados para os calos. Havendo esta disponibilidade, o conteúdo proteico dos calos poderia aumentar. Para se concluir se houve ou não aumento no conteudo proteico dos calos, as curvas de cocultura (bactéria + calo) foram comparadas com a curva obtidas com calos cultivados em meio sem nitrogênio combinado (MSM). A curva dos calos crescidos em meio contendo nitrogênio $(\mathrm{CN})$ foi a única em que se observou aumento significativo no conteúdo proteico (17\%). Este resultado era o esperado, uma vez que, o calo foi cultivado em meio contendo disponibilidade de nitrogênio.

Em estudos realizados anteriormente no Laboratório de Fisologia de Microrganismos, foi observado que Enterobacter sp. ICB113 incrementou o conteúdo proteico dos calos em 39\% e Pseudomonas sp. ICB383 46\%, enquanto que Pantoea sp. ICB409 não contribuiu para o incremento proteico do calo (MARTINS et al., 2007). A partir destes resultados, optou-se em utilizar estas bactérias no presente trabalho. No primeiro ensaio (resultados mostrados no exame de qualificação), os dados obtidos foram de difícil interpretação. Os valores não apresentaram diferenças significativas em relação à curva SN. Optou-se por repetir todos os ensaios simultaneamente, utilizando-se os mesmos reagentes para todas as medidas. Para uma melhor eficácia da maceração dos calos, utilizou-se nitrogênio líquido, facilitando a quebra da parede das células vegetais. No primeiro protocolo utilizado, a solução tampão foi colocada durante a maceração e na segunda tentativa, primeiro macerou-se os calo com nitrogênio líquido para, em seguida, adicionar-se a solução tampão e realizar a extração das proteínas.

Os dados obtidos mostraram que Enterobacter sp. ICB113 não proporcionou incremento de proteínas no calo. Pseudomonas sp. ICB383 aumentou o conteúdo proteico do calo em $18 \%$ e Pantoea sp. ICB409 o reduziu em 36\%. Os dados obtidos foram 
estatísticamente iguais aos obtidos na curva MSM. Nos dados de conteúdo proteico dos calos cultivados com as misturas bacterianas, somente a mistura Pseudomonas sp. e Pantoea sp. ocasionou um decréscimo de $42 \%$, porém todos os dados obtidos das misturas bacterianas não foram diferentes estatísticamente dos dados dos calos em meio sem nitrogênio combinado.

A presença de organismos patogênicos dentro das plantas acarreta em um aumento na quantidade de ácido salicílico (AS), que ativa genes de defesa, liberando pathogenesis-related protein (PRs) que são dependentes de $\mathrm{AS}$ e quando liberadas pela planta apresentam atividade antimicrobiana (DURNER; KLESSIG, 1999). Esta queda no conteúdo proteico dos calos, quando cultivados somente com Pantoea sp. ICB409, ou com a mistura desta bactéria com Pseudomonas sp. ICB383, pode ter ocorrido em decorrência da produção das PRs. Porém, esta queda no conteúdo proteico, só será coerente com a literatura se estas proteínas foram liberadas no meio de cultura, uma vez que, somente o calo foi submetido à extração proteica, excluindo-se o que foi liberado e acumulado no meio.

\subsection{Conteúdo de ON e EROs nos calos}

Durante a revisão bibliográfica, devido à possível patogenicidade de Pseudomonas sp. ICB383 e Pantoea sp. ICB409, optou-se por comparar a ação do calo com a ação da planta em relação às vias de defesas contra invasores. A partir disto, para se complementar os resultados de crescimento, atividade da enzima nitrogenase e acúmulo proteico, determinaram-se os conteúdos de óxido nítrico $(\mathrm{ON})$ e de espécies reativas de oxigênio (EROs).

Poucas interpretações puderam ser tiradas em relação ao conteúdo de ON, pois viu-se que a produção desta substância está envolvida com a defesa, porém, em muitas outras funções na planta. Ao se analisar os resultados foi visto que, durante os primeiros dez minutos da medida, houve uma queda inesperada nos valores de quase todas as curvas, mostrada, por exemplo, na figura 43, que pode ter prejudicado a interpretação dos resultados. Observou-se que, mesmo nas curvas controle, houve esta queda. Para se corrigir este erro, será necessária a repetição destes experimentos com intervalos menores de medida. Outro fato observado foi o grande valor do desvio padrão, que acarreta em uma grande oscilação dos valores num mesmo ponto. Uma possível resposta foi que as células da suspensão não foram corretamente dissociadas, o que acarretou em uma penetração pouco eficiente do fluoróforo e assim, houve grandes diferenças nas medidas dos valores em um mesmo ponto. Este experimento deve ser 
refeito com a realização de uma dissociação celular mais eficiente e em intervalos de tempos menores, porém, por uma maior duração.

Os resultados do conteúdo de EROs foram mais ilustrativos para interpretações, uma vez que estas substâncias estão fortemente envolvidas na eliminação de patógenos. Estes dados auxiliaram na interpretação de quais bactérias eram possíveis patógenos ou bactérias benéficas. Observou-se que, quando a suspensão celular foi cultivada com Enterobacter sp. ICB113, a produção de EROs foi muito parecida com o controle, ou seja, a presença da bactéria não causou um aumento da produção de EROs, corroborando com os dados de crescimento e atividade da nitrogenase.

Quando se analisou o conteúdo de EROs nas culturas simples de Pseudomonas sp. ICB383 e Pantoea sp. ICB409 viu-se um aumento na produção destas substâncias. Este fato ajudou a compreenção dos resultados, uma vez que acredita-se que a linhagem Enterobacter sp. ICB113 seja uma bactéria benéfica à planta e as outras duas linhagens possíveis patogênicas. Quando analisaram-se os resultados das culturas mistas, diferentes situações foram observadas: Enterobacter sp. ICB113 e Pseudomonas sp. ICB383 cultivadas juntas aumentaram a produção de EROs em comparação com as respectivas culturas simples. Enterobacter sp. ICB113 com Pantoea sp. ICB409 quando juntas, apresentaram valores mais baixos do que o observado na cultura simples de Pantoea sp. ICB409 e valores mais altos do que na cultura simples de Enterobacter sp. ICB113. Como dito anteriormente (seção 5.1) aparentemente a presença de uma bactéria benéfica "mascarou" parcialmente a presença do possível patógeno. Porém quando Enterobacter sp. foi cutivado com Pseudomonas sp. também um possível patógeno, não houve este auxílio por parte da bactéria benéfica. $\mathrm{Na}$ mistura Pseudomonas sp. ICB383 com Pantoea sp. ICB409 o resultado foi inesperado, uma vez que esperava-se a maior produção de EROs de todos os ensaios, devido a presença de dois possíveis patógenos. A produção de EROs neste ensaio foi menor do que quando as duas bactérias foram cultivas separadas.

Testes realizados durante o isolamento das bactérias mostraram que as linhagens Enterobacter sp. ICB113 e Pseudomonas sp. ICB383 são produtoras de catalase, enquanto que Pantoea sp. ICB409 não apresentou a atividade desta enzima. A partir disto, compararam-se os dados de EROs com o crescimento e a capacidade da bactéria em produzir catalase, quando as bactérias foram cultivadas com o calo. Ao se comparar o crescimento das duas bactérias Pseudomonas sp. ICB383 com Pantoea sp. ICB409 em cultura simples, viu-se que somente Pantoea sp. ICB409 foi totalmente inibida enquanto que Pseudomonas sp. 
ICB383 sofreu uma inibição parcial do crescimento (figuras 7 e 12). Isto pode ter ocorrido pois, Pseudomonas sp. ICB383 produz catalase que diminiuiu a eficácia das EROs no combate à invasão dos possíveis patógenos, enquanto que Pantoea sp. ICB409 não produz esta enzima e foi eliminada. Quando Enterobacter sp. foi cultivada com Pantoea sp. (figura 5) observou-se que houve a inibição parcial do crescimento de ambas as bactérias. Esta "proteção" que a presença de Enterobacter sp. causou na população de Pantoea sp. pode estar associada à produção da catalase que diminiui a eficácia das EROs no combate à Pantoea sp.. Pode-se notar também que Enterobacter sp. também sofreu uma inibição parcial, ou seja, as substâncias produzidas pelo calo também afetaram o crescimento desta linhagem.

Outro fato observado foi um aumento gradual da produção de EROs sem que se observasse uma queda destas substâncias. Estes resultados são diferentes da literatura, que mostra a presença de um burst destas substâncias nas fases iniciais da invasão (BOWELL et al., 2001). Na literatura não existem trabalhos avaliando a produção de EROs em culturas bacterianas mistas.

Neste trabalho, parâmetros foram analisados para se verificar se a interação bactériacalo é semelhante à interação bactéria-planta, ou seja, se o calo pode ser considerado um modelo de estudo nestas associações. Resultados obtidos no laboratório em outro projeto, mostraram que a inoculação de Pseudomonas sp. ICB383 (a mesma utilizada neste trabalho) em plântulas micropropagadas de cana-de-açúcar foram semelhantes aos encontrados aqui, uma vez que a planta expulsou a bactéria de seu interior, ou seja, foi reconhecida como uma invasora e não uma bactéria benéfica. Trabalhos com a utilização de calos são poucos e antigos na literatura, para que se possa realizar uma melhor comparação dos resultados obtidos aqui.

Outro estudo realizado no Laboratório de Fisiologia de Microrganismos consiste na comparação de linhagens de Enterobacteriaceae isoladas de cana-de-açucar com outras do mesmo gênero, isoladas em pacientes clínicos. Entre as bactérias analisadas, estão Enterobacter sp. ICB113 e Pantoea sp. ICB409 utilizadas também neste trabalho. Este trabalho poderá indicar propriedades fisiológicas e genéticas comuns entre as amostras ambientais e clínicas, caracterizando-as, então como patogênicas ou não. 


\section{CONCLUSÕES}

- O calo mostrou ser um bom modelo para se estudar a interação planta-bactéria;

- de acordo com o tipo de bactéria (patogênica ou não) o calo apresentou diferentes reações. Bactérias consideradas como benéficas tiveram seu crescimento estimulado, enquanto que as consideradas possíveis patógenos foram inibidas;

- a atividade da nitrogenase em presença de calo não apresentou relação de com a possível patogenicidade ou não das bactérias;

- a atividade da nitrogenase foi inibida ou estimulada pontualmente em presença de calo, enquanto que, o crescimento sofreu estas influências por períodos mais longos;

- a competição entre organismos é um fator que limita o crescimento dos competidores mais" fracos";

- houve sinais de competição na associação entre os possíveis patógenos e a bactéria benéfica, quando cultivadas sem o calo;

- houve sinais de competição na associação entre os dois possíveis patógenos, quando cultivadas sem o calo;

- a presença do calo afetou o crescimento dos possíveis patógenos quando em cultura mista;

- os dados de conteúdo de EROs foram ilustrativos e auxiliaram no entendimento da patogenicidade dos isolados utilizados neste trabalho.

\subsection{Perspectivas}

Para se complemetar os resultados aqui obtidos, futuros experimentos devem ser realizados:

- $\quad$ análise de outras substâncias envolvidas nas vias de defesa, como por exemplo, ácido salicílico, ácido jasmônico e etileno, para complemetar os resultados obtidos no presente trabalho;

- $\quad$ a realização de nova extração de proteínas para se verificar se houve ou não aumento no conteúdo proteico dos calos quando associados com a(s) bactéria(s), uma vez que, foram encontrados resultados contraditórios no experimentos realizados no Laboratório de Fisiologia de Microrganismos; 
- as análises de conteúdo de $\mathrm{ON}$ devem ser refeitas procurando-se otimizar a dissociação celular e menores intervalos de tempo nas medidas. 


\section{REFERÊNCIAS*1}

ANDERSON, M. D.; RUESS, R. W.; ULIASS, D. D.; MITCHELL, J. S. Estimating $\mathrm{N}_{2}$ fixation in two species of Alnus in interior Alaska using acetylene reduction an ${ }^{15} \mathrm{~N}_{2}$ uptake. Écoscience, v. 11, p. 102-114, 2004.

ARENCIBIA, A. D.; ESTEVEZ, Y.; VINAGRE, F.; BERNAL, A.; PEREZ, J.; CARMONA, E.; HEMERLY, A. S.; SANTANA, I. Induced-Resistence in Sugarcane Against Pathogenic Bacteria Xanthomonas albilineans Mediated by an Endophytic Interaction. Sugar Technology, v. 8, p. 272-280, 2006.

ARNOLD, W.; RUMP, A.; KLIPP, W.;PRIEFER, U. B.; PÜHLER, A. Nucleotide sequence of a 24,206 base pair fragment carrying the entire nitrogen fixation gene cluster of Klebsiella pneumoniae. Journal of Molecular Biology, v. 203, p. 715-738, 1988.

BARBOSA, H. R.; RODRIGUES, M. F. A.; CAMPOS, C. C.; CHAVES, M. E.; NUNES, I.; JULIANO, Y.; NOVO, N. F. Counting of viable cluster-forming and non cluster-forming bacteria: a comparison between the drop and the spread methods. Journal of Microbiology Methods, v. 22, p. 39-50, 1995.

BARNA, B.; FODOR, J.; HARRACH, B. D.; POGÁNY, M.; KIRÁLY, Z. The janus face of reactive oxygen species in resistance and susceptibility of plants to necrotrophic and biotrophic. Plant Fisiology and Biochemistry, v. 59, p. 37-43, 2012.

BARRAS, F.; VAN GIJSEM, F.; CHATTERJEE, A. K. Extracellular enzimes and pathogenesis of soft rot Erwinia. Annual Review of Phytopathology, v. 32, p. 201-234, 1994.

BASHAN, Y. Inoculants of plant growth-promoting bacteria for use in agriculture. Bitechnology Advances, v. 16, n. 4, p. 729-770, 1998.

BASHAN, Y.; HOLGUIN, G. Azospirillum-plant relationships: environmental and physiological advances (1990-1996). Canadian Journal of Microbiology s v. 43, n. 12, p. 1651-1660, 1997.

BASTIÁN, F.; COHEN, A.; PICCOLI, P.; LUNA, V.; BARALDI, R.; BOTTINI, R. Production of indole-3-acetic and gibberellins $\mathrm{A}_{1}$ and $\mathrm{A}_{3}$ by Acetobacter diazotrophicus and Herbaspirillum seropedicae in chemically-defined culture media. Plant Growth Regulators, v. 24, p. 7-11, 1998.

BAUER, W. D.; MATHESIUS, U. Plant responses to bacterial quorum sensing signals.Current Opinion in Plant Biology, v. 7, p. 429-433, 2004.

\footnotetext{
${ }^{1}$ De acordo com:

ASSOCIAÇÃO BRASILEIRA DE NORMAS TÉCNICAS. NBR 6023: informação e documentação: referências: elaboração. Rio de Janeiro, 2002.
} 
BEKRI, M. A.; DESAIR, J.; KEIJERS, V.; PROOST, P.; SEARLE-VAN LEEUWEN, M.; VANDERLEYDEN, J.; BROEK, A. V. Azospirillum irakense produces a novel type of pectate lyase. Journal of Bacteriology, v. 181, p. 2440-2447, 1999.

BENT, E.; TUZUN, S.; CHANWAY, C.P.; ENEBACK, S. Alterations in plant growth and in root hormone levels of lodgepole pines inoculated with rhizobacteria. Canadian Journal of Microbiology, v. 47, p. 793-800, 2001.

BERG, R. H.; VASIL, V.; VASIL, I. K.The biology of Azospirillum-sugarcane association. II. Ultrastructure. Protoplasma, v. 101, p. 143-163, 1979.

BERG,R. H.; TYLER, M. E.; NOVICK, N. J., VASIL, V. VASIL, N. J. Biology of Azospirillum-sugarcane association: enhancement of nitrogenase. Applied and Enviromental Microbiology, v. 39, p. 642-649, 1980.

BELIMOV, A. A.; KOJEMIAKOV, A. P.; CHUVARLIYEVA, C. V. Interaction between barley and mixed cultures of nitrogen fixing and phosphate-solubilizing bacteria. Plant Soil, v. 173, p. 29-37, 1995.

BODDEY, R. M.; DÖBEREINER, J. Nitrogen fixation associated with grasses and cereals: recent results and perspectives for future research. Plant Soil, v. 108, p. 53-65, 1988.

BODDEY, R. M.; MORAES SÁ, J. C.; ALVES, B. J. R.; URQUIAGA, S. The contribution of biological nitrogen fixation for sustainable agricultural systems in the tropics. In: INTERNATIONAL SYMPOSIUM - SUSTAINABLE AGRICULTURE FOR THE TROPICS: THE ROLE OF BIOLOGICAL NITROGEN FIXATION, 1995, Angra dos Reis, RJ, Brazil. Anais... Angra dos Reis, RJ, Brazil, 1995. p. 787-799.

BODDEY, R. M.; URQUIAGA, S.; ALVES, B. J. R.; REIS, V. Endophytic nitrogen fixation in sugarcane: present knowledge and future applications. Plant Soil, v. 252, p. 139-149, 2003.

BORDIEC, S.; PAQUIS, S.; LACROIX, H.; DHONDT, S.; BARKA, E. A.; KAUFFMAN, S.; JEANDET, P.; MAZEYRAT-GOUBEYRE, F.; CLÉMENT, C.; BAILLIEUL, S.; DOREY, S. Comparative analysis of defence responses induced by the endophytic plant growth-promoting rhizobacterium Burkholdeira phytofirmans strain PsJN and the non-host bacterium Pseudomonas syringae pv. pisiin grapevine cell suspensions. Journal of Experimental Botany, v. 62, n. 2, p. 595-603, 2010.

BOWELL, G. P.; BINDSCHEDLER, L. V.; BLEE, K. A.; BUTT, V. S.; DAVIES, D. R.; GARDNER, S. L.; GERRISH, C.; MINIBAYEVA, F. The apoplastic oxidative burst in response to biotic stress in plants: a three-component system. Journal of Experimental Botany, v. 53, p. 1367-1376, 2002.

BRADFORD, M. M. A rapid and sensitive method for the quantitation of microgram quantities of protein utilizing the principle of protein-dye binding. Analitical Biochemestry, v. 72, p. 248-254, 1976.

BURDMAN, S.; JURKEVITCH, E.; OKON, Y. Recent advances in the use of Plant Growth Promoting Rhizobacteria (PGPR) in ariculture. Microbial Interactions in Agriculture and Forestry, v. 2, p. 229-250, 2000. 
CASSÁN, F.; PERRIG, D.; SGROY, V.; MASCIARELLI, O.; PENNA, C.; LUNA, V. Azospirillum brasilense Az39 and Bradyrhizobium japonicum E109, inoculated singly or in combination, promote seed germination and early see germination and early seedling growth in corn (Zea mays L.) and soybean (Glycine max L.). European Journal of Soil Biology, v. 45, p. 28-35, 2009.

CHARLWOOD, B. V.; RHODES, M. J. C. (Ed.). Secondary products from plant tissue culture. Clarendon Press, 1990.

CHILD, J. J.; KURZ, W. G. W. Induction effect of plant cells on nitrogenase activity by Spirillum and Rhizobium in vitro. Canadian Journal of Microbiology, v. 24, p. 143-148, 1978.

COCKING, E. C. Endophytic colonization of plant roots by nitrogen-fixing bacteria. Plant Soil, v. 252, p. 169-175, 2003.

COMPANT, S.; DUFFY, B.; NOWAK, J., CLÉMENT, C.; BARKA, E. A. Use of plant growth-promoting bacteria for biocontrol of plant desease:principles, mechanisms of action, and future prospects. Applied and Enviromental Microbiology, v. 71, n. 9, p. 4951-4959, 2005 .

COSTA, M. A.; DE OLIVEIRA, R. G.; SACHETTO, M. G.; MANSUR, E. Morfogênese in vitro e susceptibilidade de calos de variedades nacionais de cana-de-açúcar (Saccharum officinarum L.) a agentes seletivos utilizados em sistemas de transformação genética. Revista Brasileira de Botânica, v. 24, p. 73-77, 2001.

DEMORANVILLE, C. J.; KAMINSKI, A. R.; BARNETT, N. M.; BOTTINO, P. J.; BLEWIS, D. G. Substances from cultured soybeans cells which stimulate or inhibit acetylene reduction by free-living Rhiziobium japonicum. Plant Physiology and Biochemistry, v. 52, p. 53-58, 1981.

DOBBELAERE, S.; VANDERLEYDEN, J.; OKON, Y. Plant Growth-promoting effects os diazotrophs in the rizosphere.Critical Reviews in Plant Sciences, v. 22, n. 2, p. 107-149, 2003.

DÖBEREINER, J. Biological Nitrogen Fixation in the tropics: social and economic contributions. Soil Biology Biochemistry, v. 29, p. 771-774, 1997.

DÖBEREINER, J.; BALDANI, J. I. Bases científicas para uma agricultura biológica. Ciência e Cultura, v. 34, p. 869-881, 1982.

DÖBEREINER, J.; BALDANI, V. L.; BALDANI, J. I. Como isolar e identificar bactérias diazotróficas de plantas não-leguminosas. Brasília: Embrapa, 1995. 60 p.

DROZDOWICZ, A.; FERREIRA SANTOS, G. M. Nitrogenase activity in mixed cultures of Azospirillum with other bacteria. Mikrobiology Z, v. 142, p. 487-493, 1987.

DURNER, J.; KLESSIG, D. Nitric oxide as a signal in plants. Current Opinion in Plant Biology, v. 2, p. 369-374, 1999. 
FLOH, E. I. S.; HANDRO, W. Floração in vitro. In: TORRES, A. C.; CALDAS, L. S. Técnicas e aplicações de cultura de tecidos de plantas. Brasília: ABCTP/EMBRAPACNPH, 1990. p. 213-226.

FRANCO, A. A.; DÖBEREINER, J. A biologia do solo e a sustentabilidade dos solos tropicais. Summa Phytopathology, v. 20, p. 68-74, 1994.

GEORGE, E. F. Plant propagation by tissue culture: the technology. $2^{\text {nd }}$ ed. Exegetics Limited, 1993.

GLENN, A. R.; DILWORTH, M. J. Ammonia movements in rhizobia. Microbiological Sciences, v. 2, p. 161-167, 1985.

HALLMANN, J.; QUADT-HALLMANN, A.; MAHAFFEE, W. F.; KLOEPPER, J. W. Bacterial endophytes in agricultural crops. Canadian Journal of Microbiology, v. 43, p. 895-914, 1997.

HAMMERSCHLANG, F. A. Resistance responses of plants regenerated from peach callus, culture to Xanthomonas campestris pv. pruni. Journal of the American Society for Horticultural Science, v. 115, n. 6, p. 1034-1037, 1990.

HIBBING, M. E.; FUQUA, C.; PARSEK, M. R.; PETERSON, B. Bacterial competition: surviving and thriving in the microbial jungle. Nature Reviews, v. 8, p. 15-25, 2010.

HOLSTEN, R. D.; BURNS, C. R.; HARDY, W. F.; HEBERT, R. R. Establishment of symbiosis between Rhizobium and plant cells in vitro. Nature, v. 232, p. 173-177, 1971.

HOLGUIN, G.; BASHAN, Y. Nitrogen-fixation by Azospirillum brasilense Cd is promoted when co-cultured with a mangrove rhizosphere bacterium (Staphylococcus sp.). Soil Biology Biochemestry, v. 28, p. 1651-1660, 1996.

HUREK, T.; HANDLEY, L. L.; REINHOLD-HUREK, B.; PICHE, Y. Azoarcus grass endophytes contribute fixed nitrogen to the plant in an unculturable state. Molecular PlantMicrobe Interact, v. 15, p. 233-242, 2002.

IMALAY, J. A. Pathways of oxidative damage. Annual Review of Microbiology, v. 57, p. 395-418, 2003.

INIGUEZ, A. L.; DONG, Y.; CARTER H. D.; AHMER, B. M. M.; STONE, J. M.; TRIPLETT, E. W. Regulation of enteric endophytic bacterial colonization by plant defenses. The American Phytopathological Society, v. 18, p. 169-178, 2005.

ISOPI, R.; FABBRI, P.; DEL GALLO, M.; PUPPI, G. Dual inoculation of sorghum bicolor (L.)Moench ssp. bicolor with vesicular arbuscular mycorrhizas and Acetobacterdiazotrophicus. Symbiosis, v. 18, p. 43-55, 1995.

ITZIGSOHN, R.; KAPULNIK, Y.; OKON, Y.; DOVRAT, A. Physiological and morphological aspects of interactions between Rhizobium meliloti and alfalfa (Medicago sativa) in association with Azospirillum brasilense. Canadian Journal of Microbiology, v. 39, p. 610-615, 1993. 
JAMES, E. K.; REIS, V. M.; OLIVARES, F. L.; BALDANI, J. I.; DÖBEREINER, J. Infection of sugar cane by the nitrogen-fixing bacterium Acetobacter diazotrophicus. Jounal of Experimental Botany, v. 45, p. 757-766, 1994.

JONES, J. D. G.; DANGL, J. The plant immune system. Nature, v. 444, p. 323-329, 2006.

KAISER, P. Diazotrophic mixed cultures of Azospirillum brasilense and Entrobacter cloacae. NATO ASI SERIES, v. 37, p. 207-212, 1995.

KHAMMAS, K. M.; KAISER, P. Pectin decomposition and associated nitrogen fixation by mixes cultures of Azospirillum and Bacillus species.Canadian Journal of Microbiology, $\mathrm{v}$. 38, p. 794-797, 1992.

KIM, J.; REES, D. C. Nitrogenase and biological nitrogen fixation. Biochemistry, New York, v. 33, p. 389-397, 1994.

KUNDU, B. S.; KUHAD, M. S.; NANDWAL, A. S. Nodulation, nitrogen fixation and biomass of rajmash (Phaseolus vulgaris L.) as influenced by Azospirillum and Rhizobium inoculants. Environment and Ecology, v. 11, p. 581-583, 1993.

KUNKEL, B. N.; BROOKS, D. M. Cross talk between signaling pathways in pathogen defense. Current Opinion in Plant Biology, v. 5, p. 325-331, 2002.

LODWIG, E.; POOLE, P. Metabolism of Rhizobium Bacteroids. Critical Reviews in Plant Science, v. 22, p. 37-38, 2003.

MADIGAN, M. T.; MARTINKO, J. M.; PARKER, J. Microbiologia de Brock. 10. ed. Local: Porto Alegre, Artmed, 2004. 608 p.

MARTINS, R. C. R. Associação in vitro de bactérias endofíticas diazotróficas com células de calo de cana-de-açúcar , 2007. 81 f. Dissertação (Mestrado em Microbiologia) - Instituto de Ciências Biomédicas, Universidade de São Paulo, São Paulo, 2007.

MARTINUZ, A.; SHOUTEN, A.; SIKORA, R. A. Sistematically induced resistence and microbial competitive exclusion: implications on biological control. Phytopathology, v. 102, n. 3, 2012.

MUR, L. A. J.; CARVER, T. L. W.; PRATS, E. NO way to live; the various roles of nitric oxide in plat- pathogen interaction.Journal of Experimental Botany, v. 57, p. 489-505, 2006.

MURASHIGE, T.; SKOOG, F. A revised medium for rapid growth and bioassays with Tobacco tissue cultures. Physiology Plant Journal, v. 15, p. 473-497, 1962.

NJOLOMA, J. P.; OOTA, M.; TAROURA, K.; SAEKI, Y.; AKAO, S. Colonization ability of Herbaspirillum spp. B501gfp1 in sugarcane, a non-host plant in the presence of indigenous diazotrophic endophytes. African Journal of Biotechnology, v. 5, p. 836-841, 2006.

O'BRIEN, J. A.; DAUDI, A.; BUTT, V. S.; BOLWELL, G. P.; Reactive oxygen species and their role in plant defence and cell wall metabolism. Planta, v. 236, p. 765-779, 2012. 
OLIVEIRA, A. L. M.; STOFFELS, M.; SCHMID, M.; REIS, V. M. J.; BALDANI, J. I.; HARTMANN, A. Colonization of sugarcane plantlets by mixed inoculations with diazotrophic bacteria. European Journal of Soil Biology, v. 45, p. 106-113, 2008.

PAERL, H. W.; PINKNEY, J. L. A mini-review of microbial consortia: their role in aquatic production and biogeochemical cycling. Microbial Ecology, v. 31, p. 225-247, 1996.

PENCE, V. C.; NOVICK, N. J.; OZIAS-AKINS, P.; VASIL, I. K. Induction of nitrogenase activity in Azospirillum brasilense by conditioned medium from cell suspension cultures of Pennisetum americanum (Pearl millet) and Panicum Maximum (Guinea grass). Zeitschrift für Pflanzenphysiologie, v. 106, p. 139-147, 1982.

PIETERSE, C. M. J.; VAN LOON, L. C. Salicylic acid-independent plant defence pathways. Trends in plant science, v. 4, n. 2, p. 52-58, 1999.

POSTGATE, J. Nitrogen fixation. 3rd ed. Cambridge: Cambridge University Press, 1998. $112 \mathrm{p}$.

PREININGER, E.; ZATYKÓ, J.; SZÜCS, P.; KORÁNYL, P.; GYURJÁN, I. In vitro establishment of nitrogen-fixing strawberry (Fragaria $\times$ ananassa) via artificial symbiosis with Azomonas insignis.In Vitro Cellular \& Developmental Biology Plant, v. 33, p. 190194, 1997.

RAMOS, H. J. O.; RONCATO-MACCARI, L. D. B.; SOUZA, E. M.; SOARES-RAMOS, J. R. L.; HUNGRIA, M.; PEDROSA, F. O. Monitoring Azospirillum-wheat interactions using the $g f p$ and $g u s$ A genes constitutively expressed from a new broad-host range vector. Journal of Biotechnology, v. 97, p. 243-252, 2002.

RAVERKAR, K. P.; KONDE, B. K. Influence of Rhizobium and Azospirillum lipoferum inoculation on Arachis hypogaea L. and detection of Rhizobium by ELISA. Indian Journal of Microbiology, v. 30, p. 209-212, 1990.

REIS JUNIOR, F. B.; MENDES, I. C.; REIS, V. M. Jornal Agrosoft. 2007. Disponível em www.agrosoft.org.br/?q=node/24996. Acesso em: 18 dez. 2011.

REINHOLD-HUREK, B.; HUREK, T. Life in grasses: diazotrophic endophytes. Trends in Microbiology, v. 6, p. 139-144, 1998.

REINHOLD-HUREK, B.; HUREK, T. Living inside plants: bacterial endophytes. Plant Biology, v. 14, p. 1-9, 2011.

REYES, I.; BERNIER, L.; ANTOUN, H. Rock phosphate solubilization and colonization of maize rhizosphere by wild and genetically modified strains of Penicillium rugulosum. Microbial Ecology, v. 44, p. 39-48, 2002.

RIVAS, R. A new species of Devosia that forms a unique nitrogen-fixing root-nodule symbiosis with the aquatic legume Neptunia natans (L.f.) druce. Applied and Environmental Microbiology, v. 68, p. 5217-5222, 2002. 
RODELAS, B.; GONZÁLEZ-LÓPEZ, J.; SALMERÓN, V.; POZO, C.; MARTÍNEZTOLEDO, M. V. Enhancement of nodulation, N2-fixation and growth of faba bean (Vicia faba L.) by combined inoculation with Rhizobium leguminosarum bv. viceae and Azospirillum brasilense. Symbiosis, v. 21, p. 175-186, 1996.

RODELAS, B.; GONZÁLEZ-LÓPEZ, J.; SALMERÓN, V.; POZO, C.; MARTÍNEZTOLEDO, M.V. Response of Faba bean (Vicia faba L.) to combined inoculation with Azotobacter and Rhizobium leguminosarum bv. Viceae. Applied Soil Ecology, v. 12, p. 5159, 1999.

ROMERO, D.; DE VICENTE, A.; RAKOTOALY, R. H.; DUFOUR, S. E.; VEENING, J. W.; ARREBOLA, E.; CAZORLA, F. M.; KUIPERS, O. P.; PAQUOT, M.; PEREZGARCIA, A. The iturin and fengycin families of lipopeptides are key factors in antagonism of Bacillus subtilis toward Podosphaera fusca. Molecular Plant-Microbe Interactions, v. 20, p. 430-440, 2007.

ROMERO-PUERTAS, M. C.; PERAZZOLLI, M.; ZAGO, E. D.; DELLEDONNE, M. Nitric oxide signaling functions in plant-pathogen interactions.Cellular Microbiology, v. 6, n. 9, p. 795-803, 2004.

ROPER, M. C. Pantoea stewartii subsp. stewartii: Lessons learnedfrom a xylem-dwelling pathogen of sweet corn. Molecular Plant Pathology, v. 12, n. 7, p. 628-637, 2011.

ROSENBLUETH, M.; MARTÍNEZ-ROMERO, E. Bacterial endophytes and their interactions with hosts.Molecular Plant-Microbe Interact, v. 19, p. 827-837, 2006.

SANTA-CATARINA, C.; SILVEIRA, V.; BALBUENA, T. S.; VIANA, A. M.; ESTELITA, M. E. M.; HANDRO, W.; FLOH, E. I. S. IAA, ABA, polyamines and free amino acids associated with zygotic embryo development of Ocotea catharinensis. Plant Growth Regulation, v. 49, p. 237-247, 2006.

SHARMA, P.; JHA, A. B.; DUBEY, R. S.; PESSARAKLI, M. Reactive oxygen species, oxidative damage, and antioxidative defense mechanism in plants under stressful conditions. Journal of Botany, v. 56, p. 1-26, 2012.

SHRESTHA, A.; TOYOTA, K.; OKAZAKI, M.; SUGA, Y.; QUEVEDO, M. A.; LORETO, A. B.; MARISCAL, A. A. Enhancement of Nitrogen-fixing Activity of Enterobacteriaceae Strains Isolated from Sago Palm (Metroxylon sagu) by Microbial Interaction with Nonnitrogen Fixers. Microbes Environments, v. 22, n. 1, p. 59-70, 2007.

SILVEIRA, V.; BALBUENA, T. S.; SANTA-CATARINA, C.; FLOH, E. I. S.; GUERRA, M. P.; HANDRO, W. Biochemical changes during development in Pinus taeda L. Plant Growth Regulation, v. 44, p. 147-156, 2004.

SIMPSON, F. B.; BURRIS, R. H. A nitrogen pressure of 50 atmosphere does prevent evolution of hydrogen by nitrogenase. Science, v. 224, p. 1095-1097, 1984.

SINGH, C. S.; SUBBA RAO, N. S. Associative effect of Azospirillum brasilense with Rhizobium japonicum on nodulation and yield of soybean. Plant and Soil, v. 53, p. 387-392, 1979. 
SMITH, R. S. Legume inoculant formulation and application, Canadian Journal of Microbiology, v. 38, p. 485-492, 1992.

SOTO-URZÚA, L.; BACA, B. E. Mecansimos de proteción de la nitrogenasa a la inactivación por oxígeno. Revista Latinoamericana de Microbiologia, v. 43, p. 37-49, 2001.

SPOEL, S. H.; DONG, X. Making sense of hormone crosstalk during plant immune responses.Cell Host \& Microbe, v. 3, 2008.

SPRENT, J. I.; DE FARIA, S. M. Mechanisms of infection of plants by nitrogen-fixing organisms.Plant Soil, v. 110, p. 157-165, 1988.

STACEY, G.; BURRIS, R. H.; EVANS, H. J. Biological Nitrogen Fixation. New York: Chapman and Hall, 1992. 943 p.

STRZELCZYK, E.; KAMPERT, M.; LI, C. Y. Cytokinin-like-substances and ethylene production by Azospirillum in media with different carbon sources. Microbiology Research, v.149, p. 55-60, 1994.

THULER, D. S.; FLOH, E. I. S.; HANDRO, W.; BARBOSA, H. R. Plant growth regulators anda mino acids released by Azospirillum sp. In chemically defined media. Letters in Applied Microbiology, v. 37, p. 147-178, 2003.

UNIÃO DA AGROINDÚSTRIA CANAVIEIRA DO ESTADO DE SÃO PAULO (ÚNICA). Disponível em: http://www.unica. com.br/pages/cana_origem.asp. Acesso em: 21 nov. 20011.

URQUIAGA, S.; CRUZ, K. H. S.; BODDEY, R. M. Contribution of nitrogen fixation to sugar cane: Nitrogen-15 and nitrogen balance estimates. Soil Science Society of American Journal, v. 56, p. 105-114, 1992.

WELLER, D. M. Biological control of soilborne plant pathogens in the rhizosphere with bacteria, Annual Review of Phytopathology, v. 26, p. 379-407, 1988.

VASIL, V.; VASIL, I. K.; ZUBERER, D. A.; HUBBELL, D. H.The biology of Azospirillumsugarcane association. I. Establishment of the association. Zeitschrift für Pflanzenphysiologie, v. 95, p. 141-147, 1979.

VALLAD, G. E.; GOODMAN, R. M. Systemic acquired resistance and induced systemic resistance in conventional agriculture. Crop Science, v. 44, p. 1920-1934, 2004.

VERMA S.C.; SINGH A.; CHOWDHURY S.P.; TRIPATHI A.K. Endophytic colonization ability of two deep-water rice endophytes, Pantoea sp. and Ochrobactrum sp. using geen fluorescent protein reporter. Biotechnology Letters, v. 26, p. 425-429, 2004.

ZENK, M. H. Chasing the enzymes of secondary metabolism: plant cell cultures as a pot of gold. Phytochemistry, v. 30, p. 3861-3863, 1991. 